\title{
Climate Fluctuations of Tropical Coupled Systems-The Role of Ocean Dynamics
}

\author{
P. Chang, ${ }^{\text {a }}$ T. Yamagata, ${ }^{\text {b }}$ P. Schopf,${ }^{c}$ S. K. Behera, ${ }^{\text {d }}$ J. Carton, ${ }^{\text {e W. S. Kessler, }},{ }^{f}$ G. Meyers,${ }^{\text {g }}$ \\ T. Qu, ${ }^{\text {h }}$ F. SCHOtT, ${ }^{\text {i }}$ S. ShetYe, ${ }^{\mathrm{j}}$ AND S.-P. XIE ${ }^{\mathrm{k}}$ \\ ${ }^{a}$ Department of Oceanography, Texas A\&M University, College Station, Texas \\ ${ }^{\mathrm{b}}$ Frontier Research Center for Global Change, Yokohama, Kanagawa, and Department of Earth and Planetary Science, \\ University of Tokyo, Tokyo, Japan \\ ${ }^{\mathrm{c}}$ College of Science, George Mason University, Fairfax, Virginia \\ ${ }^{\mathrm{d}}$ Frontier Research Center for Global Change, Yokohama, Kanagawa, Japan \\ ${ }^{\mathrm{e}}$ Department of Atmospheric and Oceanic Sciences, University of Maryland, College Park, College Park, Maryland \\ ${ }^{\mathrm{f}}$ NOAA/Pacific Marine Environmental Laboratory, Seattle, Washington \\ ${ }^{\mathrm{g}}$ CSIRO Marine Research Laboratories, Hobart, Tasmania, Australia \\ ${ }^{\mathrm{h}}$ International Pacific Research Center, University of Hawaii at Manoa, Honolulu, Hawaii \\ ${ }^{\mathrm{i}}$ Institut für Meereskunde, Universität Kiel, Kiel, Germany \\ ${ }^{\mathrm{j} N a t i o n a l}$ Institute of Oceanography, Dona Paula, Goa, India \\ ${ }^{\mathrm{k}}$ International Pacific Research Center, and Department of Meteorology, University of Hawaii at Manoa, Honolulu, Hawaii
}

(Manuscript received 24 January 2005, in final form 14 November 2005)

\begin{abstract}
The tropical oceans have long been recognized as the most important region for large-scale oceanatmosphere interactions, giving rise to coupled climate variations on several time scales. During the Tropical Ocean Global Atmosphere (TOGA) decade, the focus of much tropical ocean research was on understanding El Niño-related processes and on development of tropical ocean models capable of simulating and predicting El Niño. These studies led to an appreciation of the vital role the ocean plays in providing the memory for predicting El Niño and thus making seasonal climate prediction feasible. With the end of TOGA and the beginning of Climate Variability and Prediction (CLIVAR), the scope of climate variability and predictability studies has expanded from the tropical Pacific and ENSO-centric basis to the global domain. In this paper the progress that has been made in tropical ocean climate studies during the early years of CLIVAR is discussed. The discussion is divided geographically into three tropical ocean basins with an emphasis on the dynamical processes that are most relevant to the coupling between the atmosphere and oceans. For the tropical Pacific, the continuing effort to improve understanding of large- and small-scale dynamics for the purpose of extending the skill of ENSO prediction is assessed. This paper then goes beyond the time and space scales of El Niño and discusses recent research activities on the fundamental issue of the processes maintaining the tropical thermocline. This includes the study of subtropical cells (STCs) and ventilated thermocline processes, which are potentially important to the understanding of the low-frequency modulation of El Niño. For the tropical Atlantic, the dominant oceanic processes that interact with regional atmospheric feedbacks are examined as well as the remote influence from both the Pacific El Niño and extratropical climate fluctuations giving rise to multiple patterns of variability distinguished by season and location. The potential impact of Atlantic thermohaline circulation on tropical Atlantic variability (TAV) is also discussed. For the tropical Indian Ocean, local and remote mechanisms governing low-frequency sea surface temperature variations are examined. After reviewing the recent rapid progress in the understanding of coupled dynamics in the region, this study focuses on the active role of ocean dynamics in a seasonally locked east-west internal mode of variability, known as the Indian Ocean dipole (IOD). Influences of the IOD on climatic conditions in Asia, Australia, East Africa, and Europe are discussed. While the attempt throughout is to give a comprehensive overview of what is known about the role of the tropical oceans in climate, the fact of the matter is that much remains to be understood and explained. The complex nature of the tropical coupled phenomena and the interaction among them argue strongly for coordinated and sustained observations, as well as additional careful modeling investigations in order to further advance the current understanding of the role of tropical oceans in climate.
\end{abstract}

Corresponding author address: Dr. Paul Schopf, College of Science, George Mason University, 4400 University Dr., MSN 5C3, Fairfax, VA 22030-4444.

E-mail: pschopf@gmu.edu 


\section{Introduction}

The tropical ocean has been studied most extensively with regard to its role in the El Niño-Southern Oscillation (ENSO) phenomenon. During the decade (198594) of the Tropical Ocean-Global Atmosphere (TOGA) program, a concerted international research effort was undertaken primarily within the tropical Pacific Ocean with the goal of better describing ENSO as a coupled ocean-atmosphere phenomenon and understanding its underlying dynamics, as well as exploiting its predictability to develop forecast systems using coupled ocean-atmosphere models. The immensely successful TOGA led to improvements in our understanding of how the dynamics of the equatorial waveguide plays the role of ocean memory in the ENSO cycle. It has led to an understanding of how this oceanic mechanism, working in concert with ocean-atmosphere feedbacks, gives rise to a class of coupled modes that are so critical to our understanding of ENSO physics. This understanding forms the theoretical basis for predicting ENSO and associated climate fluctuations on seasonalto-interannual time scales. What emerged from these studies during the TOGA decade was an appreciation that forecasting ENSO was indeed possible, and that accurate estimation of the upper-ocean state in the tropical Pacific was critical for such a forecast. This appreciation led to the development of the TOGA observing system in the tropical Pacific, and activity in developing initialization and assimilation schemes to exploit this valuable information about the ocean state, as well as continuing efforts to improve models and coupling strategies that facilitate the development of coupled model prediction systems. There is now a large body of literature devoted to issues concerning the role of the tropical Pacific Ocean in ENSO, including the monograph by Philander (1990) and a collection of papers in a special issue of the Journal of Geophysical Research (1998, Vol. 103, No. 14) dedicated to reviewing the progress of ENSO research in prediction during the TOGA decade. This review focuses on recent progress that has been made after TOGA and during the early years of the ongoing Climate Variability and Prediction (CLIVAR) Program.

The role of tropical oceans in climate goes far beyond ENSO. The global energy balance requires strong poleward heat transport out of the Tropics through both atmospheric and oceanic processes. Conditions in the tropical oceans make them highly effective in this heat transport. This is achieved through a number of oceanic processes. Among them are the entrainment of colder subsurface waters into the surface layer that enables the equatorial ocean to absorb atmospheric heat input, and the subsequent transport of these surface waters to the extratropics. This so-called warm water formation and escape (WWFE) process (Csanady 1984) in the upper tropical oceans is in sharp contrast to the deep and bottom water formation process in the polar oceans, both of which form a critical part of the global heat budget. Together with the atmospheric circulation, the tropical ocean circulation creates a unique environment for ocean-atmosphere interactions, which are critical elements of the global heat budget. It is in the Tropics where the warmest surface water resides, supporting atmospheric deep convection that is itself highly sensitive to changes in sea surface temperatures (SSTs). It is in this region where the ocean mixed layer is tightly coupled to the subthermocline ocean, allowing changes in the subsurface ocean to have a direct impact on SST. It is in this region where a sharp thermocline is formed and maintained by the large-scale ocean circulation, making changes in ocean circulation an important player in global climate variability. It is also in this region where the poleward oceanic heat transport is at its maximum, making it a critical part of the global heat budget. As will be discussed, the conditions that make all this possible are not mere accidents. Indeed, one of the major achievements of CLIVAR research has been a significant advance in our understanding of ocean dynamics and coupling processes that determine the structure of the tropical oceans and their direct connection to the subtropics.

There is no doubt that ENSO is the most spectacular and profound climatic phenomenon in the tropical ocean-atmosphere coupled system, whose impact reaches far beyond the tropical Pacific. Considerable progress has been made in the understanding of its variability and predictability over the past two decades. But it is by no means true that ENSO is the only mode of climate variability in the tropical coupled system. Nor does it mean that our understanding of this phenomenon is complete. While the effort is continuing to improve our understanding of ENSO dynamics and to refine the ENSO prediction system during the early years of CLIVAR, the scope and dimensions of this research have expanded considerably to explore the role of other climate phenomena in the tropical coupled system. These recent studies clearly indicate the need to improve our understanding of these other climate phenomena in order to extend our success in ENSObased seasonal climate prediction to the global domain.

In the Pacific sector, considerable recent research has been directed toward investigating the cause of decadal changes in the "mean state" of the coupled system and its relationship to ENSO. Although the observational 
record is too short to provide a "canonical" description of mean state changes, empirical studies show that the pattern of the low-frequency variation, albeit similar to ENSO in many aspects, has some distinctive characteristics. Among the distinctions is that its center of action in the Tropics shifts westward toward the western Pacific and Indian Oceans. Also, its meridional extent is considerably broader than the canonical ENSO pattern and its variability in the Tropics is linked to interdecadal climate fluctations over the North Pacific during boreal winter (Deser et al. 2004). This seasonal feature points to the fact that Pacific interdecadal variability involves not only tropical coupled dynamics, but also processes that involve interactions/exchanges between the Tropics and extratropics. In particular, the oceanic aspect of this tropical-extratropical exchange process and its role in determining the nature of the interdecadal changes in the Pacific coupled system has received focused attention in recent years.

In the tropical Atlantic, much of the recent research has been focused on two dominant patterns of coupled ocean-atmosphere variability that are closely linked to major climate fluctuations in the region. The so-called Atlantic zonal mode is often viewed as the Atlantic counterpart of the Pacific ENSO and varies primarily on interannual time scales, whereas the meridional mode seems unique to the tropical Atlantic coupled system and varies on multiple time scales. Collectively, these phenomena are termed as tropical Atlantic variability (TAV). TAV is tightly phase locked to the Atlantic seasonal cycle with distinctive seasonality. Although Pacific ENSO plays a dominant role in the remote forcing in TAV, those two phenomena can occur without remote influence from ENSO, suggesting that they are inherent to the tropical Atlantic coupled system. The role of the ocean in TAV remains largely unexplored. Recent studies suggest that processes controlling the zonal mode may be confined within the equatorial ocean, but those affecting the meridional mode may extend well beyond the Tropics, possibly including tropical-extratropical ocean exchanges and interactions with the Atlantic meridional overturning circulation (MOC).

In the Indian Ocean, recent anomalous events that took place during 1994 and 1997 led to the discovery of a new ocean-atmosphere coupled phenomenon now widely known as the Indian Ocean dipole (IOD) mode (Saji et al. 1999; Yamagata et al. 2003b, 2004) or the Indian Ocean zonal (IOZ) mode (Webster et al. 1999). The IOD mode has been shown to affect not only climate fluctuations in the Indian Ocean sector but also around the globe. Its discovery has generated vigorous interest in the study of ocean-atmosphere coupled dynamics over the Indian Ocean sector and the role of IOD in global climate variability. A prominent feature of the IOD is the characteristic east-west dipole pattern in SST anomalies that is in turn coupled to large thermocline anomalies. The atmospheric response to the SST dipole pattern is observed in wind and outgoing longwave radiation (OLR; Behera et al. 1999, 2003b; Yamagata et al. 2002) and sea level pressure (Behera and Yamagata 2003). These oceanic and atmospheric conditions imply that the Bjerknes-type (Bjerknes 1969) feedback mechanism is responsible for the IOD evolution. Therefore, the ocean memory is expected to play an important role through equatorial wave adjustment, but this needs to be investigated by more observation.

The purpose of this paper is to provide an overview of recent studies concerning the role of the oceans in a wide spectrum of climate phenomena within the tropical coupled system. For the sake of convenience, the discussion is divided geographically into three tropical ocean basins. For a comparative view of the mean state, seasonal cycle, and interannual variability among the tropical oceans, the readers are referred to Wang et al. (2004). We begin our discussion of the tropical Pacific Ocean in section 2, then move to the tropical Atlantic Ocean in section 3, and finally visit the tropical Indian Ocean in section 4. For each basin, instead of giving a general discussion of the ocean circulation, we focus on the oceanic processes that are most relevant to the specific phenomena in the region after a brief description of the phenomena and the feedback mechanisms. This division does not imply that the phenomena within each tropical ocean basin are independent of those in other basins. On the contrary, many of these phenomena are interrelated and interact among each other. In section 5 , we discuss the challenges that lie ahead.

\section{Pacific ENSO and decadal changes in ENSO}

Although its impact is global, the origin of ENSO resides in the tropical Pacific. The interaction between the atmosphere and ocean within the tropical Pacific basin plays a fundamental role in determining the characteristics of ENSO. Numerous studies have been devoted to documenting and understanding its evolution, its apparent preferred time scale, its phase locking to the annual cycle, its irregularity, and its impact. For a detailed account of the history of ENSO, the readers are referred to many review papers and monographs, in particular, the excellent text by Philander (1990) and the special issue of the Journal of Geophysical Research (1998, Vol. 103, No. 14). There is little dispute that 
ENSO is a genuine ocean-atmosphere phenomenon borne out of active interaction between the two components of the climate system. Its occurrence cannot be explained by either atmospheric or oceanic processes alone. In the following we first give a brief summary of our general understanding of this phenomenon, and then focus on the more recent studies that are mostly concerned with ENSO's predictability and its lowfrequency variability.

As a useful approximation, ENSO can be described as a climate perturbation around the mean state of the tropical Pacific coupled system. The mean state consists of an east-to-west gradient in SST and overlying trade winds (Walker circulation) of the tropical atmosphere that support a positive dynamical feedback: the temperature difference along the equator reinforces the strength of the trade winds by favoring large-scale ascent and atmospheric heating over the western equatorial Pacific and large-scale descent and atmospheric cooling over the eastern equatorial Pacific. In turn, the easterly wind stress acting on the ocean surface causes the thermocline to rise and the cold subsurface water to upwell in the east. The trade winds and associated equatorial upwelling maintain the climatological distribution in the tropical Pacific SST: that is, a western warm pool and eastern cold tongue structure in the equatorial Pacific. Because of the positive feedback, a modest change in either the equatorial SST or in the trade winds can trigger a chain reaction in the coupled system. For instance, if there is a weakening in the equatorial trade wind (a westerly wind anomaly), the equatorial upwelling will decrease. This causes a relaxation in the west-to-east slope of the thermocline and decreases the west-to-east sea surface temperature contrast. Since the Walker circulation is maintained by this surface temperature gradient, the weakening in the zonal temperature gradient will cause further weakening of the trade winds, which in turn causes further warming in the eastern equatorial Pacific. This feedback mechanism, known as Bjerknes' hypothesis, is the key element responsible for the development of warm (and cold) ENSO episodes.

The canonical picture of ENSO based on a variety of observations is entirely consistent with Bjerknes' hypothesis. The robust features accompanying warm ENSO events include 1) quasi-stationary warm SST anomalies in the eastern and central Pacific; 2) a relaxation of the trade winds associated with positive SST anomalies in the eastern and central equatorial Pacific at event onset; 3 ) a deepening in the east and a shoaling in the west of the thermocline along the equator, which lead the SST changes; 4) a tendency for the anomalously deep thermocline in the eastern-central Pacific to return to climatological values prior to the peak of the ENSO event; and 5) an increase in the trades in the far western Pacific one to two seasons prior to the onset of the ENSO event. These features underscore the tight coupling between the atmosphere and ocean during ENSO evolution.

ENSO events last approximately 12-18 months and occur every two to seven years with large variation in strength. Further analysis indicates that for most ENSO events the maximum warming in the eastern equatorial Pacific occurs in December and January. This property has been referred to as the phase locking of ENSO to the annual cycle. Linear (and nonlinear) wave dynamics of the equatorial waveguide are crucially important in giving rise to the quasi-oscillatory nature of ENSO. Oceanic Kelvin and Rossby waves propagate energy and momentum received from the wind stress, providing the oceanic memory that is so important to ENSO. [Similar waves exist in the atmosphere, but their propagation rates are far greater than the oceanic counterparts. Therefore, the adjustment time scale of the tropical atmosphere to changes in SST is much shorter (10 days or less) than the adjustment time scale of the equatorial ocean (approximately 6 months) to changes in wind stress. The short adjustment time of the atmosphere suggests the assumption (good to first order) that the atmosphere is in a statistical equilibrium with the SST on time scales longer than a few months.] Thus, the memory of the state of the climate system primarily resides in the ocean.

The free oceanic Kelvin and Rossby waves can be strongly modified by air-sea coupling. The Bjerknes feedback can destabilize these waves, giving rise to unstable coupled modes that resemble the slow westwardpropagating oceanic Rossby mode and the eastwardpropagating oceanic Kelvin mode. These coupled modes represent the extrema of the continuum of unstable coupled atmosphere-ocean modes. In fact, the coupling between the atmosphere and ocean generates a new breed of modes whose characteristics depend on the time scale of dynamical adjustment of the ocean relative to the time scale of SST change due to the air-sea coupling (Hirst 1986, 1988; Neelin 1991; Neelin and Jin 1993; Jin and Neelin 1993a,b). Stability analysis of a simple ENSO model linearized around a given mean state reveals a rich variety of structures in the coupled modes in a space spanned by parameters characterizing the two time scales (Neelin 1991; Neelin and Jin 1993; Jin and Neelin 1993a,b; Neelin et al. 1994, 1998). The coupled mode of most relevance to ENSO in reality appears to reside in a parameter regime where the time scales associated with the local air-sea inter- 
action are comparable to the dynamical adjustment time of the tropical Pacific Ocean.

The evolution of the coupled mode in this parameter regime can be described in two phases. During the development phase, the Bjerknes positive feedback dominates, which causes the anomalies to grow. During the decay phase, the equatorial wave adjustment process of the ocean plays a role of delayed negative feedback. Rossby wave packets carry off-equatorial thermocline anomalies of opposite sign to the equatorial anomaly generated by the Bjerknes feedback to the western boundary where they are reflected into equatorial Kelvin waves that subsequently propagate eastward along the equator. These negative feedbacks counteract the Bjerknes positive feedback and cause the system to have perpetual turnabouts from warm to cold states and back again. The time scale that is associated with the ocean wave adjustment provides the "memory" of the coupled system that is essential for the oscillations in this ENSO paradigm.

Mathematically, the behavior of the ENSO mode can be described by a heuristic differential-delay equation in terms of sea surface temperature anomaly. Therefore, this coupled mode is widely known as the "delayed-oscillator mode" (Battisti and Hirst 1989; Schopf and Suarez 1988, 1990). While the delayed oscillator appears to explain many features of both observations and models, it has not been directly verified through observation; in particular, the implied symmetry of cold and warm states seems unrealistic (Kessler 2002a). At the low frequencies of ENSO, determining wave reflection efficiency and other necessary components of the theory is extremely difficult (Zang et al. 2002), but the work of Schopf and Suarez (1990) pointed out that a wave reflection efficiency of as little as $15 \%$ could still sustain a viable oscillating system. The importance of Rossby wave dynamics and western boundary reflection was also noted by Schneider et al. (1995).

A related prototype ENSO model, known as the recharge oscillator, has been proposed by Jin (1997), in which the role of the equatorial Kelvin and Rossby waves in the ocean adjustment is described as the slow recharge/discharge of the equatorial heat content. This view makes use of the fact that the Rossby/Kelyin wave transit time across the basin is short in comparison with the period of ENSO, and therefore one may make a quasi-steady approximation, replacing the Rossby waves with Sverdrup balance, as described by Anderson and Gill (1975). This removes the wave transit time as a natural time scale of the problem, replacing it with a free parameter of the system. The free parameter determines the time it takes to recharge the off- equatorial heat content in response to changes in offequatorial wind stress curl. A major advantage of this approach is that the essential mechanism, interior Sverdrup flow, is more amenable to measurement, and monitoring of the low-frequency convergence of the tropical thermocline can be undertaken (Johnson and McPhaden 1999; McPhaden and Zhang 2002, 2004). The challenge to such monitoring, however, occurs because the hard-to-measure western boundary current transports may counteract the interior mass convergence.

In these theories, the ocean's role lies in the dynamical response of the thermocline throughout the Tropics to anomalous wind forcing, transmitting information across the basin through large-scale dynamics. When averaged over periods of a year or more, the delayed and recharge oscillators are fundamentally equivalent, both relying on wind-stress-curl-generated thermocline depth and geostrophic flow changes. Both oscillators are self-sustained, with the thermocline depth carrying the memory across both phases of the cycle. Alternative viewsof the ocean's role emerge in theories that ENSO is due to an advective mechanism (Picaut et al. 1997) or is due to equatorial-Kelvin-waves-only theories based on "westerly wind bursts" and stochastic forcing. The distinction between these views emerges through a concern over how equatorial wave signals alter the SST, which has important implications for whether simple predictive systems can be built. Neither of these alternative views seeks to determine the time scale of ENSO or its recurrence. Instead, they are concerned with the dynamics during the onset of ENSO. In the next section, we examine the source of ENSO irregularity.

\section{a. ENSO irregularity and predictability limit}

The detailed features of any single ENSO event vary considerably from case to case, including when and where the initial warming starts. For example, the 1997/ 98 event increased surface temperature near Peru by more than $5^{\circ} \mathrm{C}$. In contrast, in the $1986 / 87 \mathrm{ENSO}$ event the warming extended eastward only as far the midPacific (near $170^{\circ} \mathrm{W}$ ) and the maximum temperature was a modest $1{ }^{\circ} \mathrm{C}$ above normal. The warming from 1990 to 1994 consisted of three weak warm events and had a persistent "horseshoe shaped" SST anomaly. This irregularity reflects the complexity of the coupled ocean-atmosphere system and hints at the difficulties in predicting ENSO. Much remains to be done on the fundamental question of the predictability limit for ENSO. Beyond noting that some model systems seem to exhibit predictive skill for ENSO over a short time, 
we do not know whether this limit is essentially due to lack of model skill, the inability to adequately specify the initial conditions, or not-yet-understood fundamentals of the physical system.

Theories on the cause of ENSO irregularity can be broadly grouped into three categories: The first view argues for the importance of nonlinearity within the tropical coupled system. The nonlinearity arises from strong air-sea feedback that puts the coupled mode in an unstable dynamic region. In this regime, ENSO cannot only be described as a self-sustained oscillator, but it can interact nonlinearly with either the annual cycle (Jin et al. 1994; Tziperman et al. 1994; Chang et al. 1994; Wang et al. 1999) or other coupled modes (e.g., Mantua and Battisti 1995), giving rise to deterministic chaos. The loss of predictability is primarily due to the uncertainty in the initial conditions. This view relies upon fairly robust ocean wave dynamics that provide the underlying time scales for the problem.

The opposing view to this is the stochastic ENSO theory in which "weather" noise (which may include time scales up to the intraseasonal) generated by the internal dynamics of the atmosphere plays a fundamental role in not only giving rise to ENSO irregularity, but also in maintaining ENSO variance. In this view, the coupled mode is in a stable damped regime, and thus the ENSO cycle cannot be self-sustained without external noise forcing (Penland and Sardeshmukh 1995; Flügel and Chang 1996; Moore and Kleeman 1999a,b; Kleeman and Moore 1997; Thompson and Battisti 2000, 2001; Flügel et al. 2004). All noise forcing is not equal, however, and the spatial structure of some types of high-frequency atmospheric phenomena may project especially well onto optimally growing perturbations (Kessler and Kleeman 2000; Moore and Kleeman 1999b). There is observational evidence that the seasonal march of atmospheric convection (Vecchi et al. 2004) and intraseasonal disturbances (Takayabu et al. 1999) play an important role. The development of an ENSO event is not governed by the temporal characteristic of a single coupled mode, but is rather due to the interference of many coupled modes. Nonmodal growth within the coupled system is responsible for SST anomaly growth during an ENSO event, which can be influenced both by initial conditions and by stochastic forcing. Therefore, initial condition error as well as weather noise play an important role in limiting the predictability of ENSO. This view permits consideration of more variants on the role of the ocean. In particular, it permits the view that ENSO arises essentially through equatorial processes (including both wave propagation and ocean-atmosphere feedbacks) while the off-equatorial ocean behavior can be relegated to lower importance.

In between these two viewpoints is the view that ENSO is self-sustained (due to weak nonlinearity) and is periodic (Battisti 1988; Suarez and Schopf 1988; Jin 1997; Kirtman 1997). Its behavior is governed by the temporal characteristics of the single most dominant coupled mode plus the influence of weather noise. In this scenario of ENSO, predictability comes from the oscillatory nature of the dominant mode (Chen et al. 2004), while the loss of predictability is primarily due to noise influence. Different from the stochastic ENSO theory where the noise influences the nonmodal growth of the coupled system, the role of the noise in this case is to disrupt the regular oscillation of the dominant mode (Fedorov et al. 2003). In this regime, the ocean wave dynamics and reflection properties must also be sufficient to sustain the oscillation.

Pinpointing exactly where in the parameter regime ENSO resides in reality is difficult, if not impossible, given the available observations. Many of the recent studies on this issue are based on relatively simple coupled model simulations and prediction experiments. Some of the evidence supporting stochastic ENSO theory is based on the finding that in the damped regime the coupled model forced by stochastic processes produces the best fit to observed ENSO statistics (e.g., Thompson and Battisti 2001; Penland et al. 2000). Other evidence comes from the finding that there is a lack of support for a continuous ENSO cycle, as depicted by the delayed oscillator theory, in the observations (Li and Clarke 1994; Kessler and McPhaden 1995; Weisberg and Wang 1997; Harrison and Vecchi 1999; Zhang and Rothstein 2000; Larkin and Harrison 2002; Kessler 2002a; Lengaigne et al. 2004). In particular, there is little observational evidence that the initiation of an ENSO event relies on the memory of a previous event, though the termination of an event is generally consistent with the delayed oscillator mechanism. The break in the cycle suggests that the system is in a damped regime and the onset of ENSO relies on external influences (Kessler 2002a). Other studies dispute the stochastic hypothesis by providing evidence that seems to be more consistent with the self-sustained ENSO theory. As demonstrated in Schopf and Suarez (1988) and discussed in Jin (1997), a system with a stable, periodic oscillation in the absence of noise can become irregular with the addition of stochastic forcing and will present statistics that appear to be more stable. Chen et al. (2004) provide retrospective forecasts of ENSO over a 148-yr period and show that all prominent ENSO events can be hindcasted at lead times up to two years (Fig. 1). Such a long predictability is in 
a
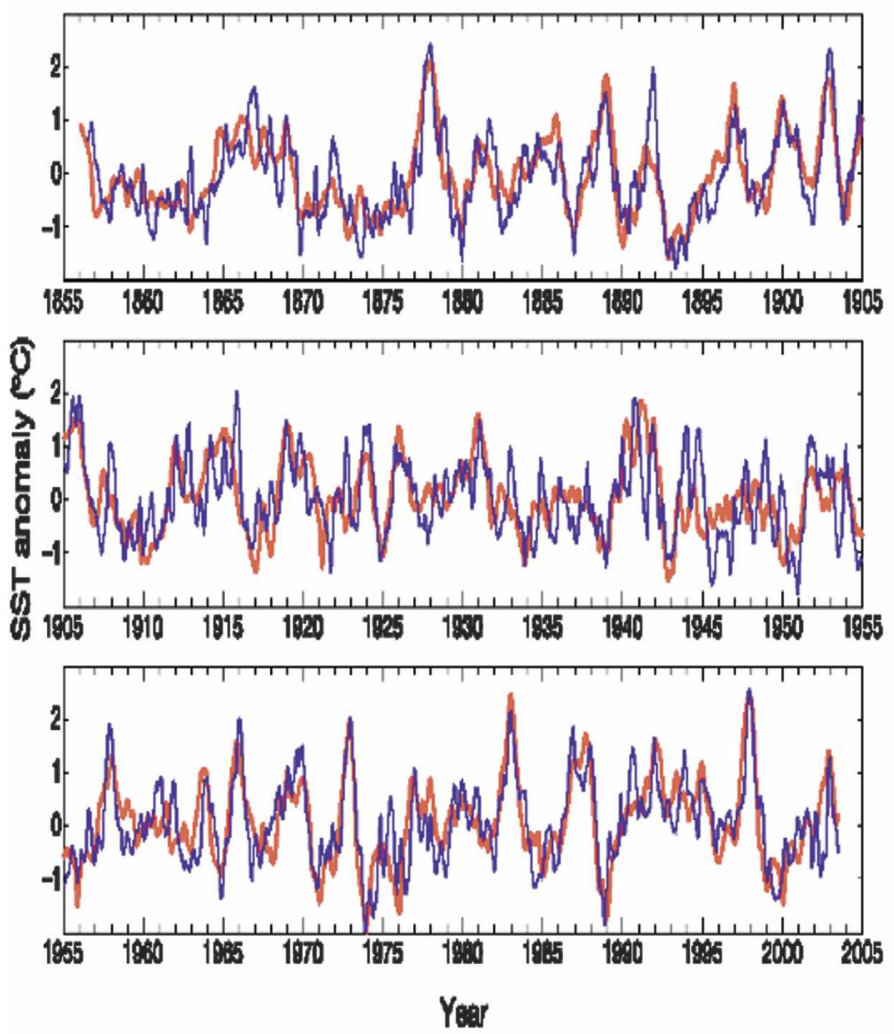

b

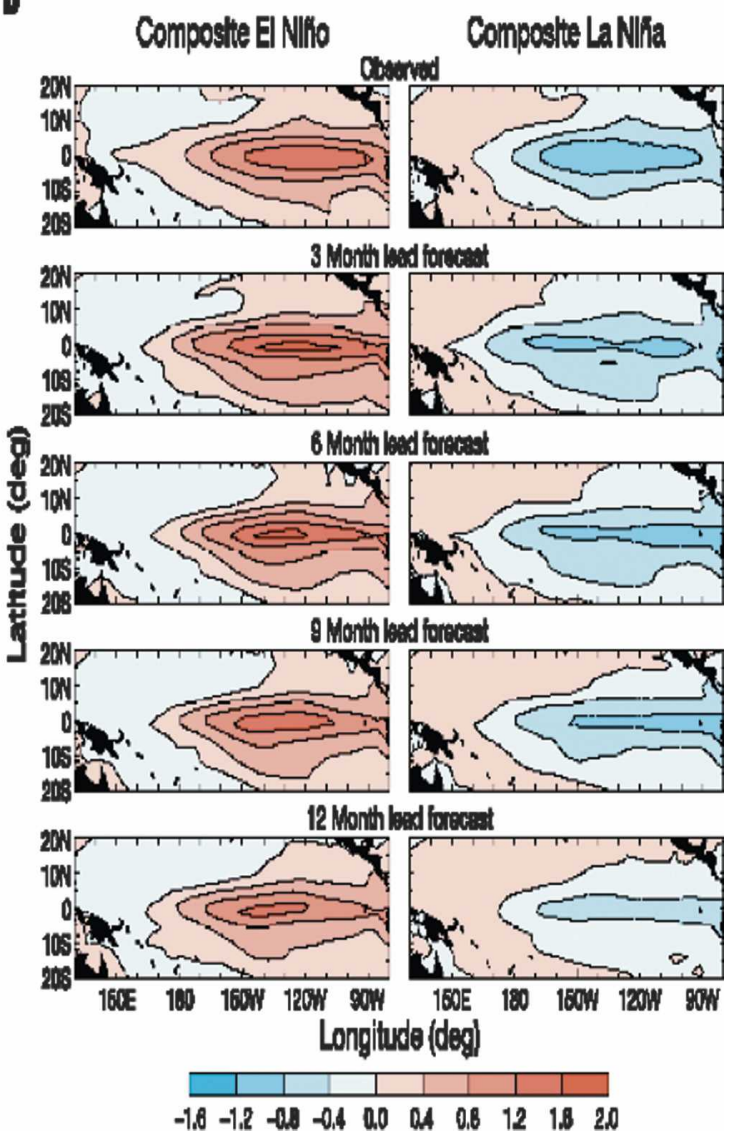

FIG. 1. Retrospective forecasts of ENSO from 1857 to 2003. (a) Niño-3.4 time series (red: observed; blue: predicted at lead time of 6 months) and (b) composite ENSO events. (From Chen et al. 2004.)

better agreement with the self-sustained ENSO theory than the stochastic theory; however it remains to be tested in the crucible of an actual forecast.

\section{b. Decadal changes in ENSO and in mean state}

When the entire observational record is considered, many studies have pointed out that there is a noted change in ENSO statistics over the past $100 \mathrm{yr}$, including a decadal-scale modulation in ENSO amplitude (Gu and Philander 1997) and ENSO's phase locking to the annual cycle (Balmaseda et al. 1994). The change that has caught the most attention took place in the mid-1970s. Many have argued that the characteristics of ENSO have changed after 1977, including its predictability (e.g., Balmaseda et al. 1994; Chen et al. 1995). Model studies (Kirtman and Schopf 1998) have seemed to show that there is the possibility of a relationship between the amplitude of ENSO cycles and the limit of its predictability-some decades may be much more predictable than others. In addition to the low- frequency secular changes of ENSO, there is also evidence for a broad-scale interdecadal climate fluctuation over the Pacific sector with its phase transitions in 1925, 1947, and 1977 (Graham et al. 1994; Trenberth and Hurrell 1994; Mantua et al. 1997; Minobe 1997; Zhang et al. 1997; Dettinger et al. 2000; Chao et al. 2000; Mantua and Hare 2002; Deser et al. 2004). Some studies suggest that the low-frequency modulation of ENSO and the interdecadal fluctuation may be linked, as there appear to be notable changes in ENSO statistics before and after the 1977 climate transition (e.g., Fedorov and Philander 2000). More recent studies have cast some doubts on the linkage between the two. Deser et al. (2004) show that the 1925 and 1947 phase transitions are not evident in ENSO indices, even though the 1977 transition is (Fig. 2). Yeh and Kirtman (2004, 2005) further argue, based on observational and modeling studies, that the Pacific interdecadal fluctuation is not related to the modulation of ENSO, suggesting that the two phenomena are governed by different physical processes. We defer the discussion on the Pacific interdec- 
ENSO

\section{Epoch Difiference}
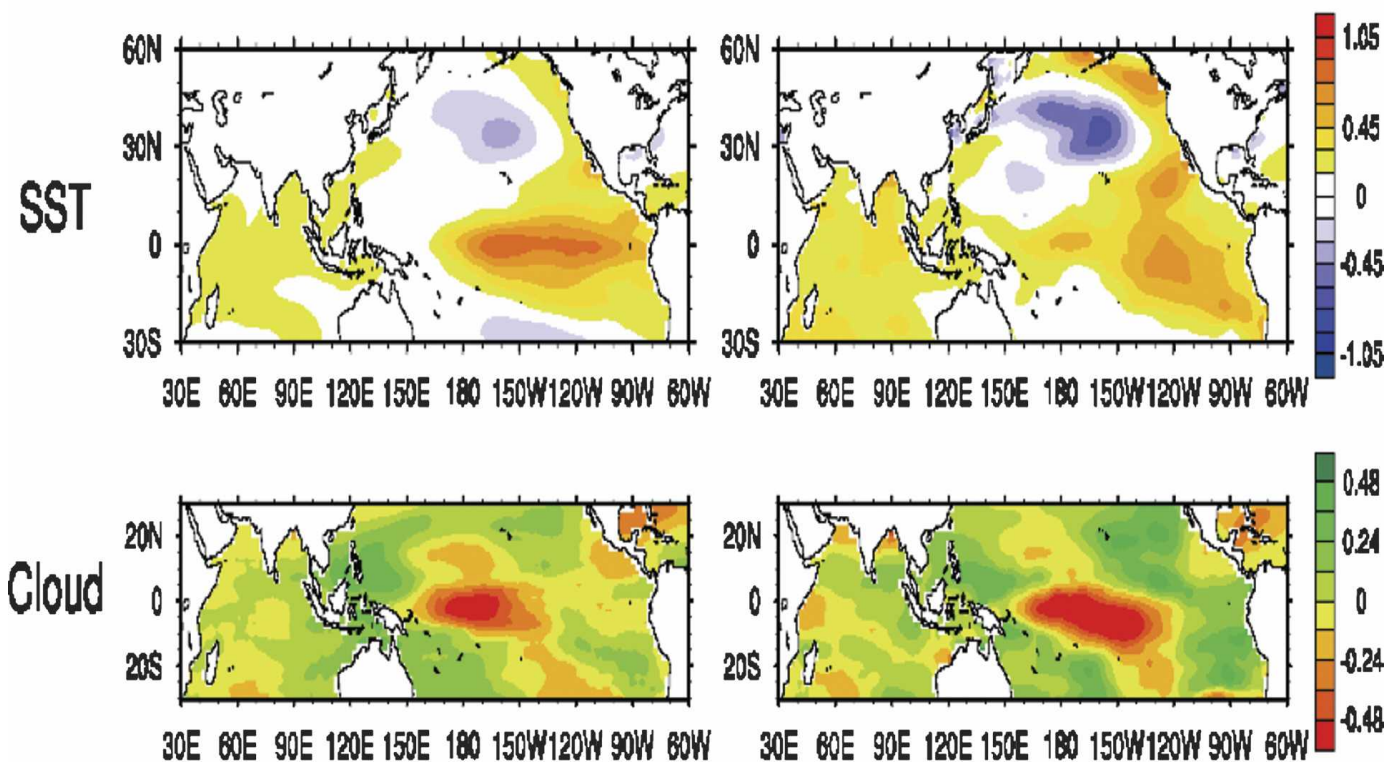

FIG. 2. Comparison between (left) ENSO and (right) epoch difference patterns of (top) SST and (bottom) cloudiness anomalies during boreal winter. The ENSO patterns are based upon linear regression of the anomaly fields upon the cold tongue index (CTI) during 1947-97, and the epoch difference maps are obtained by subtracting the period 1947-76 from the period 1977-97. The color bar scale for the SST (cloudiness) anomalies is given on the right-hand side of the figure in units of ${ }^{\circ} \mathrm{C}$ (oktas). Note that the ENSO-related anomalies are per unit std dev of the CTI. (From Deser et al. 2004.)

adal fluctuation to the next section. Here we review some of the ideas that have been put forward about the cause of ENSO irregularity and the dynamics of ENSO predictability.

\section{1) STOCHASTIC MECHANISM}

Some studies argue that the stochastically driven, damped ENSO system can exhibit "decadal regime shifts" that resemble the observed ENSO amplitude modulation (Flügel and Chang 1999; Thompson and Battisti 2001; Kleeman et al. 2003; Yeh et al. 2004; Flügel et al. 2004), and thus propose that the stochastic ENSO mechanism should be regarded as a null hypothesis for decadal modulation of ENSO.

Kirtman et al. (2005) used a new coupled general circulation model (CGCM) coupling strategy, called an interactive ensemble procedure (Kirtman and Shukla 2002), to reduce the impact of internal atmospheric variability on coupled ENSO dynamics. This approach allows a test of the stochastic ENSO hypothesis within a comprehensive coupled system framework. Kirtman et al. (2005) reported that in their CGCM there are well-defined areas in the western tropical Pacific where the coupled variability cannot be explained by the sto- chastic ENSO theory. It implies that in western tropical Pacific the ocean-atmosphere feedback may be so strong that nonlinearity must be taken into consideration.

\section{2) Mean state changes}

A number of recent studies (Timmermann et al. 1999; An and Jin 2000; Fedorov and Philander 2000; Fedorov et al. 2003; Urban et al. 2000; Wang and An 2001, 2002) propose that the low-frequency changes in ENSO can be attributed to changes in the mean state of the coupled system. An implicit assumption built into this proposal is that ENSO behavior is, to a large extent, controlled by the most unstable coupled mode whose characteristics depend sensitively on the mean state of the coupled system.

Using a simple coupled ocean-atmosphere model, Fedorov and Philander (2000) explored the properties of the most unstable coupled mode in the parameter space spanned by the mean thermocline depth $H$ and the mean strength of the trade wind stresses $\tau$. Their finding suggests that with a moderate change in $H$ and/or $\tau$, the dominant coupled mode can migrate from an SST-mode regime where the entrainment of cold 

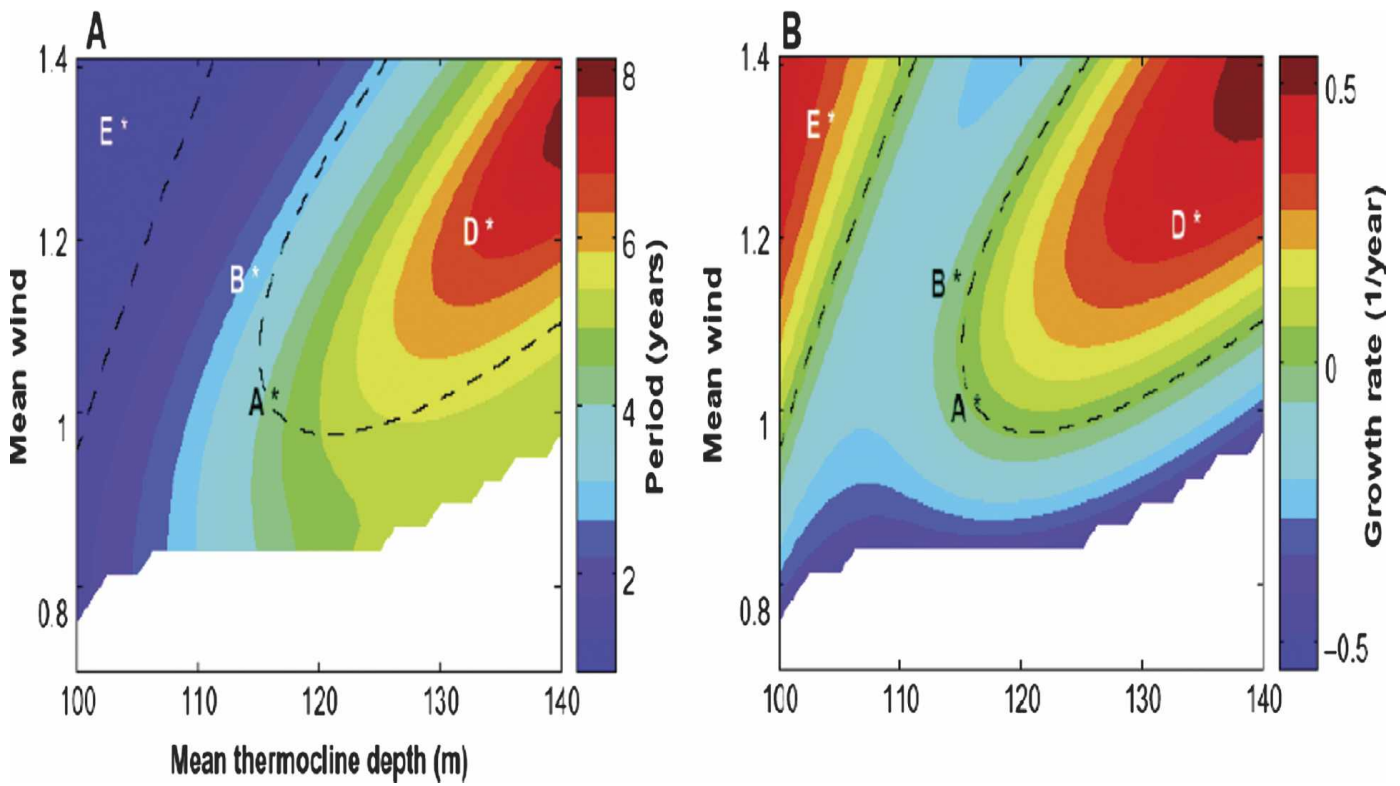

FIG. 3. The period (A) and growth rate (B) of the most unstable coupled mode as a function of mean thermocline depth $(\mathrm{H})$ and strength of the trade winds $(\tau)$. (From Fedorov and Philander 2000.)

water across a shallow thermocline is a controlling factor in regulating SST to a delayed-oscillator-mode regime where thermocline fluctuations induced by equatorially trapped waves are a major factor in controlling SST changes (Fig. 3). The SST-type modes reside in a state where the mean thermocline depth is shallow, so that entrainment is effective in changing SST, whereas the delayed-oscillator-type modes reside in a state where the mean thermocline is deep, so that SST changes require vertical movements of the thermocline. Fedorov and Philander suggest that the present-day mean state of the tropical Pacific will put ENSO in an area close to neutral stability. They went on to further argue that the change in ENSO statistics during the 1980 s and 1990s can be attributed to the relatively warm conditions in the eastern tropical Pacific, which is caused by a weakening in the trade winds (a small decrease in $\tau$ ) and deepening in the thermocline depth (a small increase in $H$ ). According to their stability analysis, such a small change in the mean state is sufficient to alter the structure of the most unstable mode, causing it to move closer to the delayed-oscillator-type mode, which tends to have a longer period $(5 \mathrm{yr})$ than that (3 yr) of the SST-type mode. Kirtman and Schopf (1998) argued that the decadal modulation in ENSO predictability can be attributed to the fact that ENSO resides near the neutral stability boundary and external stochastic processes can move it above or below the stability boundary, causing changes in its predictability. The predictability is shorter in the decades when ENSO is below the neutral stability boundary than in the other decades when ENSO is above the neutral stability boundary, because the cycle is damped in the former and self-sustained in the latter.

\section{3) Anthropogenic Forcing}

Timmermann et al. (1999) and Collins (2000) presented modeling evidence, based on comprehensive coupled general circulation model simulations, that anthropogenic greenhouse warming can have an influence on stability of the coupled system through gradual change in the upper-ocean stratification. In particular, these studies noted that greenhouse gas-induced warming can lead to an increase in mean stratification of the upper equatorial ocean, which in turn leads to an increase in both the amplitude and frequency of ENSO in the models. This finding contradicts earlier modeling studies that suggest little change in ENSO behavior (Tett 1995) or even weakened ENSO variability in response to anthropogenic greenhouse warming (Knutson and Manabe 1994; Knutson et al. 1997). Knutson et al. attributed the weakened variability to $\mathrm{CO}_{2}$-induced changes in the model's time-mean basic state, including a reduced time-mean zonal SST gradient. They further note that the multidecadal amplitude modulations of ENSO become more pronounced with increased $\mathrm{CO}_{2}$. Insufficient ocean model resolution in the earlier modeling studies was partly blamed for the different model response (Timmermann et al. 1999). The results of the 
recent model studies are also consistent with a coupled model sensitivity study by Meehl et al. (2001) that shows that a lower vertical diffusivity yields a greater ENSO variability, because of the sharper and lessdiffused thermocline.

\section{4) NONLINEAR DYNAMICS}

The view that ENSO is inherently nonlinear and chaotic has led to investigations that the decadal variation in ENSO may arise from a nonlinear, internal source. A number of investigators (Burgers and Stephenson 1999; Jin et al. 2003; An and Jin 2004) point out the fact that the probability distribution function (PDF) of ENSOrelated SST anomalies is skewed to the positive value, which cannot be explained by the linear theory. In particular, there seems to be more warm ENSO events than cold events in the past two decades, including the two most intense El Niño episodes in 1982/83 and 1997/ 98 (Fedorov and Philander 2000). Timmermann et al. (2003), based on a theoretical ENSO model, proposed a nonlinear bursting mechanism for the occurrence of extreme El Niño events and suggested that the nonlinearities in the tropical heat budget can contribute to El Niño decadal amplitude changes. An and Jin (2004) analyzed the upper-ocean heat budget of the National Centers for Environmental Prediction (NCEP) ocean data assimilation (Ji et al. 1995; Behringer et al. 1998; Vossepoel and Behringer 2000) and the simple ocean data assimilation (SODA) product (Carton et al. 2000) and found that nonlinear vertical and zonal oceanic advection act to enhance the amplitude of warm ENSO episodes and reduce the amplitude of cold ENSO episodes, resulting in the warm-cold asymmetry. They further argued that the nonlinear heating-induced changes in ENSO amplitude have a rectification effect on the climate mean state (Jin et al. 2003). Rodgers et al. (2004) have examined decadal variability in a coupled GCM and find that the decadal changes in the mean state may not be discernable from residuals in the statistics. Schopf and Burgman (2006) present a pure kinematic argument to explain ENSO asymmetry and residual effect on the mean state without invoking changes in stability of the coupled system. In their mechanism, if El Niño can be viewed as an oscillating front between warm and cold water, an increase in the excursion of the front (the "strengthening" of El Niño) results in a change to the Eulerian time mean. But at any single instant, the state is characterized by the same front separating the same warm and cold water. This study raises an interesting question: Do changes in the amplitude of ENSO necessarily imply changes in the stability of the coupled system?

\section{5) Observational eVidence}

Parallel to the theoretical debate on whether there is a linkage between changes in ENSO statistics and changes in mean state, there is a lack of agreement from observational analyses on this issue. Some studies report findings that support the modeling and theoretical results, while others do not. For example, Urban et al. (2000) presented an analysis based on a 155-yr ENSO reconstruction from a central tropical Pacific coral and found that there is a tendency for ENSO frequency to shift from a shorter period (less than $3 \mathrm{yr}$ ) to a longer period as the mean state becomes warmer from the mid-late nineteenth century to the present. Solow and Huppert (2003), on the other hand, performed a test on the evolutionary spectral analysis of a century-long sea level pressure time series at Darwin, as well as the Niño-3 SST time series, and found that local variations in ENSO over the past century are not inconsistent with overall stationarity. Cobb et al. (2003) pieced together a fossil-coral record over the past $1100 \mathrm{yr}$ and found no consistent evidence that variations in ENSO statistics are linked to changes in mean climate conditions in the tropical Pacific. Some of the inconsistencies may reflect the fact that the dominant fluctuation patterns at decadal or longer time scales are different from those associated with the low-frequency modulation of ENSO, as noted recently by Deser et al. (2004) and Yeh and Kirtman (2004, 2005). Clearly, there is a need to continue scrutinizing the existing instrumental and paleoproxy datasets for further evidence of a possible relationship between variations in ENSO and changes in the mean state. While the search for this relationship continues, there is considerable interest in developing a thorough understanding of the role of the tropical ocean in interdecadal or longer-term fluctuations of the coupled mean state, as these changes can have an impact on global climate, even if they are not directly linked to ENSO. In the following section, we review some of the key aspects concerning the role of the ocean in low-frequency changes of the tropical mean state.

\section{c. Role of the ocean in tropical mean climate}

\section{1) Subtropical Cells AND EQuAtorial THERMOCLINE VARIABILITY}

Two of the key features of the tropical oceans that hold primary interest for climate study are the sharp thermocline and the "cold tongue" of surface waters along the equator at the eastern side of the ocean basins. This latter feature is prominent in the Pacific and seasonally apparent in the Atlantic. It is a manifestation of the surfacing of the thermocline in the east. The 
structure of the thermocline affects the sensitivity of the surface temperature to the subsurface ocean variability, which in turn affects the coupling between the ocean and atmosphere. Simple models for ENSO have shown sensitivity to the sharpness and tilt of the thermocline, and a growing body of literature has developed around the issue of how the mean conditions of the thermocline may be altered on longer time scales.

The equatorial thermocline is now understood to connect to the subtropical thermocline through a circulation system known as the subtropical cells (STCs) or shallow overturning circulation. The canonical zonalaverage picture of the STC circulation shows that subducted water from the subtropical gyres flows toward the equator at depths of about $100-400 \mathrm{~m}$, feeds into the Equatorial Undercurrent (EUC), upwells in the eastern equatorial region and returns to the subtropics in the surface layer. Sea surface temperature distributions reflect this circulation pattern: the SST is much colder in the eastern equatorial region where upwelling prevails than in the western basin. This circulation system can respond to changes in atmospheric conditions not only within the Tropics, but also in the extratropics.

This overturning flow occurs in the presence of a complex upper-ocean circulation system. In the tropical Pacific and Atlantic the circulation is characterized by alternating bands of eastward-and westward-flowing currents: a narrow eastward surface current-the North Equatorial Countercurrent (NECC)-between $3^{\circ}$ and $10^{\circ} \mathrm{N}$, the two broad westward surface currents-the North and South Equatorial Currents (NEC and SEC) - to the north of $10^{\circ} \mathrm{N}$ and to the south of $3^{\circ} \mathrm{N}$, respectively, and a swift subsurface jet-the EUCcentered at the equator over a depth of approximately $150 \mathrm{~m}$ and a width of approximately $300 \mathrm{~km}$.

The fundamental dynamics of the STC circulation was set forth by McCreary and Lu (1994). Their theoretical and modeling studies demonstrated the connection between the ventilated thermocline theory (Luyten et al. 1983), used to describe the subtropical thermocline gyres, and the supply of water to the equatorial cold tongue. They provide a description of a shallow circulation driven by wind stress curl and a specification of the surface density field. Since the net Ekman flow across the equatorward side of the subtropical gyres is poleward, the subsurface geostrophic flow must have a net flow toward the equator. Together with the work of Lu et al. (1998), these models point out consequences of the beta effect and the large-scale wind curl as causing a net convergence of relatively cold water into the equatorial belt. In these theories, the subducted water is presumed to flow in an essentially geostrophic, adiabatic fashion, with water mass transformation only pos- sible when the flow is in contact with the near-surface layers. Therefore, the net convergence of cold subducted water would imply that this water must emerge at the surface within the Tropics. With the mean easterly trade winds, the necessary upwelling conditions apply at the eastern end of the equator, along the American coasts, and in a few isolated regions such as the Peru upwelling and the Costa Rican dome (Umatani and Yamagata 1991; Kessler 2002b). (McCreary and Lu provide some intriguing examples of how the circuit of cold water can be completed off the equator even if no equatorial winds are available to cause upwelling.) Some leakage of Northern Hemisphere thermocline water through the Indonesian throughflow is accounted for in the $\mathrm{Lu}$ et al. work and has been quantified in diagnostic models (Blanke et al. 2001).

Further studies with more complex ocean circulation models have investigated the source waters of the equatorial undercurrent or equatorial cold tongue (Rothstein et al. 1998, Harper 2000; Huang and Liu 1999; Malanotte-Rizzoli et al. 2000; Rodgers et al. 2003; Fukumori et al. 2004) and are largely in agreement that the source waters of the equatorial undercurrent and equatorial cold tongue lie well within the subtropical gyres. Observations support the canonical view of the STCs (Johnson and McPhaden 1999).

With the STC circulation connecting the subtropics with the equator, it became a question of interest as to whether anomalies could propagate from the subtropics to the equator and thereby influenced ENSO. Small changes in the transport of properties along the STCs could lead to changes in the equatorial thermocline and, as discussed previously, alter the stability properties of the ENSO system.

From the climate perspective, the ventilated thermocline theory is limited by its focus on the ocean. To make a description of the STC flow, both the wind stress and the surface density patterns must be specified. Altering either will induce changes to the STC that may be reflected in a changed structure in the equatorial thermocline. Early work examined the subduction of temperature anomalies onto the mean STC circulation (Gu and Philander 1997). This concept drew upon the observational work by Deser et al. (1996), which suggests that extratropical temperature anomalies propagate equatorward. Further modeling studies elucidated the concept that anomalies that have a signature in potential density will not simply flow along the isopycnals but will propagate as planetary waves via undulations of isopycnals (Lysne et al. 1997; Huang and Pedlosky 1999; Liu 1999a,b). An exception to this behavior is found if the temperature anomalies are compensated by salinity, so that they remain on isopycnal 


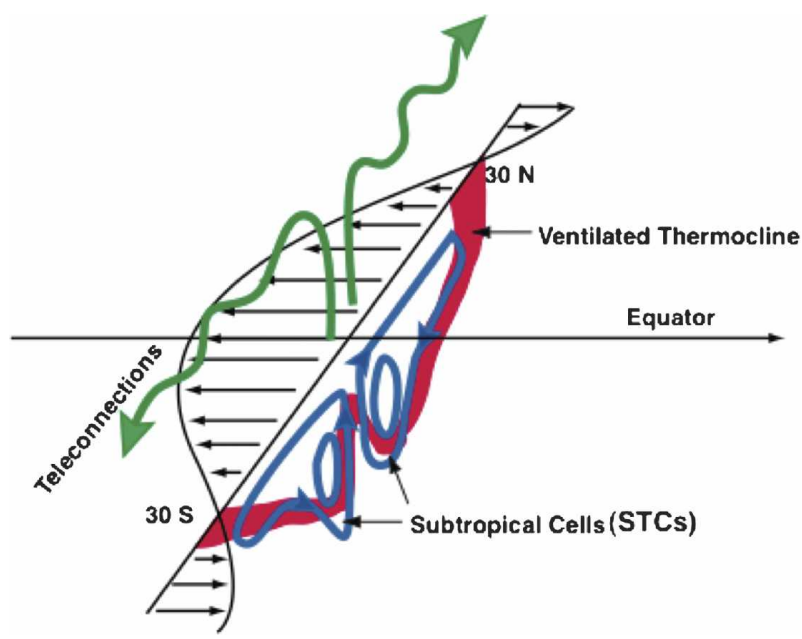

FIG. 4. Schematic sketch of the hypotheses of STC-induced decadal changes in the tropical Pacific mean state by Gu and Philander (1997) and Kleeman et al. (1999). The Gu-Philander mechanism emphasizes the advection of thermal anomalies by the STCs, while Kleeman et al. mechanism emphasizes changes in STCs. Note that the sketch shows a zonally averaged view of the STCs. In reality, much of the equatorward geostrophic transport probably occurs in the western boundary current.

surfaces, forming "spiciness" anomalies. The spiciness anomalies may be advected by the mean STC circulation (Schneider et al. 1999; Schneider 2000; Zhang et al. 2001; Yeager and Large 2004). A second mechanism for STC-induced variability hypothesizes that changes in the wind stress curl patterns alter the strength of the STCs. They may undergo decadal variations that cause changes in the equatorial thermocline by affecting either the upwelling rate or the relative supply of colder or warmer water (Kleeman et al. 1999; Klinger et al. 2002; Nonaka et al. 2002). Figure 4 provides a conceptual sketch of a zonally averaged view of the mechanisms proposed by Gu and Philander (1997) and Kleeman et al. (1999). Both mechanisms have been extensively studied in models of the Pacific, although no resolution has been reached. Some studies suggest that oceanic teleconnections are not efficient enough to cause modulations in the Tropics (Schneider et al. 1999; Hazeleger et al. 2001) and others suggest that oceanic teleconnections seem to be working in the Southern Hemisphere (Chang et al. 2001a; Giese et al. 2002; Bratcher and Giese 2002).

With the Tropical Atmosphere Ocean (TAO) array and the extensive measurement programs in place for ENSO prediction, McPhaden and coworkers have been able to quantify the changes in the STCs over the past several decades. Zhang et al. (1999) noted that the STC strength had been spinning down over the past $30 \mathrm{yr}$ and that this could cause a warming in the eastern $\mathrm{Pa}$ - cific. More recent measurements (McPhaden and Zhang 2004) indicate that the circulation has rebounded. The conclusions of McPhaden and Zhang are based on the understanding that the interior cross-gyre flow is geostrophic and large scale. What remains to be examined is whether there is compensation for the equatorward flow in the western boundary current systems.

The work on STCs has largely focused on understanding the mechanisms for its variability and the understanding of its dynamics. It has been somewhat taken for granted that the changes induced in the equatorial structure will lead to a modification in ENSO, altering its amplitude, predictability, or frequency. Actual demonstration of this connection remains to be made or observed. One counter suggestion has been made using model studies. Yeh and Kirtman (2004) obtained model results that exhibit (at least) two modes of decadal variability in the Pacific. One has a high pattern correlation with the observed decadal changes seen by McPhaden and Zhang (2004; Figs. 5 and 6) but is not correlated with changes in ENSO variance over time. A second mode correlates well with the amplitude of ENSO (Fig. 6) but has a spatial pattern more akin to the residual modes described by Rodgers et al. (2004). One possible view of the situation is that the lowfrequency variations in the STCs generate a broad tropical response in the upper ocean, but these do not lead to significant changes in ENSO. At the same time decadal variation of ENSO may arise as a stochastic process [as in Flügel et al. (2004) and other works above] that exhibits the residual effect described by Schopf and Burgman (2006).

\section{2) Maintenance of the equatorial THERMOCLINE}

Continuing beyond the consideration of decadal changes, the examination of the role of the tropical ocean in long-term mean climate requires further study of STCs and their details. Investigators have begun to examine the basic structure of the shallow overturning and its relation to the general circulation of the atmosphere. If the concept that the STCs form an isolated cell in the upper ocean is correct, then these circulations connect the two largest heat sources and sinks in the Pacific - the equatorial cold tongue and the region of the Kuroshio off Japan. The heat transport by the shallow circulations has been examined by Held (2001) and Klinger and Marotzke (2000). Water in the midlatitudes approaches thermal equilibrium with the atmosphere before being subducted and sequestered away from the heat fluxes at the surface. This water is then brought back to the surface at the equator. The circuit 


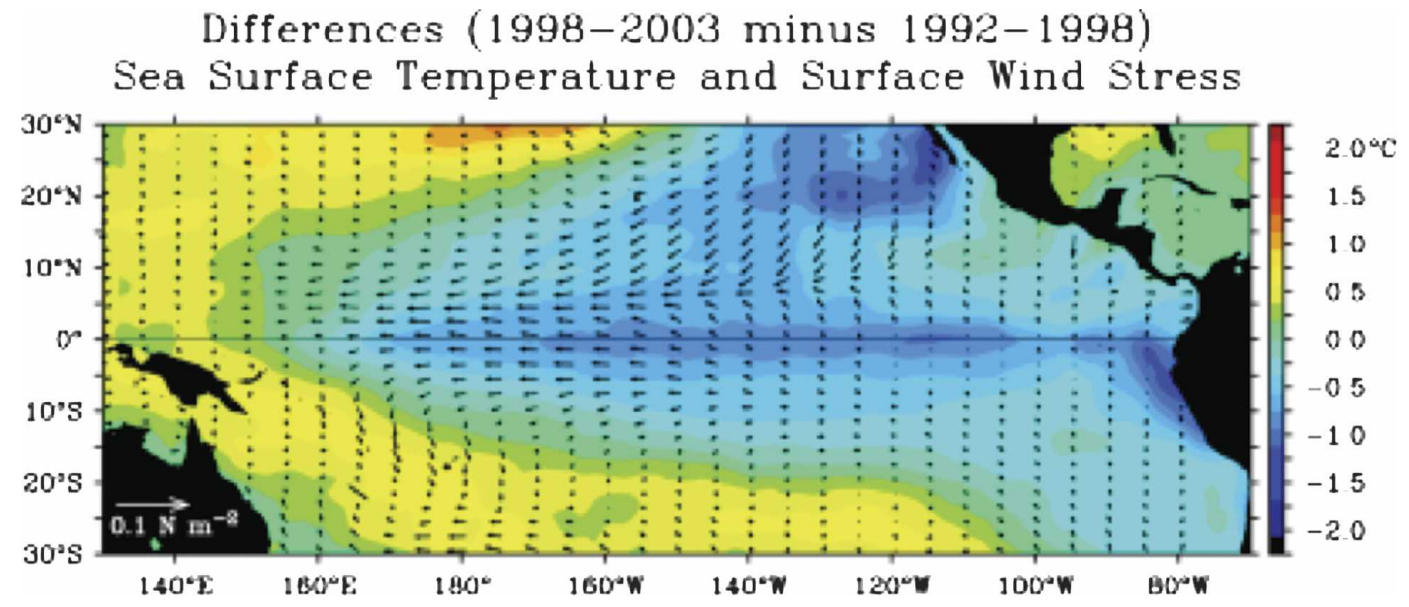

FIG. 5. Decadal differences in SST and winds in the tropical Pacific. (From McPhaden and Zhang 2004.)

of flow from cool midlatitudes to the equator acts as a strong conductor, linking the equator to the region of subduction. Boccaletti et al. (2004) frame the problem in a slightly different fashion by asking the question of how the heat transport by STCs can work as a constraint for the equatorial thermocline depth, but also find that the connection between the heat gain in the ocean in the equatorial cold tongue and its return to the atmosphere in the subtropics is strong. This implies that a large component of the net heat transport by the ocean is accomplished by the STCs.

In the simplest view of the STCs as ventilated thermocline pathways complemented by surface poleward flow, the subsurface flow was envisioned as adiabatic and geostrophic, leading the concept of "potential vorticity pathways." If the flow were indeed adiabatic, then some part of the equatorial cold tongue should appear significantly colder than it is. Closer examination of model results indicates that substantial diapycnal transformation is occurring along the flow (Rodgers et al. 2003). The model studies of Boccaletti et al. (2004) demonstrate that increasing the background thermal diffusivity within the ocean has a strong impact on the heat transport as well as the overall structure of the cold tongue. The McCreary and Lu (1994) view of the STC envisions water beneath the thermocline that does not surface in the Tropics. It must connect relatively cold waters from the subpolar gyres from one hemisphere to the other. Such a layer need not transport any heat but can be in simple thermal equilibrium with the atmosphere in the higher latitudes. In the presence of diapycnal mixing, however, this water will cool the lower limb of the STC, having the practical effect of connecting the equatorial surface water to latitudes further poleward than the adiabatic STC theory would indicate. Much of this mixing occurs in the highly sheared regions above and below the equatorial undercurrent, but significant diapycnal mixing is also indicated along the pathways between subduction and the equatorial region where the flow returns to the surface. The physics of mixing in models is still not reliable enough to quantify the role of along-path mixing, and the wide variety of model representations of the role of the STCs testifies to the sensitivity of models to their vertical diffusivities. A major model development task in CLIVAR is to improve and verify these subtle, but far-reaching, parameterizations.

One of the most important and vigorous regions of diapycnal mixing in the open ocean is in and around the equatorial undercurrent. Upwelling transport into the upper layer of the east-central Pacific appears to balance the Ekman divergence across $\pm 5^{\circ}$ latitude, about $30-50 \mathrm{~Sv}\left(1 \mathrm{~Sv} \equiv 10^{6} \mathrm{~m}^{3} \mathrm{~s}^{-1}\right)$. Part of this transport flows eastward along upward-sloping isopycnals, but there is a significant diapycnal conversion of water mass properties, in which thermocline water flowing into the region at temperatures of $18^{\circ}-24^{\circ} \mathrm{C}$ is warmed to flow out meridionally at temperatures $5^{\circ} \mathrm{C}$ or so higher, a heat gain on the order of $50-80 \mathrm{~W} \mathrm{~m}^{-2}$ (Bryden and Brady 1989; Weisberg and Qiao 2000; Meinen et al. 2001). This entrainment occurs as the surface gains heat through solar shortwave radiation that is spread downward into the upper thermocline by turbulent mixing. Although the turbulent mixing processes have been the subject of many studies (see Gregg 1998 for a review) the details and mechanisms of these, and how they may be represented in ocean circulation models, are not well understood.

The picture of the STC circulation is further complicated by an asymmetry between the Northern and Southern Hemispheres and the involvement of lowlatitude western boundary currents in the circuit. The 

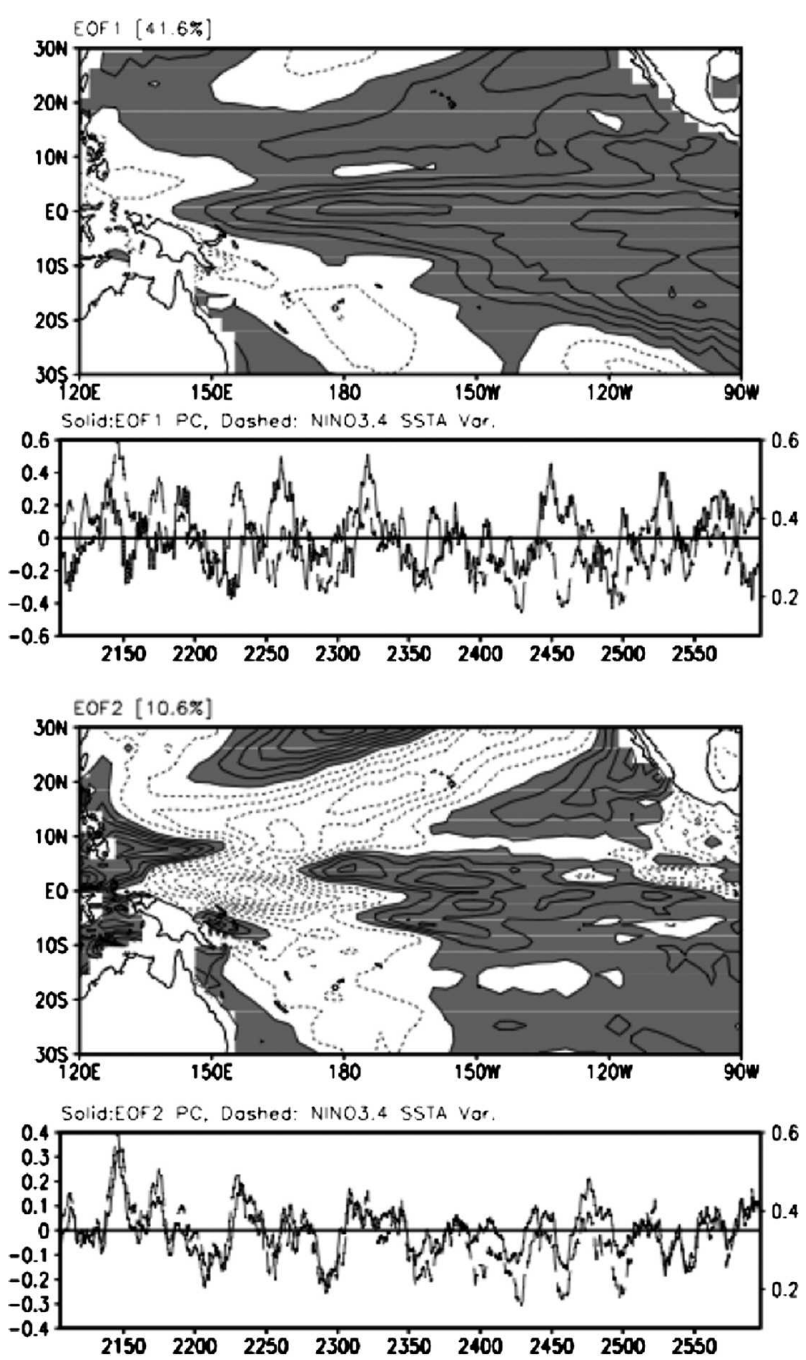

FIG. 6. Leading EOFs of the low-passed SST from the coupled GCM experiments of Yeh and Kirtman (2004). The leading EOF has a low correlation with the Niño-3.4 SSTA variance, while EOF2 has a high correlation. Note the similarity of the EOF1 pattern with the observed changes from McPhaden and Zhang (2004)

bias of the atmospheric intertropical convergence zone (ITCZ) to lie in the Northern Hemisphere imprints a narrow band of anomalous potential vorticity (PV) across the Pacific around $10^{\circ} \mathrm{N}$. This forms a "PV barrier" that causes the equatorward flow of the thermocline water to divert toward the western boundary. In the Southern Hemisphere, no such barrier exists, and the flow to the equator is potentially much more direct (see, e.g., Johnson and McPhaden 1999; Nonaka and Takeuchi 2001).

Detailed surveys of the processes within the lowlatitude western boundary currents have not been made, particularly an examination of whether and how significant diapycnal mixing might occur. An intriguing feature of the western boundary current is that the bifurcation from southward to northward flow is not barotropic, but tilts with depth, as first noted by Reid and Arthur (1975). As noted by Pedlosky (1996), a complete theory for the western boundary current bifurcation is not yet in hand. McCreary and Lu (1994) offer a discussion of the western boundary bifurcation in a 2.5-layer reduced gravity model, but a more complete treatment is lacking. Geostrophic calculations based on historical data indicate that in the mean the bifurcation shifts from about $13^{\circ} \mathrm{N}$ near the surface to at least $18^{\circ} \mathrm{N}$ at depths around $1000 \mathrm{~m}$ in the North Pacific (Qu et al. 1997, 1999) and from about $15^{\circ} \mathrm{S}$ to at least $20^{\circ} \mathrm{S}$ in the South Pacific (Qu and Lindstrom 2002). This tilt varies with time. On seasonal time scales, the NEC has a northernmost bifurcation in winter and a southernmost bifurcation in summer $\mathrm{Qu}$ and Lukas (2003). Although there are no sufficient data for analyzing the interannual variation, results from highresolution GCM suggest that the NEC has a northernmost bifurcation during El Niño years and a southernmost bifurcation during La Niña years (Kim et al. 2004). The variation in the South Pacific is not known at this point. While this point may seem a detail in our understanding of the boundary current, the theory of McCreary and Lu relies upon separation of equatorward and poleward flow at the western boundary. Since the subsurface limb of the STC is the important component of the flow for this theory, and since this boundary can change by $5^{\circ}$ of latitude, a more complete understanding of this behavior seems in order.

\section{d. Summary}

Some of the major progress made in Pacific ENSO and its decadal changes during the initial phase of CLIVAR can be briefly summarized as follows.

1) Further progress has been made in the fundamental understanding of ENSO physics, particularly in the area concerning the effect of atmospheric internal variability (both in the Tropics and extratropics) on the development and maintaince of ENSO. This has led to a better understanding of how atmospheric internal variability can limit ENSO predictability.

2) Although many issues remain unresolved, the early years of CLIVAR have witnessed a number of advances in documenting decadal changes in ENSO and in understanding the underlying processes of these changes. A wide range of theoretical frameworks have been proposed to understand the dynamics of the low-frequency variability of ENSO, 

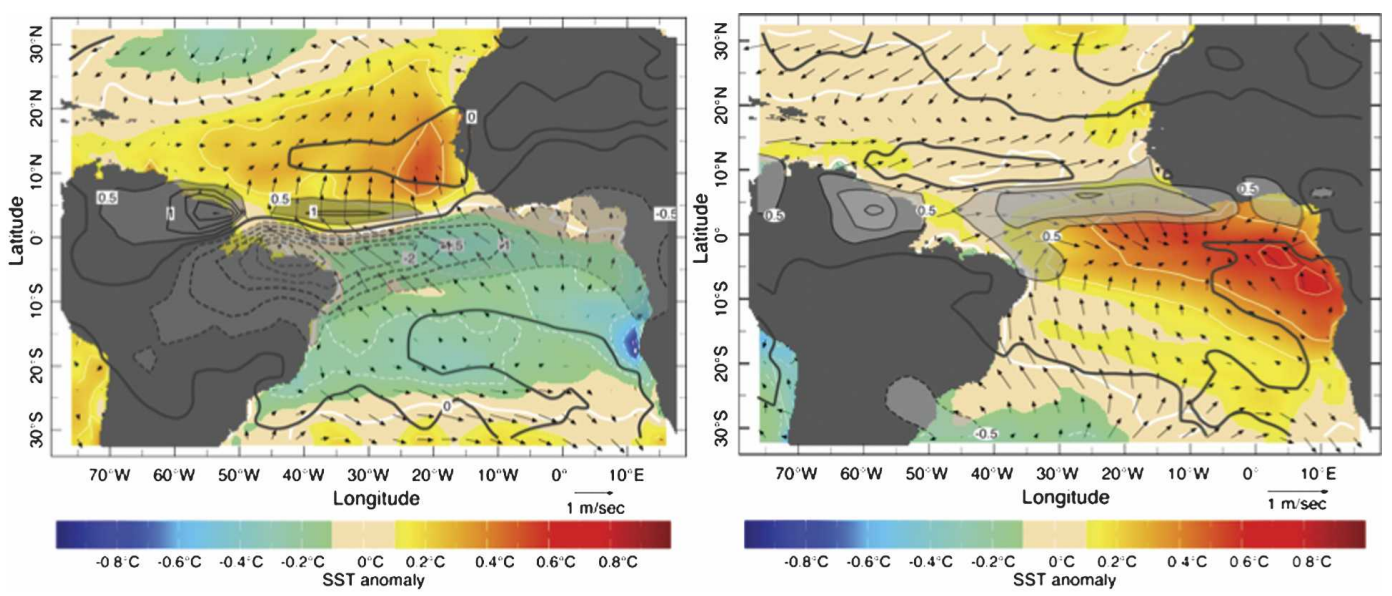

FIG. 7. The dominant pattern of surface ocean-atmosphere variability in the tropical Atlantic region during (left) boreal spring and (right) boreal summer. The black contours depict the first EOF of the regional March-April and June-August rainfall anomaly (from Global Precipitation Climatology Project data 1979-2001) (mm day ${ }^{-1}$ ). The EOFs explain $33 \%$ and $23 \%$ of the seasonal variance in the boreal spring and summer, respectively. The colored field is the March-April and June-August SST anomaly regressed on the principal component time series of the rainfall EOF $\left[\left({ }^{\circ} \mathrm{C}\right)\right.$, see scale below; white contours every $0.2^{\circ}$ are added for further clarity]. Arrows depict the seasonal mean surface wind vector in $\mathrm{m} \mathrm{s}^{-1}$, regressed on the same time series (see arrow scale below frame). (From Kushnir et al. 2004.)

including stochastic mechanism, mean state changes, anthropogenic forcing, and nonlinear dynamics.

3) The general concept of the STCs has emerged as a useful framework for understanding the potential role of the ocean in decadal changes of ENSO, because the maintenance of the equatorial thermocline is closely linked to the STC dynamics. Decadal changes in the STCs have been demonstrated by both observational and modeling studies.

With the initial progress, there are still fundamental gaps in our understanding of ENSO dynamics and decadal changes in ENSO. Some of the key remaining issues and major uncertainties in this area of research are as follows.

1) There is still a lack of complete understanding of the factors that limit the predictability of ENSO. The intrinsic limit of ENSO predictability remains uncertain.

2) Quantifying the cause of low-frequency variability of ENSO has proven to be very difficult, because of insufficient observations and imperfect climate models. As a result, large uncertainties exist in assessing low-frequency changes in ENSO induced by anthropogenic climate change or by natural climate variability. There is little current understanding of the predictability associated with the decadal variation of ENSO.

3) Our current understanding of the role of the ocean in decadal changes of ENSO is incomplete. Some of the key elements concerning the STC variation and its connection to the atmosphere are still missing.

\section{Tropical Atlantic variability}

The dominant climate fluctuations in the tropical Atlantic sector seem to include two distinctive patterns associated with the year-to-year variation in the annual migration of the Atlantic marine ITCZ complex. These two patterns manifest themselves most clearly during the two seasons when the Atlantic ITCZ moves farthest south during the boreal spring (March-April) and farthest north during the boreal summer (June-August).

During boreal spring the warmest SSTs appear in the deep Tropics and maximum seasonal precipitation moves to the western equatorial Atlantic and the adjacent land region of tropical South America. During this season the anomaly of rainfall from its seasonal cycle is characterized by a dipolar pattern across the thermal equator, as shown by the leading EOF of the MarchApril rainfall anomaly (Fig. 7).

Correlated with this precipitation anomaly is an anomalous meridional SST gradient and crossequatorial winds. These correlations reflect a dynamically consistent situation where a stronger-than-normal northward SST gradient drives northward crossequatorial winds with weaker-than-normal trades in the north and stronger-than-normal trades in the south. Precipitation and SST are below normal on the southern flank of the climatological ITCZ position and above 
normal to the north. This circulation pattern implies a weakening and northward shift of the ITCZ toward the warmer hemisphere. Because the coupled variability in this pattern exhibits a north-south contrast, it is often refered to as the "meridional mode" of variability (Servain et al. 1999). In passing, we note that a similar meridional mode has been identified in the tropical Pacific that also has peak variability during the boreal spring (Chiang and Vimont 2004).

The SST anomaly associated with the meridional mode also forces precipitation anomalies on neighboring continents. Indeed, Wallace et al. (1998) assert that the link between rainfall over northeast Brazil and the meridional mode is the most robust signal outside of the tropical Pacific Ocean. For more discussion of the impact of the meridional mode, readers are referred to Marshall et al. (2001) and Xie and Carton (2004).

During boreal summer a cold tongue of SST develops in the equatorial eastern Atlantic Ocean, while the ITCZ moves to its northernmost position, extending over the adjacent land region of West Africa. The leading EOF of precipitation during this season shows an anomaly pattern that is maximum along the northern coast of the Gulf of Guinea. The corresponding anomalous pattern of SST is maximum in the eastern basin with a convergent pattern of equatorial trade winds (Fig. 7).

The coupled pattern described above bears a certain resemblance to the Pacific ENSO; it is often referred to as the "Atlantic Niño" mode or the "equatorial mode" (Merle 1980; Hisard 1980; Zebiak 1993; Carton and Huang 1994; Ruiz-Barradas 2000). Here, we simply refer to it as the "zonal mode" of the tropical Atlantic. However, it is important to note that the relationship of the zonal mode to the annual cycle of SST differs markedly from ENSO. The differences, discussed below, hint that the processes involved may be quite different, despite the similarity in their appearance. It is also worth pointing out the distinction between the rainfall pattern associated with this coupled mode and the rainfall variability over the semiarid Sahel between $10^{\circ}$ and $20^{\circ} \mathrm{N}$. The former has an interannual time scale and owes its existence largely to equatorial SST variability (Wagner and da Silva 1994), while the latter varies on interdecadal time scales and represents an internal mode of the African summer monsoon variability (Giannini et al. 2003).

South of the equator along the western coast of Africa warm and cold episodes occur that are confined to the coastal zone of Angola and Namibia (Shannon et al. 1986; Gammelsrød et al. 1998; Florenchie et al. 2004). These episodes, referred to as Benguela Niños/Niñas, occur following some, but not all extrema of the equa- torial zonal mode (e.g., in year 1984) and have an effect on regional rainfall variability (Rouault et al. 2003) and fish distribution and abundance (Boyer et al. 2001).

\section{a. Coupled air-sea feedbacks in TAV}

\section{1) Thermodynamic FeEdBACKS}

The meridional mode involves off-equatorial SST changes. These SST changes are intimately linked to changes in surface heat fluxes, particularly latent heat flux, as shown by a large number of observational and modeling studies (e.g., Carton et al. 1996). This linkage gives rise to the Wind-Evaporation-SST (WES) feedback mechanism (Xie and Philander 1994), which is inherently a tropical mechanism. The feedback works as follows: Imagine that a small change in hemispheric SST gradient is introduced. The atmosphere will respond with a change in meridional pressure gradient through hydrostatic adjustment of the atmospheric boundary layer (Lindzen and Nigam 1987; Hastenrath and Greischar 1993) as well as midtropospheric diabatic heating, which together drive a cross-equatorial boundary layer flow, changing the meridional position of maximum surface wind convergence and therefore the ITCZ. The anomalous cross-equatorial flow is deflected by the Coriolis force in the Southern and Northern Hemispheres in such a way that it increases the wind speed over the hemisphere where a negative SST anomaly exists, cooling it further through surface evaporation, and it decreases the wind speed over the hemisphere where a positive SST anomaly exists, warming it further. The net effect is a positive feedback on the original SST anomaly (Chang et al. 1997). The weakness of the feedback (a few $\mathrm{W} \mathrm{m}^{-2}$ ) implies that this mechanism must have long time scales. In the tropical Atlantic, the WES feedback mechanism is a defining characteristic of the meridional mode.

There is growing observational evidence supporting WES feedback in the development phase of the meridional mode (Ruiz-Barradas et al. 2000; Chiang et al. 2002; Czaja et al. 2002; Kushnir et al. 2002; Frankignoul et al. 2004). Atmospheric GCMs have also been used to test the WES hypothesis by examining the response of the GCMs to SST forcing (Chang et al. 2000; Sutton et al. 2000; Okumura et al. 2001; Terray and Cassou 2002; Okajima et al. 2003). Nearly all the GCMs show a crossequatorial circulation pattern in response to a hemispheric SST gradient in the deep Tropics, as in the observations. However, the surface heat flux response is more perplexing. While some models show a positive thermodynamic feedback in the deep Tropics (e.g., Chang et al. 2000; Saravanan and Chang 2004), others show a negative feedback (e.g., Sutton 2000). Wang and 

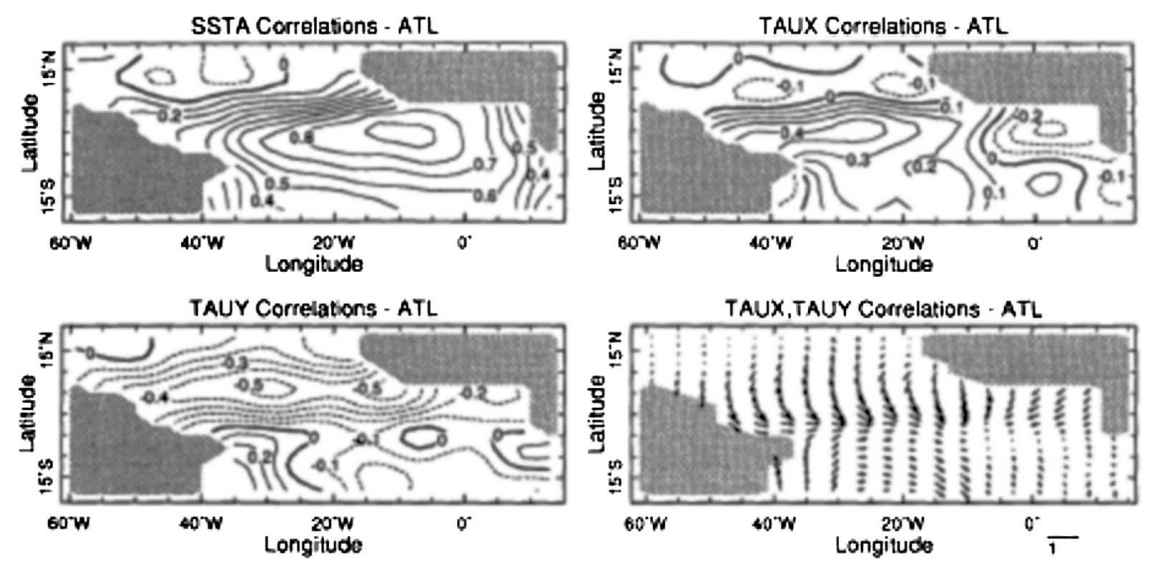

FIG. 8. Correlation between SST, pseudostresses, and the Atl-3 index, respectively. The Atl-3 index is defined as area-averaged SST anomaly over $3^{\circ} \mathrm{S}-3^{\circ} \mathrm{N}, 20^{\circ} \mathrm{W}-0^{\circ}$. The SST and pseudostress data are derived from the analysis by Servain et al. (1987), on a $2^{\circ} \times 2^{\circ}$ grid for the period 1964-88. (From Zebiak 1993.)

Carton (2003) and Frankignoul et al. (2004) compare different atmospheric and coupled GCM simulations of TAV and discuss the difficulties faced by current GCMs in reproducing the WES feedback. Besides WES, there seem to be additional feedback mechanisms that act between SST and clouds (Wang and Enfield 2001; Tanimoto and Xie 2002). The lack of reliable surface heat flux measurements has prevented a rigid test of these hypotheses.

\section{2) Dynamic FeEDBACKs}

In contrast to the thermodynamic meridional mode, the underlying feedback in the zonal mode, like the Pacific ENSO mode, is thought to be the dynamical Bjerknes mechanism (Bjerknes 1969). In contrast to ENSO, however, compelling evidence is less forthcoming. This is partly because the Atlantic signal is much weaker and less coherent than Pacific ENSO. The first well-documented SST-wind relationship was probably provided by Merle (1980) for the 1963 warm event, one of strongest warm events on the record. The connection between changes in the trade winds and SST was confirmed by Servain et al. (1982) in a statistical analysis. The warm event that occurred in 1984 also received considerable attention because it coincided with the Seasonal Equatorial Atlantic/Français Océan Climate Atlantique Equatorial (SEQUAL/FOCAL) program, which provided an extensive array of subsurface ocean measurements. The studies that focused on this event (discussed later) revealed some similarity in SST, winds, convection, and upper-ocean circulation anomalies to those during an El Niño. But again the short observational record prevented a robust analysis of the relationship between SST and the atmospheric response.
A comprehensive investigation was carried out by Zebiak (1993), who contrasted the statistical relationship between the surface wind stress and SST for Pacific ENSO to that for the Atlantic zonal mode using historical observational datasets. The study showed that although there is a common overall SST-wind relationship between the two oceans in the sense that for either ocean, the appearance of coherent warm (cold) SST anomalies coincides with westerly (easterly) changes in zonal wind to the west, there are important differences (Fig. 8). These differences include that 1) the correlation between the zonal wind and equatorial SST anomaly is considerably lower in the tropical Atlantic than in the Pacific (0.4 versus 0.7 ), while the correlation between the meridional wind in the vicinity of the ITCZ and equatorial SST anomaly remains comparable in both oceans ( 0.5 versus 0.6$) ; 2)$ the spatial correlation structure between the zonal wind and SST anomaly is narrower in the tropical Atlantic than in the tropical Pacific; 3) the coherence between equatorial and eastern coastal SST is much less in the Atlantic and the zonal wind variability is displaced proportionally farther to the west in the basin than in the Pacific; 4) while in the Pacific, the ENSO-related SST anomalies in the eastern and central basin tend to vary out of phase with those in the western basin, and the SST anomalies associated with the Atlantic zonal mode tend to vary together at all longitudes with nearly equal amplitude (although an eastward shift of thermocline water is evident); and 5) in the Pacific, the zonal wind anomaly appears to migrate eastward during an ENSO event, whereas in the Atlantic, there is no migratory component to the zonal wind variability and the strongest variability is situated in the western portion of the basin as 
opposed to the interior basin in the Pacific ENSO. The more recent study by Ruiz-Barradas et al. (2000) employed a joint ocean-atmosphere analysis based on NCEP and SODA reanalysis datasets to further validate the statistical relationship revealed by Zebiak (1993).

Recent atmospheric GCM studies (Chang et al. 2000; Sutton et al. 2000; Okumura and Xie 2004; Frankignoul et al. 2004) show that during boreal summer the atmosphere does respond to equatorial Atlantic SST anomalies in a manner that is consistent with the Bjerknes feedback, even though the details are different in different models. These studies further confirmed that in spite of the relatively weak SST perturbations in the equatorial Atlantic, the atmosphere is capable of generating a wind response that can potentially trigger a positive feedback along the equatorial waveguide following the Bjerknes mechanism. However, whether such a positive feedback can sustain itself depends on whether the subsurface ocean response is strong enough and whether this subsurface response can induce a sizable change in SST. This oceanic aspect of the Bjerknes feedback in the tropical Atlantic is less well established.

\section{b. External sources of atmospheric influences}

Because the coupled feedbacks involved in TAV are much weaker than those in ENSO, external influences are likely to play an important role. At least two external sources of influences on the meridonal mode have been proposed: Pacific ENSO and the NAO. Both of these phenomena peak during the boreal winter. One common mechanism through which they exert their influences on TAV is by altering the strength of the northeasterly trade winds in the northern tropical Atlantic, which in turn causes changes in the surface latent and sensible heat fluxes. The altered heat flux then forces the ocean mixed layer to produce a maximum SST response in the boreal spring.

\section{1) Remote Influence of ENSO}

The existence of a statistical relation in boreal spring between ENSO and the tropical Atlantic has been noted for some time now (e.g., Covey and Hastenrath 1978; Aceituno 1988; Enfield and Mayer 1997; Penland and Matrosova 1998; Giannini et al. 2000; MestasNunez and Enfield 2001; Alexander and Scott 2002). The most significant influences of El Niño in the tropical Atlantic sector include 1) a zonal seesaw in sea level pressure between the eastern equatorial Pacific and Atlantic Oceans during the onset and peak phase of ENSO, with a high sea level pressure anomaly in the northern tropical Atlantic; 2) a weakening in the meridional sea level pressure gradient between the North Atlantic subtropical high and the ITCZ accompanied by weaker-than-average northeasterly trades; 3) a warming of SST during boreal spring following the mature phase of ENSO; and 4) a northward shift of the ITCZ and a decrease of rainy season precipitation in northeastern Brazil. Some of these features are shown in Fig. 9a. However, the detailed dynamical processes responsible for setting up this ENSO remote influence are still not entirely clear. Among the proposed mechanisms are a tropical mechanism via anomalous Walker circulation (Klein et al. 1999; Giannini et al. 2000; Saravanan and Chang 2000; Chiang and Sobel 2002; Huang et al. 2002) and an extratropical mechanism via a stationary Rossby wave train teleconnection pattern (e.g., Wallace and Gutzler 1981; Horel and Wallace 1981; Hoskins and Karoly 1981; Giannini et al. 2000).

A more recent, study by Giannini et al. (2004) suggests that ENSO does not passively exert its influence on the tropical Atlantic, but rather interferes actively with coupled air-sea feedbacks in the region. When, in seasons prior to the mature phase of ENSO, the air-sea feedback in the tropical Atlantic happens to be evolving consistently with the expected development of the ENSO teleconnection, ENSO and TAV act in concert to force large climate anomalies in the region. When it happens to be evolving in opposition to the canonical development of ENSO, then the net outcome is less obvious and less predictable. Giannini et al. call this the "preconditioning" role of TAV in the development of the ENSO teleconnection. These constructive and destructive interferences between ENSO and TAV have been shown by Barreiro et al. (2005) to have an important consequence on the seasonal predictability of boreal spring climate condition in the tropical Atlantic sector. For example, during the years when the existing Atlantic conditions reinforce the remote influence of ENSO (constructive interference), the boreal spring climate anomaly can be forecasted skillfully up to two seasons in advance.

In terms of ENSO's influence on the zonal mode, reports from existing literature are inconsistent. On the one hand, some observational analysis (e.g., Zebiak 1993; Enfield and Mayer 1997) finds no statistical evidence for linkage between the SST variability of Pacific ENSO and the Gulf of Guinea, suggesting that the coupled variability in the equatorial Atlantic is largely independent of ENSO. On the other hand, the modeling study by Latif and Barnett (1995) suggests that Pacific ENSO does influence the eastern equatorial Atlantic through an adjustment of the entire tropical 


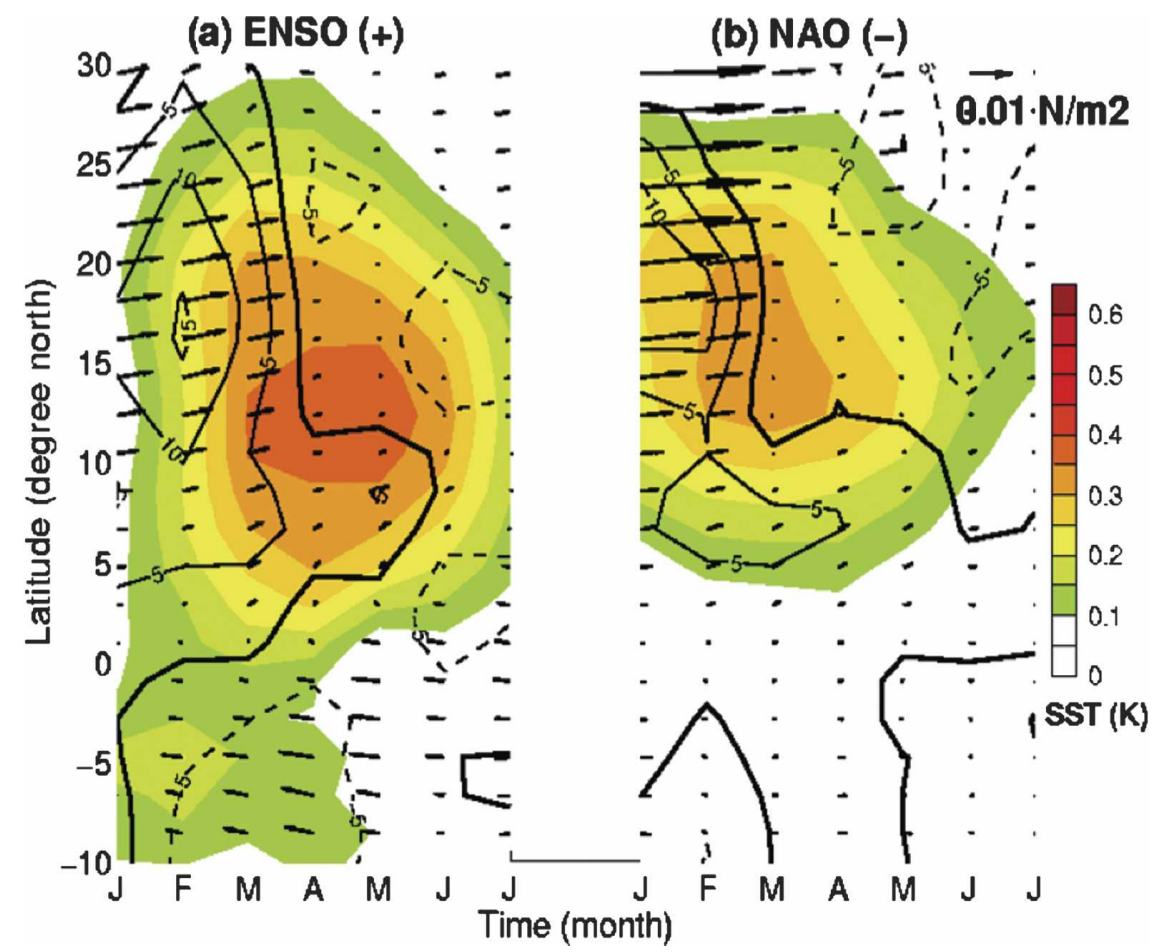

FIG. 9. Regression of zonally averaged surface wind stresses (vector), surface heat flux (contour), and SST anomalies onto (a) Niño-3 and (b) negative NAO indexes as a function latitude and time lag (from the winter to the summer). The zonal average was taken between $40^{\circ}$ and $20^{\circ} \mathrm{W}$. The Niño-3 index is defined as area-averaged SST anomaly over $5^{\circ} \mathrm{S}-5^{\circ} \mathrm{N}$, $90^{\circ}-150^{\circ} \mathrm{W}$ during boreal winter (December-February) and the NAO index is based on the winter (December-March) sea level pressure index of Hurrell (1995). (From Czaja et al. 2002.)

Walker cell. There is some evidence that certain events in the equatorial Atlantic are indeed linked to strong ENSO events. For example, Delecluse et al. (1994) and Carton and Huang (1994) showed that the strong 1984 warming in the eastern equatorial Atlantic resulted from the zonal wind anomaly related to the severe 1982/83 ENSO.

One reason that the zonal mode appears to be less affected by the remote influences than the meridional mode may be related to the different seasons to which these two phenomena are phase locked. The fact that the equatorial mode appears primarily in the boreal summer makes it difficult for ENSO and the NAO to have a direct influence on it, because both of these phenomena peak in the boreal winter. This, however, raises the question of whether the zonal mode is related to the variability in the Southern Hemisphere. Only a few recent studies (Venegas et al. 1997; Wu and Liu 2002; Sterl and Hazeleger 2003; Barreiro et al. 2005) have begun to investigate this issue. Some of the initial findings suggest that the southern summer atmospheric variability (and to a less extent the winter variability) can play a preconditioning role in the onset of the anomalies in the deep Tropics during the following austral fall.

\section{2) Remote INFLuence of THE NAO}

The notion that the NAO can have an impact on TAV can be traced back to at least Namias (1972), who pointed out that increased cyclonic activity in the Newfoundland area is related to abundant rainfall in the Nordeste. Studies that followed show that the NAO is correlated with a tripole pattern of SST anomalies over the North Atlantic in boreal winter/spring. This pattern of SST arises primarily from the oceanic response to month-to-month atmospheric fluctuations associated with the NAO (e.g., Seager et al. 2000). The southernmost lobe of the SST tripole reaches down into the subtropics/Tropics of the North Atlantic, potentially affecting the coupled variability in the deep Tropics. There appears to be little dispute that the NAO is one major source of external influence on TAV and the former exerts its influence on the latter through modulating the intensity of the semipermanent subtropical 
high pressure system centered around $40^{\circ} \mathrm{N}$ over the North Atlantic, which in turn affects the northeasterly trades and the latent heat flux at the ocean surface (Fig. 9b; Xie and Tanimoto 1998; Chang et al. 2001b; Czaja et al. 2002; Kushnir et al. 2002).

There is, however, disagreement on the extent to which the NAO can affect TAV: Is the deep tropical variability simply a mirror image of the changes in the strength of the subtropical high? Or does the NAO merely play a role in exciting TAV, whose evolution is also influenced by the coupled feedback in the deep Tropics? Czaja et al. (2002) argue that the SST variability within the latitudinal band of $10^{\circ}-20^{\circ} \mathrm{N}$ can be largely explained as the passive response of a slab mixed layer ocean to changes in wind-induced latent heat flux associated with fluctuations in the subtropical high, without the need to invoke a significant role for local air-sea feedback. Others (e.g., Xie and Tanimoto 1998; Chang et al. 2001b; Kushnir et al. 2002) reason that the local feedback is essential in maintaining an organized deep tropical response that consists of a strong cross-equatorial wind and a cross-equatorial SST gradient during the boreal spring.

Some of the disagreements between these two schools of thought are probably due to the different emphasis in each of these studies. Czaja et al. (2002) place their emphasis on the North Atlantic Oscillations's (NAO's) influence on SST variability between $10^{\circ}$ and $20^{\circ} \mathrm{N}$ in the northern tropical Atlantic (NTA), while others focus their attention on the crossequatorial SST gradient variability in the deep Tropics. In fact, Czaja et al. did hint at the existence of the WES feedback in their observational analysis (see Fig. 9a) but concluded that the feedback is too far south to have a significant impact on the evolution of the NTA SST variability. The other differences are more fundamental and lie very much at the heart of controversial debate on whether TAV can have a remote influence on the NAO, or whether the latter only involves dynamic processes local to the mid- to high-latitude regions. The interested readers are referred to recent reviews by Kushnir et al. (2004) and Xie and Carton (2004).

\section{c. Role of the ocean in TAV}

\section{1) Tropical ocean PRocesses}

The pronounced seasonal variation of the tropical Atlantic Ocean circulation is, at least partially, responsible for the distinct seasonal manifestation of TAV on seasonal-to-interannual time scales. During the boreal winter-spring, entrainment cooling is weak and the averaged mixed layer depth within the deep Tropics is shallow, making the mixed layer temperature highly sensitive to surface heat flux perturbations. It is during these seasons that the wind-induced latent heat flux, via either remote influences or local feedback, is most effective in producing SST anomalies in the tropical Atlantic. In addition, during the boreal spring nearly uniform warm SSTs cover the entire tropical Atlantic. This makes the underlying atmosphere highly sensitive to small cross-equatorial perturbations (Chiang et al. 2002), and thus the meridional mode tends to dominate TAV during this season. Enfield et al. (1999) report a marginally significant coherence with an antisymmetric phase only during this season. During boreal summer seasonal entrainment is at its maximum; the thermocline is shallowest in the equatorial eastern Atlantic with a strong zonal gradient of SST and strong equatorial trades. This oceanic setting is highly favorable for dynamic interaction between the zonal wind and SST along the equator, and thus the zonal mode appears more dominant. The eastern tropical Pacific Ocean undergoes a similar seasonal variation, except that the equatorial thermocline variation is not nearly as strong as that in the equatorial Atlantic. Whether this difference in the subsurface seasonal variation contributes to the different seasonal phase locking between the Pacific ENSO and the Atlantic zonal mode remains to be explored.

The evolution of the meridional mode can be described in three phases: 1) initiation phase, 2) development phase, and 3) decay phase. The initiation phase typically begins in the boreal winter during which both ENSO and NAO are at their peak. As previously mentioned, the latent heat flux change induced by the change of the northeasterly trade winds provides the major source of forcing for the northern tropical Atlantic SST. The SST response can be roughly described by a $1 \mathrm{D}$ mixed layer driven by surface heat fluxes as the seasonal entrainment cooling begins to weaken and the mixed layer depth begins to shoal. The development phase usually takes place in the boreal spring when the entrainment cooling diminishes and the mixed layer depth is at its seasonal minimum.

During this phase, the thermodynamic feedback between surface heat flux and SST, such as WES, can further enhance the SST signal, causing the development of a strong anomalous cross-equatorial SST gradient. The role of subsurface ocean dynamics appears to be rather passive and does not seem to have a major impact on SST. This was first demonstrated by Carton et al. (1996). Alexander and Scott (2002) show that an atmospheric GCM coupled to a 1D ocean mixed layer model is capable of capturing some of the basic features of the observed SST evolution associated with the remote influence of ENSO during boreal spring. Chang et 
al. (2003) conducted ensembles of seasonal predictions using the National Center for Atmospheric Research (NCAR) Community Climate Model version 3 (CCM3) coupled to a slab ocean by initializing the model with observed SST in December and found that the simple coupled model was quite skillful in forecasting boreal spring SST anomalies in much of the north tropical Atlantic. Subsequent analyses of these experiments by Saravanan and Chang (2004) and Barreiro et al. (2005) show that the high skill of the model comes from the combined effect of local thermodynamic coupling and the remote influence of ENSO. Collectively, these recent studies lend strong support to the view that the formation of the meridional mode during the boreal spring results from remote atmospheric influences and regional thermodynamic feedbacks, both of which can be captured by a simple 1D mixed layer ocean.

One exception to this is the coastal region in the vicinity of the Guinea dome (Yamagata and Iizuka 1995) where simple mixed layer models consistently underestimate the strength of the SST variability (Alexander and Scott 2002; Barreiro et al. 2005). The OGCM study of Carton et al. (1996) shows that the SST variability does depend on alongshore fluctuations in wind stress via coastal upwelling. Visbeck et al. (1998) and Chang et al. (2001b) show that much of the SST variability in this region is related to the NAO-induced fluctuations in the northeasterly trade winds that affect the SST through changing the surface latent heat flux and upwelling. The relative importance of the heat flux-induced and upwelling-induced SST changes has not been quantified.

Ocean dynamics are likely to play a more important role during the decay phase of the meridional mode, which occurs during the boreal summer when the southeasterly trade winds begin to regain their strength and the seasonal entrainment cooling is rapidly developing. The seasonal deepening of the mixed layer makes surface heat flux influences less effective, while the shoaling thermocline in the eastern equatorial Atlantic makes the subsurface ocean processes more tightly coupled to the surface processes. Experiments with an AGCM coupled to a slab ocean indicate that without active ocean dynamics the thermodynamic feedbacks tend to exaggerate the coupled variability (e.g., Saravanan and Chang 2004; Barreiro et al. 2005), suggesting that the role of the ocean in the tropical Atlantic is mainly damping, thereby providing a negative feedback to counteract the thermodynamic air-sea feedback.

There are three potential mechanisms through which this negative feedback can be achieved: 1) transport of temperature anomalies by the mean circulation (e.g.,
Chang et al. 1997, 2001b; Seager et al. 2001) and by surface Ekman flow (Xie 1999), 2) transport of the mean temperature gradient by circulation anomalies (e.g., Joyce et al. 2004), and 3) nonlinear heat transport by circulation anomalies acting on temperature anomalies (e.g., Jochum et al. 2004b). Chang et al. (2001b) present an argument emphasizing the role of the advection of anomalous SST by the mean cross-equatorial ocean transport within the context of a hybrid coupled model. By analyzing the model upper-ocean heat budget, they show that while stronger (weaker) trades increase (decrease) the surface heat loss and cool (warm) the ocean, creating an anomalous cross-equatorial SST gradient, advection of the anomalous SSTs by the northward cross-equatorial mean current will always tend to weaken the anomalous SST gradient. In reality, the South Equatorial Current and the North Brazil Current carry approximately $13 \mathrm{~Sv}$ of water across the equator (Schott et al. 2002a), which can potentially play an important role in this negative feedback process. Chang et al. (2001b) further argue that the negative ocean feedback can introduce a delay in the coupled loop, which may set a time scale for the meridional mode. Seager et al. (2001) also found the dominance of the horizontal advection of anomalous temperatures by the mean meridional currents but reported no evidence of any obvious phase lag introduced by the oceanic advection.

Joyce et al. (2004) recently presented an analysis based on both observations and model simulations that argues for the importance of the transport of the mean temperature gradient by circulation anomalies. They show that the wind-driven response of the tropical Atlantic thermocline depth is such that it opposes the cross-equatorial SST gradient. Briefly, the mechanism proposed by Joyce et al. (2004) can be described as follows: In response to a northward cross-equatorial SST gradient anomaly, a southerly wind anomaly develops in the deep tropical Atlantic. This anomalous wind veers to the east upon crossing the equator, which in turn generates a negative wind stress curl anomaly just north of the equator (Fig. 10). The curl then drives cross-equatorial Sverdrup transport in the ocean that is in the opposite direction of the meridional wind, that is, from the warm to the cold side of the equator. Since the mean SST gradient in the tropical Atlantic is northward, the southward cross-equatorial Sverdrup flow tends to advect warm water from the anomalously warm Northern Hemisphere to the anomalously cold Southern Hemisphere, and thus damp the anomalous SST gradient. Joyce et al. (2004) further show that this negative ocean feedback can introduce a lag of approximately one year into the coupled system. Therefore, 

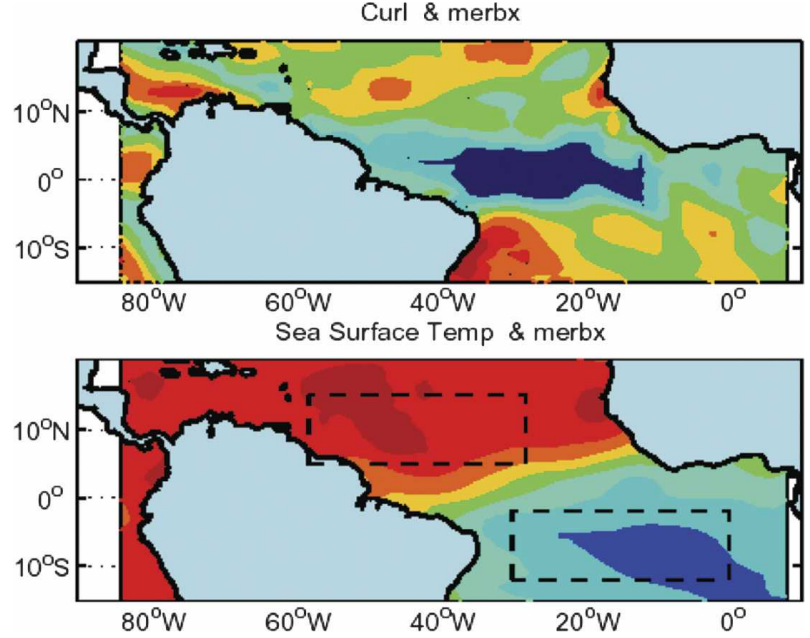

FIG. 10. Correlation maps of a cross-equatorial wind stress index against wind stress curl and SST anomaly. (From Joyce et al. 2004.)

potentially it can play a role of setting a time scale for the meridional mode. One intriguing aspect of this mechanism is the potential linkage between the crossequatorial SST gradient and ocean circulation changes. Joyce et al. (2004) show that the cross-equatorial wind variability is connected to the change in the NECC.

In a recent numerical study, Jochum et al. (2004b) suggest that the nonlinear heat transport induced by tropical instability waves (TIWs) may also play a role in negative feedback. It has been known for some time that the TIWs are an important part of the equatorial heat budget (e.g., Philander and Hurlin 1988; Weisberg and Weingartner 1988). Jochum et al. (2004a,b) and Hashizume et al. (2001) show that in the Atlantic the TIWs can exist from May to January and can potentially perturb the seasonal cycle of the ITCZ during boreal spring. Philander and Delecluse (1983) show that an increased southerly wind across the equator associated with a northward SST gradient leads to a strengthening of the EUC, which should lead to stronger T1W activity and an increased southward heat flux, again a negative feedback.

In reality, it is likely that all the above-described mechanisms act simultaneously to weaken the crossequatorial SST gradient. Their relative importance, however, may depend on season and location, and have not been fully explored. It remains to be seen if any of these mechanisms alone are of sufficient strength to explain the decay of the SST gradient.

The dynamic processes that govern the equatorial SST changes in the Atlantic Ocean appear to be more complex and less understood than those involved in ENSO. The observations made during SEQUAL/
FOCAL clearly indicate that the anomalous warming in the summer of 1984 was proceded by weaker-thannormal trade winds, which led to the usually deep thermocline depth in the eastern equatorial basin (Philander 1986). The anomalous weak trade winds caused the zonal pressure gradient along the equator to disappear in January-February 1984 (Katz et al. 1986), which in turn drove the anomalous eastward current just south of the equator, contributing to the 1984 warm event (Hisard et al. 1986; Weisberg and Colin 1986). This oceanic response resembles, in many respects, conditions in the Pacific during a warm ENSO event. Hisard et al. (1986) note that although the events such as that of 1984 are rare, similar oceanic conditions were also observed during 1963. An updated analysis of the relationship between the thermocline and SST for the Atlantic zonal mode by Vauclair and du Penhoat (2001) identifies two more warm events, 1994/95 and 1997/98, where the equatorial warming appears to be El Niñolike, in the sense that there is a relaxation of the equatorial easterlies and a deepening of the equatorial thermocline prior to boreal summer warming. But perhaps more interestingly, the study shows that the relationship in the Atlantic is more fragile and statistically less significant than in the Pacific.

Not all the warm events follow the El Niño-like relationship. Indeed, the overall correlation between the SST and thermocline depth anomalies has a maximum value of 0.4 in the eastern equatorial cold tongue region, which is substantially lower than the corresponding value for ENSO. The correlation between the zonal wind anomaly in the western equatorial basin and equatorial thermocline variation is also low, achieving a maximum value of 0.2 when the zonal wind leads the thermocline by 4 months. Furthermore, the EOF mode that characterizes the thermocline variability associated with the zonal mode only explains less than $10 \%$ of total thermocline variance in the tropical Atlantic. These observational analyses suggest that the Bjerknes type of feedback appears to operate sporadically for certain events in the equatorial Atlantic, but its strength is much weaker than in the Pacific. The basin size may be the ultimate cause of the differences between the Pacific and Atlantic in the strength of the Bjerknes feedback and the relative importance of thermocline depth and upwelling changes in the subsurfaceto-SST feedback; theoretical studies show that the equatorial mode is more unstable in the larger Pacific basin (Hirst 1986; Battisti and Hirst 1989).

The simple coupled model experiments carried out by Zebiak (1993) provide further insight into the similarities and contrasts between the dominant ocean processes controlling the Pacific ENSO and the zonal 
mode. In the Pacific, the ENSO-related SST variability in the eastern equatorial Pacific is significantly forced by the mean upwelling acting on the anomalous vertical temperature gradient, and therefore thermocline variability and large-scale equatorial ocean dynamics are crucial in determining the onset of the SST anomaly. In the Atlantic, the primary driving force for the SST anomaly in the eastern equatorial region comes from anomalous upwelling acting on mean vertical temperature gradient. The mean upwelling, though it also contributes to forcing SST anomalies, is much less significant.

This anomalous upwelling is primarily induced by local surface Ekman current divergence in response to changes in local winds. Therefore, in the equatorial Atlantic local Ekman feedback, in which the zonal SST gradient drives wind anomalies that induce upwelling, may play a more important role than the Bjerknes feedback, which relies on subsurface temperature changes induced by the equatorial thermocline adjustment to wind changes in the western basin. In the eastern tropical Pacific, it has been proposed that the Ekman feedback may play a role in the seasonal onset of the cold tongue (Mitchell and Wallace 1992; Chang and Philander 1994) but is less important on interannual time scales (Koberle and Philander 1994), while in the equatorial Atlantic this mechanism seems to dominate both the seasonal cycle (Carton and Zhou 1997) and the zonal mode (Zebiak 1993). If these modeling results hold, it would mean that the subsurface memory mechanism that is so critically important for the evolution of ENSO (see Neelin et al. 1998 for a reveiw) may be less effective in the zonal mode.

Carton and Huang (1994), however, point out that the role of subsurface ocean dynamics can be different in different warm events. By contrasting responses of an OGCM to the observed wind changes during 1983/ 84 and 1987/88, they show that the subsurface ocean plays a preconditioning role for the warm event in 1984 in the sense that there was a buildup of a positive heat content anomaly in the western tropical basin during the summer and fall of 1983, but such a role was not evident for the warm event in 1988. Delecluse et al. (1994) attempt to quantify the role of the 1982/83 El Niño in the 1984 Atlantic warm event by conducting a set of AGCM experiments to isolate the ENSO-forced atmospheric variability from the total fields over the tropical Atlantic sector and then conducted a set of OCGM experiments forced with output from the AGCM. This study shows that the strong 1982/83 El Niño helped to precondition the Atlantic warming that occurred in 1984, but that local feedback is required to retain both the strength and phase of the equatorial warming in the Atlantic. Based on this finding, they propose that Pacific ENSO may influence the onset of the zonal mode more than one year in advance. Vauclair and du Penhoat (2001) argue that the warm events that occurred in summer of 1995 and 1998 may also be linked to the corresponding El Niño events. However, these authors also note that the event in 1988 appears to be independent of the 1986/87 El Niño. At the moment, it is not clear why El Niño affects some Atlantic warm events but not the others. Nor is it clear what causes such a long lag (more than a year) between the warming in the equatorial Pacific and Atlantic.

As noted earlier, the decay phase of the meridional mode coincides with the onset phase of the zonal mode, raising the possibility that the two phenomena may be interrelated. Servain et al. $(1999,2000)$ report a significant correlation between the cross-equatorial SST gradient variation and the zonal slope of $20^{\circ} \mathrm{C}$ isotherm depth variation along the equator in both observed data and OGCM simulations during 1980-97. There are, however, two caveats associated with this result. First, the high correlation reported by Servain et al. (1999, 2000) appears to be only robust for the 1980s and 1990s. An analysis of an ocean model simulation forced with the NCEP reanalysis winds for the period 1949 to 2000 by Murtugudde et al. (2001) reveals that the correlation between the cross-equatorial SST gradient variation and the zonal slope of $20^{\circ} \mathrm{C}$ isotherm depth variation are much lower for the period before 1980. Murtugudde et al. (2001) conjecture that the 1976 "climate shift" has an impact on TAV. Prior to 1976, TAV was dominated by the meridional mode and was less affected by the Pacific ENSO, and the connection between the zonal and meridional modes was weak. After 1976, TAV is dominated by the zonal mode, the ENSO influence is stronger, and the connection between the two Atlantic modes is also stronger.

If this conjecture could be proven, it would suggest that the connection between the meridonal and zonal modes may be felt through the remote influence of ENSO. Second, as discussed earlier, in contrast to ENSO the Atlantic equatorial SST anomaly is only relatively weakly correlated to the thermocline changes. Therefore, a high correlation between the cross-equatorial SST gradient variation and the zonal slope of $20^{\circ} \mathrm{C}$ isotherm depth variation along the equator does not necessarily mean that a strong crossequatorial SST gradient anomaly would lead to a strong equatorial SST anomaly. Obviously, much remains to be studied on the relationship between the two TAV modes. Of particular interest is their relationship during the boreal spring and summer when the two phenomena coexist. 
The dynamic processes that contribute to the decay of the zonal mode are generally less understood. For ENSO, the decay of the equatorial SST anomaly in the eastern Pacific has been attributed to the thermocline perturbation generated by Rossby waves of opposite sign to the initial thermocline anomaly. It is not clear to what extent a similar mechanism works for the Atlantic zonal mode. The simple model study by Zebiak (1993) suggests that the dominant processes that contribute to the decay of the SST in the eastern equatorial Atlantic are horizontal advection, particularly the meridional component, and the damping effect of the surface heat flux, but not the thermocline fluctuation. In fact, these clamping processes are so strong that the model does not support any self-sustained oscillation in the tropical Atlantic. Nevertheless, Zebiak (1993) concludes that at least in the simple model framework the primary mechanism for the Pacific ENSO and Atlantic zonal mode is basically the same: the so-called delayed oscillator mechanism. Whether or not this conclusion holds in reality needs further investigation.

There have been even fewer studies on the dynamics of the Benguela Niño and Niña. The most recent studies on this subject (Florenchie et al. 2003, 2004) suggest that the remote forcing mechanism via equatorial wave dynamics is more plausible than the local feedback mechanism. In particular, the warm and cold events over the past two decades have been linked to the zonal wind stress anomaly in equatorial western Atlantic, in line with the earlier studies by Hirst and Hastenrath (1983) and Picaut (1985), and many Benguela Niños coincide with strong warm phases of the zonal mode (e.g., 1963, 1984, and 1995).

\section{2) INTERACTIONS WITH EXTRATROPICAL OCEAN} PROCESSES

As in the tropical Pacific, the upper circulation of the tropical Atlantic is connected to the extratropical circulation via STCs (Mercier 2003). What complicates the circulation system in the tropical Atlantic is the effect of the MOC on the wind-driven circulation. As a result of recent observational synthesis efforts (e.g., Schmitz and McCartney 1993; Schmitz 1996; Stramma and Schott 1999; Stramma et al. 2003; Schott et al. 2003; Snowden and Molinari 2003; Zhang et al. 2003), a firstorder description of the three-dimensional structure and the pathways of the tropical Atlantic circulation system is emerging (see Snowden and Molinari 2003 for a recent review). There is an estimated total of $21 \mathrm{~Sv}$ of water upwelled into the surface layer of the tropical Atlantic on an annual average, of which roughly $5 \mathrm{~Sv}$ appears to be associated with the Northern Hemisphere STC, $10 \mathrm{~Sv}$ is associated with the Southern Hemisphere
STC, and the remaining $6 \mathrm{~Sv}$ is associated with the meridional overturning circulation MOC (Roemmich 1983; Zhang et al. 2003). The origin of the latter can be traced back into the western Indian Ocean (Sprintall and Tomczak 1993; Tomczak and Godfrey 1994). Among the $10 \mathrm{~Sv}$ associated with the Southern Hemisphere STC, $4 \mathrm{~Sv}$ of flow can enter the equatorial zone through an interior pathway extending from $10^{\circ} \mathrm{W}$ to the western boundary, and the other $6 \mathrm{~Sv}$ of subducted water merges into the northward flowing North Brazil Current/North Brazil Undercurrent. This branch is joined by the $6 \mathrm{~Sv}$ of the MOC return flow that is apparently brought into the Atlantic by the Agulhas Current and the associated eddies and carried northwestward by the Benguela Current and the SEC before joining the North Brazil Current/North Brazil Undercurrent south of $10^{\circ} \mathrm{S}$ (Stramma and Schott 1999). Therefore, the western boundary pathway is the most effective way for the communication between the Tropics and extratropics in the Southern Hemisphere. In the Northern Hemisphere, the strength of STC is only a half of that of the Southern Hemisphere STC (Schott et al. 1998; Bourlès et al. 1999a,b; Zhang et al. 2003; Wilson et al. 1994), and the fate of the subducted water in the Northern Hemisphere, upon crossing $10^{\circ} \mathrm{N}$, is less clear observationally.

Considerable recent research effort has been devoted to the understanding of the hemispheric asymmetry of the Atlantic STCs. Fratantoni et al. (2000) hypothesize that the presence of the MOC return flow in the Atlantic is the main cause of the asymmetry. Chepurin and Carton (1996) and Jochum and Malanotte-Rizzoli (2001) further argue that there is another factor that has to do with the existence of a potential vorticity barrier created by the Ekman suction associated with the Atlantic ITCZ in the northern tropical latitudes. This vorticity barrier inhibits much of the interior communication, forcing the majority of the water subducted in the North Atlantic to flow westward into the western boundary before turning equatorward by the western boundary current. This combines with the fact that the strength of the equatorward-flowing western boundary current along the northeastern coast of the South America is significantly weakened by the MOC return flow (Fratantoni et al. 2000) and is responsible for blocking the inflow of North Atlantic waters into the equator.

Hazeleger et al. (2003) confirm, based on a Lagrangian trajectory analysis of a high-resolution global OGCM simulation, that the EUC is mainly ventilated from the south and the main subduction sites are located along the South Equatorial Current. Inui et al. (2002) suggest that the interior communication window 
between the equatorial ocean and the north subtropical Atlantic can be sensitive to wind stress forcing in the region. Da Silva and Chang (2004) show, based on an analysis of an Ocean Data Assimilation (ODA) product from the Geophysical Fluid Dynamics Laboratory (GFDL), that the seasonal variation of the zonal slope of the thermal ridge along the boundary between the NECC and NEC in response to the seasonal variation of the ITCZ can also have an important impact on the pathways in the NTA.

The asymmetric nature of the tropical Atlantic circulation causes the cold thermocline water from the Southern Hemisphere to upwell in the eastern equatorial Atlantic. The upwelled water subsequently is converted into warm surface water via heat exchange with the atmosphere and partly transported toward the northern high latitudes via surface currents. This unique warm water formation and escape process (Csanady 1984; Lee and Csanady 1999) makes the Atlantic the only ocean where the net meridional heat transport is everywhere northward (e.g., Trenberth and Caron 2001; Ganachaud and Wunsch 2001). In contrast, the meridional heat transport in the Pacific is poleward in each hemisphere and there is little cross-hemispheric heat transport.

Variability in these tropical-extratropical exchanges via STCs and the MOC likely plays an important role in TAV at decadal and longer time scales. However, at present, the importance of the large-scale ocean circulation can only be made by theoretical argument and numerical model experiment, due to the lack of longterm ocean observations. The meridional mode with its decadal time scales appears to be a likely candidate for involvement [both instrumental and paleoproxy records show an enhancement of spectral power in the 10-13-yr frequency band (Mehta 1998; Rajagopalan et al. 1998; Tourre et al. 1999; Black et al. 1999)].

Alternatively, some investigators (e.g., Dommenget and Latif 2000; Enfield et al. 1999; Melice and Servain 2003) argue that the ocean does not play a significant role. They argue that the SST variation in each hemisphere may be driven independently by dynamic processes in its own hemisphere. For example, Melice and Servain (2003) shows that SST anomalies in the north tropical Atlantic are related to the NAO, while anomalies in the south tropical Atlantic are related to lowfrequency fluctuations of the southern subtropical high. Occasionally, SST anomalies in each hemisphere line up with the opposite sign, giving rise to a strong crossequatorial gradient. Since extratropical fluctuations, such as the NAO, are predominantly caused by chaotic dynamics inherent to the atmosphere, this scenario would argue that fluctuations of the meridional mode are governed by a red noise process and strong interhemispheric SST anomalies occur by chance. This scenario can be regarded as a null hypothesis for decadal variation of TAV.

Competing hypotheses argue for the importance of the interplay between the regional ocean-atmosphere coupling and oceanic feedback. One proposed mechanism that emphasizes a more active role for ocean circulation in the decadal variation of TAV invokes interactions between the tropical and extratropical ocean circulation via STCs. In the tropical Atlantic, the Southern Hemisphere STC supplies most of the water to the equatorial thermocline, and thus is more likely to bring extratropical anomalies into the equatorial zone. Furthermore, since the Southern Hemisphere STC appears to be nearly steady, at least during the last decade (Stramma et al. 2003), the mechanism proposed by Gu and Philander (1997) may be more relevant and applicable to the South Atlantic.

Indeed, the numerical simulation by Lazar et al. (2002) shows the propagation of thermal anomalies around the subtropical gyre in the South Atlantic, some of which appear to reach the equatorial region after approximately $10 \mathrm{yr}$ (Fig. 11). This led to the proposal that the Southern Hemisphere STC, through its action on tropical SST in the equatorial upwelling zone, may provide a way by which slow ocean processes modulate the meridional gradient of tropical SST, and hence the low-frequency cycles of the interhemispheric SST gradient. One caveat to this is that the anomalies traced to the equator in the model appear to be very weak. Therefore, unless local air-sea feedback is sufficiently strong to amplify the extratropical signal, it seems unlikely that this disturbance alone can have significant impact on the tropical SST. At present, the evidence of amplication of the extratropical signal has not been forthcoming.

The Northern Hemisphere STC, on the other hand, exhibits much more temporal variability, making it a possible candidate for the second type of STC mechanism involving fluctuations in volume transports (Kleeman et al. 1999). However, this STC is much weaker than its Southern Hemisphere counterpart and involves more complex dynamics. One particularly interesting aspect of the Northern Hemisphere STC is that its structure and pathways may be sensitive to the MOC changes (e.g., Fratantoni et al. 2000; Jochum and Malanotte-Rizzoli 2001). Based on the ocean model experiment results of Fratantoni et al. (2000) and Jochum and Malanotte-Rizzoli (2001), it is possible that a decrease in the MOC could cause more symmetric Atlantic STCs, which could lead to an increase in the supply of thermocline water from the Northern Hemisphere 


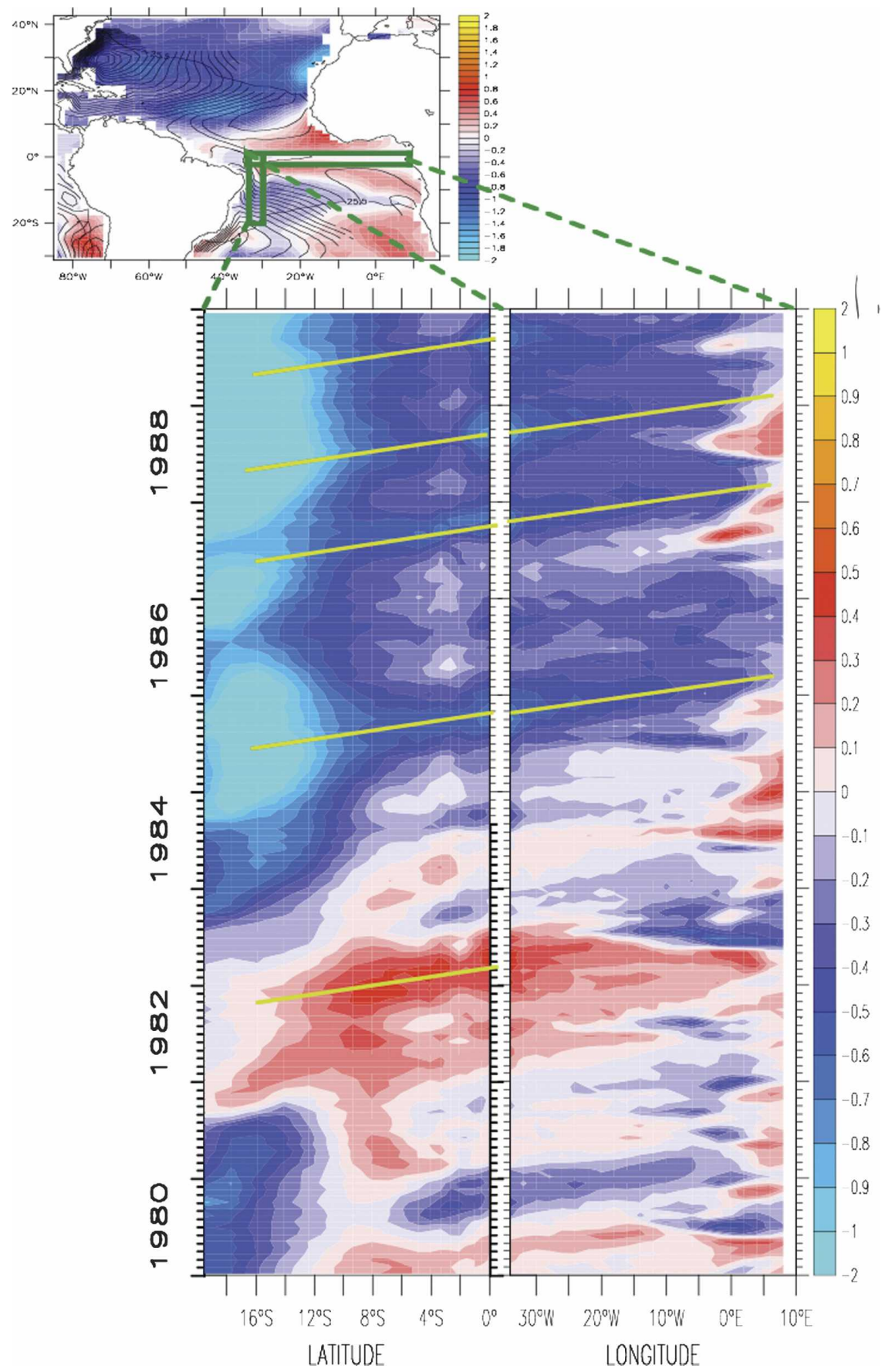

FIG. 11. Propagation of salinity-compensated temperature anomalies on isopycnal $\sigma 25.5$, within the thermocline along the Brazilian coast and then within the EUC as seen in an ocean GCM forced at the surface by NCEP-NCAR reanalysis data. (See Lazar et al. 2002.)

Equatorial Undercurrent and a resulting change in upper equatorial ocean thermal structure. How viable this mechanism is in term of influencing SST and the overlying atmosphere and how such a feedback loop would work are still very unclear.
There are other proposed mechanisms whereby MOC changes could affect the surface ocean conditions. Yang (1999) proposes that MOC changes can affect the interhemispheric SST changes. His mechanism, which involves MOC modulation of cross- 


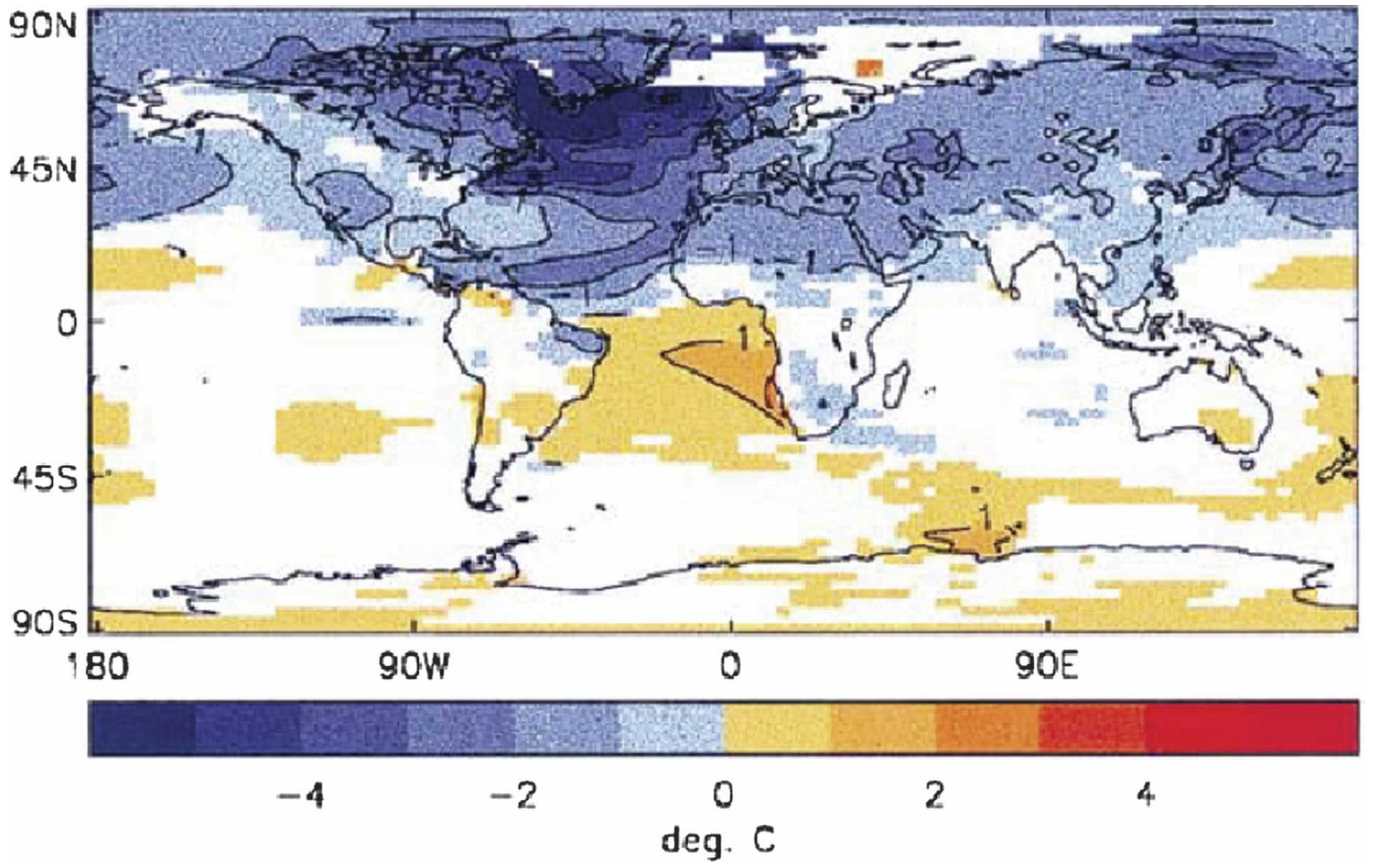

FIG. 12. Change in surface air temperature during years 20-30 after the shutdown of the thermohaline circulation in HadCM3. (From Vellinga and Wood 2002.)

equatorial heat transport, is supported by some numerical simulation experiments. The experiments show that the relatively short adjustment time scale $(5 \mathrm{yr})$ that links the high-latitude and tropical oceans is set by Kelvin and Rossby wave propagation. The resulting adjustment processes follow closely the theoretical analysis described by Kawase (1987) and Cane (1989). As the wave adjustment takes place along the western boundary and the equator, the maximum SST anomalies simulated by the idealized model appear in a narrow region along the western boundary.

In a recent study that follows Yang's reasoning, Johnson and Marshall (2002) articulate the importance of the so-called equatorial buffer mechanism. The fast propagation of Kelvin waves along the western boundary and then along the equator makes the equatorial region a buffer zone, which acts to limit and delay the response of the Southern Hemisphere to a sudden change in deep-water formation in the northern high latitudes. The disconnect between the two hemispheres causes convergence or divergence of heat in the equatorial region during the adjustment period, which can then produce a sizable change in the SST. The tight coupling between the atmosphere and ocean in the deep Tropics can potentially amplify the resulting thermal signal and lead to a large-scale response in the coupled system. The extent to which this buffer mechanism works in the real climate system needs to be fur- ther examined in a more realistic coupled model framework.

Observational evidence regarding the potential effects of northern deep-water formation anomalies on the tropical circulation and stratification may be forthcoming. A large volume of Labrador seawater that was formed in the early 1990s (Molinari et al. 1998; Stramma et al. 2004) is propagating southward along the western boundary of the North Atlantic. It was located east of the Bahamas in 1996 and was just recently detected to have advanced to $8^{\circ} \mathrm{N}$ (R. Fine 2004, personal communication). Hopefully, an observational system will be in place to study its propagtion in the equatorial zone in comparison with the model predictions as summarized here.

While many details remain to be worked out regarding the oceanic connection between the MOC and $\mathrm{TAV}$, there are several recent studies suggesting that a sudden change in the MOC strength can produce a significant response in the Tropics. Coupled CGM model studies by Vellinga and Wood (2002) and Dong and Sutton (2002) have shown a southward shift of the ITCZ over the Atlantic, accompanied by a dipolelike SST pattern with a cooler (warmer) temperature in the Northern (Southern) Hemisphere (Fig. 12) in response to a collapse of the thermohaline circulation in the Atlantic Ocean-a pattern that is consistent with the Atlantic meridional mode. Both of these studies are based 
on a version of the Third Hadley Centre Coupled Ocean-Atmosphere GCM (HadCM3). While Vellinga and Wood (2002) focus on the quasi-equilibrum response, Dong and Sutton (2002) focus on the adjustment of the coupled system. The latter study finds that the tropical Atlantic response to the change in the high latitudes is established within a relatively short time. Particularly worth noting is the coupled system adjustment when the colder SST reaches the equator and a cross-equatorial SST gradient develops within 4-6 yr after the high-latitude disturbance was introduced. The SST gradient causes a southward shift of the ITCZ in the tropical Atlantic sector, which apparently initiates an El Niño event in the tropical Pacific. The most recent coupled GCM study by Zhang and Delworth (2005) not only confirms these previous modeling results, but further shows that the Atlantic MOC change can alter weather patterns globally through changes in the Tropics, and this pattern is consistent with paleoproxy data. While the exact mechanism for the linkage between the high latitudes and Tropics in that coupled model still appears unclear, it is possible that the equatorial buffer mechanism may play a role. On the other hand, Chiang et al. (2003) report similar ITCZ response in an AGCM coupled to a slab ocean, raising the following question: Does the high-to-low-latitude communication occur through an oceanic bridge or an atmospheric bridge?

\section{d. Summary}

Some promising advancement areas for TAV research during the initial phase of CLIVAR are briefly highlighted as follows.

1) The tropical Atlantic meridional mode and zonal mode have emerged as two dominant regional climate phenomena. Important progress has been made in understanding the underlying physics of these climate fluctuations. A general consensus is emerging that the thermodynamic feedback is a key element of the meridional mode dynamics, whereas the dynamic feedback is an important part of the zonal mode dynamics.

2) The combined effect of remote influence of ENSO and the thermodynamic feedback can lead to useful seasonal prediction of the climate anomaly associated with the meridional mode during boreal spring.

3) The potential that the tropical Atlantic coupled system can respond effectively to changes in the MOC, because of the interaction between the STCs and MOC, has been demonstrated, raising the possibility that the Atlantic coupled system may be of particular importance to anthropogenic climate change.
Despite the encouraging progress, many fundamental problems remain unanswered. The following is a list of some of the key issues and major uncertainties in TAV research.

1) Although a number of oceanic processes have been proposed to play a role in the meridional mode, there is no consensus on which of these processes dominate. In particular, it remains uncertain whether any of these oceanic processes, through interacting with the atmosphere, can introduce a preferred time scale to TAV.

2) Use of prediction skill for the SST anomaly in the equatorial Atlantic has not been demonstrated, indicating a lack of basic understanding of predictable dynamics associated with the Atlantic zonal mode. The extent to which the oceanic memory mechanism associated with the delayed oscillator operates in the Atlantic zonal mode remains undetermined.

3) Many details concerning the role of tropical-extratropical exchanges via STCs and the MOC in TAV at decadal and longer time scales remain to be worked out. Currently, it is still unclear how changes in the MOC affect the pathways of the STCs, and how these changes in the STCs affect the SSTs, and finally how these SST changes can affect the coupled climate variability in the tropical Atlantic.

\section{Indian Ocean dipole}

Recent progresses in Indian Ocean research led to the discovery of an ocean-atmosphere coupled phenomenon known as the IOD mode (Saji et al. 1999; Yamagata et al. 2003b, 2004), which is also known as the IOZ mode (e.g., Webster et al. 1999; Clark et al. 2003). The IOD is characterized by an east-west dipole pattern in SST anomalies. The anomalous SSTs are found to be closely associated with changes in surface winds; equatorial winds reverse direction from westerlies to easterlies during the peak phase of the positive IOD events when SST is cool in the east and warm in the west (Fig. 13a). The air-sea interaction is evident from the lagged correlation among the equatorial zonal wind index (derived as in Saji et al. 1999), the anomalies of SST, and heat content (Fig. 13a); the latter two are significantly correlated to the former at one season ahead. It is also found that the ocean conditions related to the IOD have significant lead correlation to the East African short rains (Behera et al. 2005). Therefore, the surface wind anomalies are part of a basinwide anomalous Walker circulation (Yamagata et al. 2002, 2003b) related to the ocean-atmsophere coupling of IOD. The anomalous response of the tropical atmosphere to the 
(a)

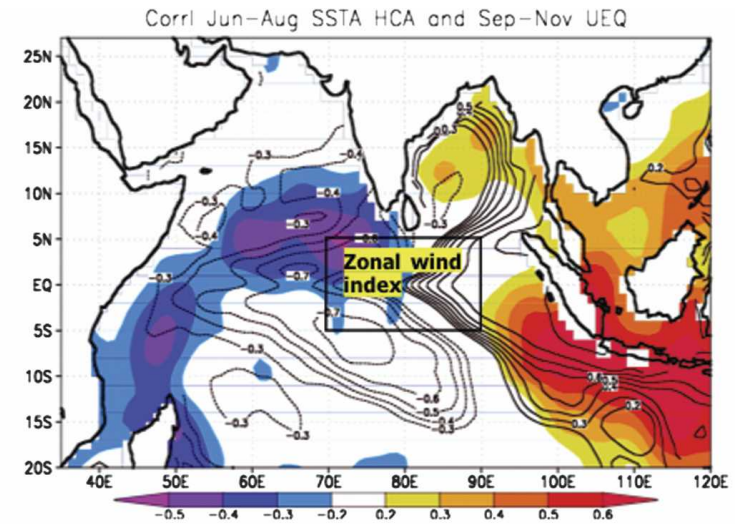

(b)

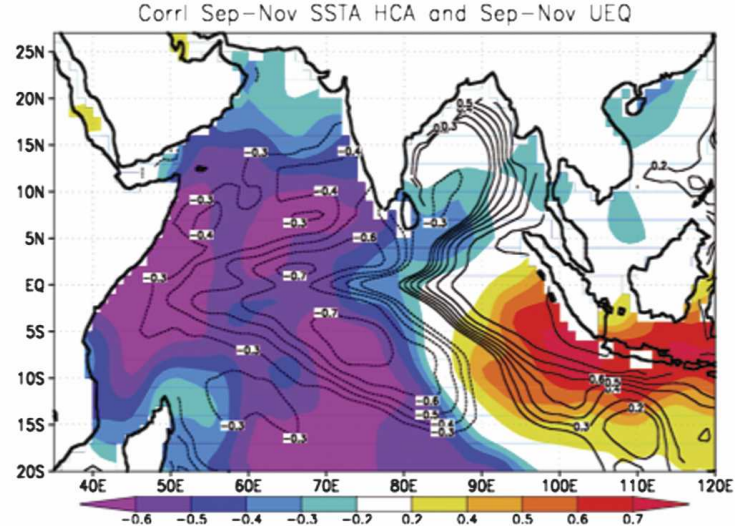

FIG. 13. (a) Lag-correlation between the zonal wind index from equatorial Indian Ocean in September-November, and the SST anomalies derived from the Global Sea Ice and SST dataset (GISST; Rayner et al. 2003) in June-August and heat content anomalies derived from SODA (Carton et al. 2000) in September-November. The correlation coefficients with the anomalies of SST (heat content) are shaded (contoured). (b) Same as in (a), but for concurrent correlation in September-November.

IOD SST anomalies, with the subsidence over colder pole and the upward motion over the warmer pole, is further supported by AGCM experiments (Guan et al. 2003; Ashok et al. 2003b). In the coupled feedback process, those zonal wind anomalies affect the anomalies in the upper ocean, elevating (deepening) the thermocline in the east (west), and thus giving rise to a subsurface dipole (Rao et al. 2002a; Feng and Meyers 2003; Shinoda et al. 2004a) as found in Fig. 13b.

The notion that the IOD is an independent physical mode inherent to the tropical Indian ocean-atmosphere coupled system has been discussed recently (Saji et al. 1999; Yamagata et al. 2003b, 2004; Behera et al. 2006). The independent nature of IOD events is observed in some years even in a simple visual analysis of the raw data; for example, strong, positive IOD events occurred in 1961, 1967, and 1994. The historical positive and negative IOD events that occur without the presence of El Niño or La Niña have been called "pure" events. The independent nature of the IOD is also seen in pure composites of SST anomalies (Yamagata et al. 2004) in the observed data (Figs. 14a,b). It may be noted that the SST anomalies are stronger in the pure IOD composite as compared to the all-IOD composite. A dipolelike pattern emerges in the Indian Ocean in the composite for all ENSO years because of cooccurrence of some IOD events with ENSO. The Indian Ocean pattern almost disappears, in a pure ENSO composite (Figs. 14c,d). A careful analysis shows that a significant number of the IOD events are independent of ENSO and only about $30 \%$ of them co-occur with ENSO (Rao et al. 2002a; Yamagata et al. 2003b, 2004). Therefore, the IOD cannot be simply explained as a passive response to ENSO as in the case of TAV. Its distinctive characteristics require invoking regional ocean-atmosphere interaction.

Like other tropical phenomena, the evolution of the IOD is strongly locked to the annual cycle; the phenomenon typically develops during May/June, peaks in September/October, and diminishes in December/ January. Its development phase coincides with the onset of the Indian summer monsoon, while its peak phase roughly coincides with the onset of boreal winter monsoon. We notice that the IOD peak phase is different from that of ENSO. There are further marked differences in the rainfall variability associated with IOD and ENSO. Behera and Yamagata (2003) showed that the IOD influences the Darwin pressure variability, that is, one pole of the Southern Oscillation. This Indian Ocean influence on ENSO variability is also reported in a few recent studies (e.g., Wu and Kirtman 2004; Annamalai et al. 2005b). Positive IOD and El Niño have similar impacts in the Indonesian region owing to anomalous atmospheric subsidence and thereby induce drought there. However, the variability in East African short rains during boreal fall are more likely to be associated with the IOD (Black et al. 2003; Saji and Yamagata 2003b; Behera et al. 2005) rather than ENSO as indicated by previous studies (Ropelewski and Halpert 1987; Ogallo 1989; Hastenrath et al. 1993; Mutai and Ward 2000). The impact of the IOD is not limited only to the equatorial Indian Ocean. It is found that the IOD influences the global climate system (e.g., Saji and Yamagata 2003b) through changes in the global atmospheric circulation. For example, the IOD influences the Southern Oscillation in the Pacific (Behera and Yamagata 2003), rainfall variability during the Indian summer monsoon (Behera et al. 1999; Ashok et al. 2001), the summer climate condition in East Asia 
a)
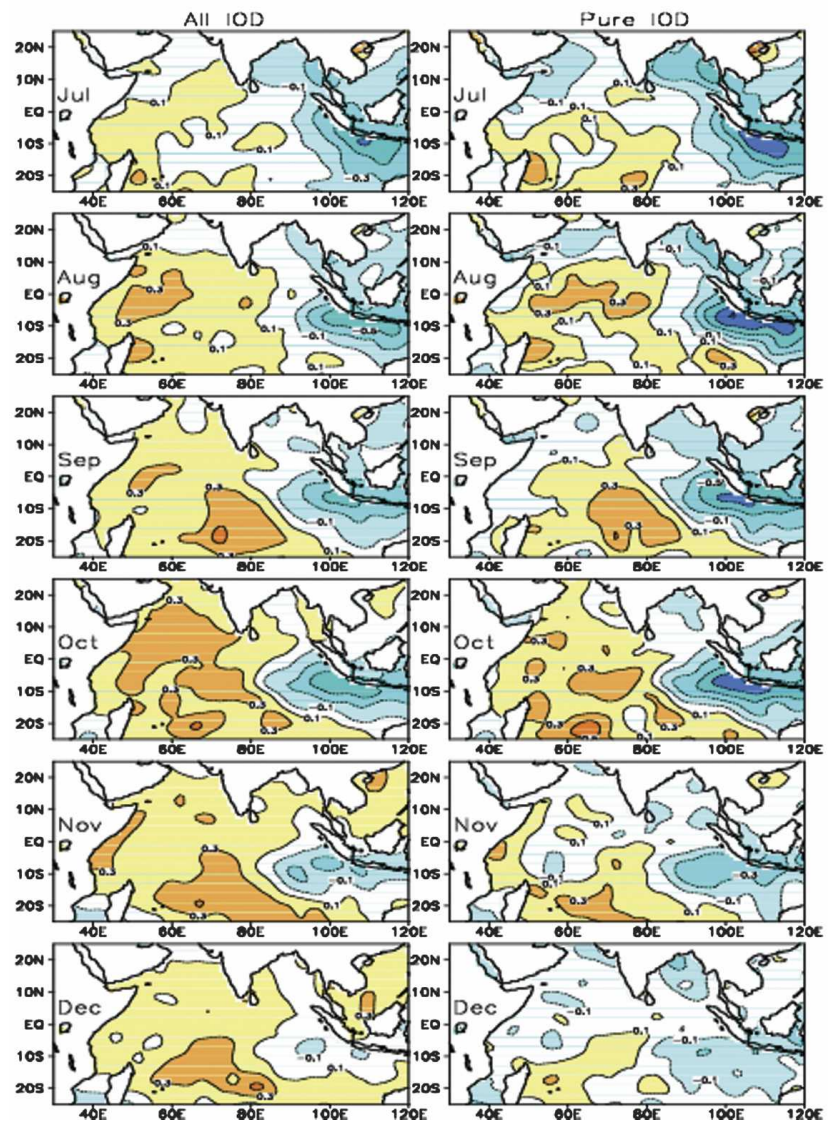

c)

d)
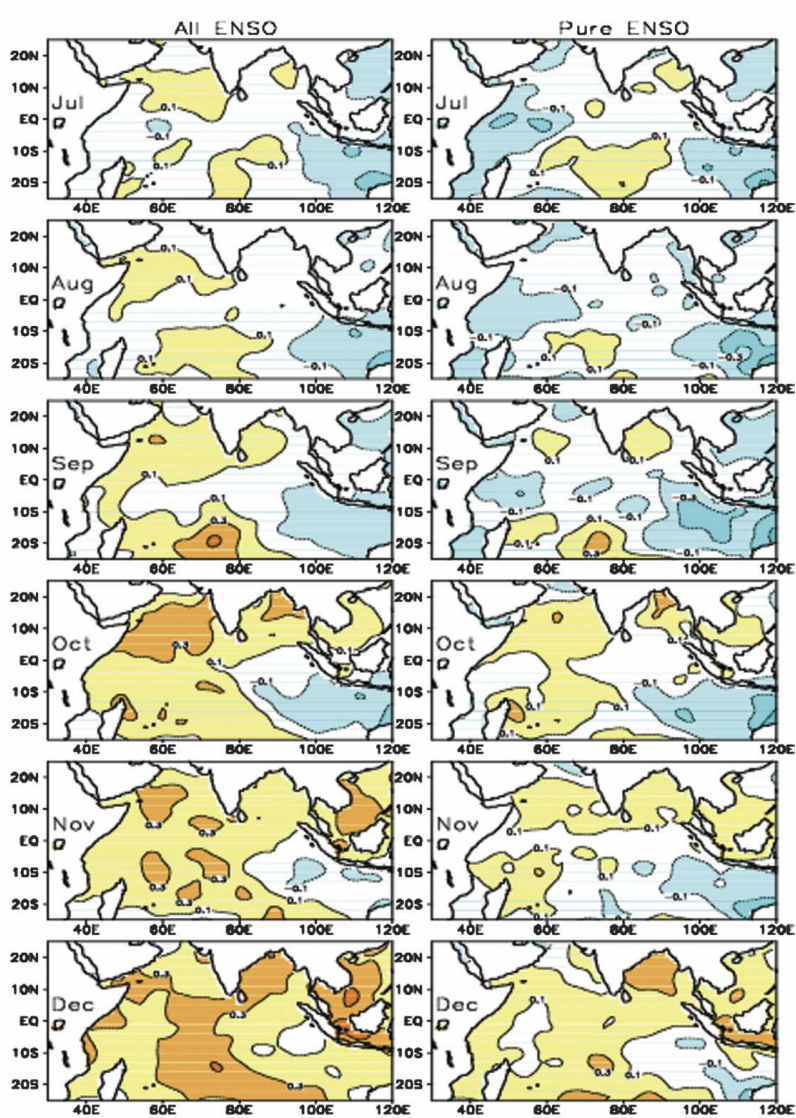

FIG. 14. Composite of SST anomalies for (a) all IOD events, (b) pure IOD events, (c) all ENSO events, and (d) pure ENSO events. (Adapted from Yamagata et al. 2004.)

(Guan and Yamagata 2003; Guan et al. 2003), the African rainfall (Black et al. 2003; Clark et al. 2003; Behera et al. 2003a, 2005; Rao and Behera 2005), the Sri Lankan Maha rainfall (Zubair et al. 2003), and the Australian winter climate (Ashok et al. 2003b). Figure 15 distinguishes the global rainfall variability associated with the IOD from those of ENSO, based on partial correlation and pure composite analysis of observed data (Saji and Yamagata 2003b; Yamagata et al. 2004).

Discovery of the IOD has stimulated exciting research in other disciplines of science such as paleoclimate, marine biology, and atmospheric chemistry. In a recent paper, Abram et al. (2003) reported that the scattered particulates from severe wildfires in the Indonesian region during the 1997 IOD event caused exceptional coral bleaching in the Mentawai Island (off Sumatra) reef ecosystem. They also traced the IOD signal back to the mid-Holocene period using the fossil coral records from the region, revealing the first evidence of paleo-IOD. In another context, Fujiwara et al.
(1999) found that the variability in tropospheric ozone distribution over Indonesia is related to the IOD phenomenon.

\section{a. Coupled air-sea feedback in the IOD}

The evolution of the IOD during its development and peak phase clearly involves active oceanatmosphere interaction. The coupled mechanism appears to be predominantly dynamical in nature, involving feedbacks between winds and SSTs through upper equatorial ocean dynamics (Fig. 13a). As noted earlier, during the peak phase of the positive IOD events, SST is colder than normal in the east and warmer than normal in the west (Fig. 13b). The atmosphere responds to this anomalous SST with a basinwide anomalous Walker circulation (Yamagata et al. 2002, 2003b) causing the equatorial winds to reverse direction from westerlies to easterlies. The anomalous winds lift (deepen) the thermocline in the east (west) giving rise to a basinwide subsurface dipole as shown in Fig. 13b (Rao et 

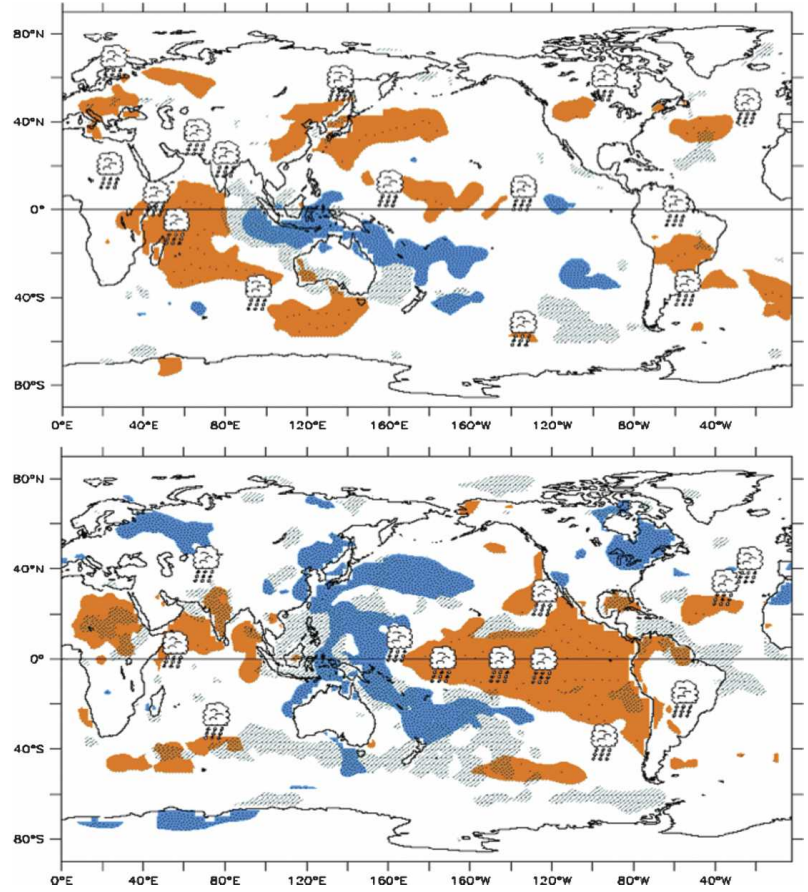

FIG. 15. Schematic diagram of (top) IOD and (bottom) ENSO teleconnections based on the partial correlations/pure composite of Saji and Yamagata (2003b) and Yamagata et al. (2004). The orange (blue) shading indicates warm (cold) conditions during positive IOD or El Niño. Clouds (gray shading) represent rainy (dry) conditions during positive IOD or El Niño. The opposite is true during negative IOD and La Niña events.

al. 2002a; Feng and Meyers 2003). Since the seasonal southeasterly winds along the Java coast are also strengthened during the positive IOD events, the anomalous coastal upwelling combined with the shallow thermocline causes anomalous SST cooling near the coast, in addition to enhanced evaporative cooling in a larger area offshore (Behera et al. 1999). The deeper thermocline in the west forms through the Ekman pumping/Rossby wave mechanism (Murtugudde et al. 2000; Rao et al. 2002a; Xie et al. 2002; Feng and Meyers 2003) and generates a warm SST anomaly there. The SST gradient across the ocean is thus increased by mechanisms acting in both the east and the west, which leads to further enhancement of the atmospheric response. These oceanic and atmospheric conditions fit to the general description of a Bjerknes-type feedback (Bjerknes 1969), suggesting that the Bjerknes mechanism is a key for the IOD evolution. Behera et al. (1999), Yamagata et al. (2002), and Behera and Yamagata (2003) provide further observational evidence for the dipole pattern of OLR anomalies and sea level pressure anomalies associated with the IOD.

Coupled model studies are generally supportive of the independent nature of the IOD as an intrinsic physical mode and the importance of local oceanatmosphere feedbacks in its evolution. We particularly note that various CGCMs are now successful in reproducing the IOD events and have provided a solid dynamical basis for its existence. Iizuka et al. (2000) found a remarkable similarity between the observed IOD and model IOD from their moderately high resolution CGCM. The model IOD in their results shows a quasibiennial tendency and is largely independent of the model ENSO (e.g., Behera et al. 2006). The characteristic of IOD and its independence from ENSO are also observed in the Scale Interaction Experiment-Frontier Research Center for Global Change version 1 (SINTEXF1) simulation (Yamagata et al. 2004), which shows improvement in simulated ENSO power spectra owing to the high-resolution atmospheric model (cf. Guilyardi et al. 2004). In addition, Yamagata et al. (2004) demonstrated that the coupled Rossby waves in the southern equatorial Indian Ocean are associated with IOD, as in the observation (e.g., Xie et al. 2002; Rao and Behera 2005). Behera et al. (2003a, 2005), after deriving an index for the East African short rains, have shown that the SINTEX-F1 coupled model (Luo et al. 2003, 2005a,b; Masson et al. 2005) reproduces an east-west SST dipole in the correlation between the short rains index and SST anomalies in the Indian Ocean. The correlation evolves one season prior to the peak IOD season that coincides with the season of short rains.

The independent development of IOD is reported by most other CGCM studies (Yu et al. 2002; Gualdi et al. 2003; Lau and Nath 2004; Cai et al. 2005; Fischer et al. 2005) but for two exceptions (Baquero-Bernal et al. 2002; Yu and Lau 2004). The latter two studies suggest that IOD is primarily forced by ENSO. Based on an experiment in which ENSO is suppressed, BaqueroBernal et al. (2002), in particular, suggest that the dipole mode only detected during boreal fall in their CGCM is not necessarily related to the ocean dynamics. Rather they claim that it is forced stochastically by the atmosphere. In contrast, Behera et al. (2006), based on a similar experiment using the SINTEX-F1 CGCM, demonstrate that the subsurface Indian Ocean plays a significant role in the IOD development even in the absence of ENSO.

Cai et al. (2005), using the Commonwealth Scientific and Industrial Research Organisation (CSIRO) Mark3 coupled model, have found that most of the model IOD evolves after the demise of model ENSO without a simultaneous relationship between them. The strong association of their model IOD with the model ENSO at $1-\mathrm{yr}$ lag is attributed to the model bias caused by a too-active intrusion of the Indonesian throughflow 
from the western tropical Pacific owing to coarse ocean model resolution. From a 900-yr GFDL CGCM experiment, Lau and Nath (2004) found recurrent evolution of IOD patterns. As in the observation, some strong IOD episodes in their model occur even in the absence of ENSO. They suggest that the IOD evolution is attributable to multiple factors: internal air-sea positive feedback processes, remote influences due to ENSO, and extratropical changes in the Southern Ocean. Gualdi et al. (2003) found significant correlations between sea level pressure anomalies in the southeastern Indian Ocean and sea surface temperature anomalies in the tropical Indian and Pacific Oceans in both observations and a multidecadal simulation. In particular, a positive SLP anomaly in the southeastern part of the basin is shown to produce favorable conditions for the development of an IOD event that was discussed in detail by Li et al. (2003).

As in the case of Pacific ENSO, CGCMs are proving to be useful in predictability experiments of the IOD. Using the National Aeronautics and Space Administration (NASA) Seasonal-to-Interannual Prediction Project (NSIPP) coupled model, Wajsowicz (2005) has shown that ensemble hindcasts of the SST anomalies averaged over the two poles of the IOD are encouragingly good at 3 months lead time for the decade 19932002 including extreme positive events in 1994 and $1997 / 98$. The onset of the $1997 / 98$ event is delayed by about a month, though the model ensemble correctly predicts the peak and decay phases. At 6 months lead time, the forecast skill of the eastern pole deteriorates. Using the high-resolution SINTEX-F1 prediction system, Luo et al. (2005, manuscript submitted to J. Climate) have shown good skill in predicting the 1994 IOD event at 2-3 seasons lead. Retrospective ensemble forecasts for the past two decades show a winter prediction barrier due to the intrinsic strong seasonal phase locking of IOD and a weak spring barrier associated with the Pacific variability.

The dynamically consistent long time series data obtained from CGCM simulations are useful for studies of low-frequency variability (Ashok et al. 2004). Using output from a 200-yr integration of the SINTEX-F1 CGCM, Tozuka et al. (2006, hereafter TLMY) investigated the decadal climate variability in the tropical Indian Ocean. In their analysis, the first EOF mode of the bandpass (9-35 yr) filtered sea surface temperature anomaly represents a basinwide mode that has a close connection with the Pacific ENSO-like decadal variability. The second EOF mode shows a clear east-west dipole pattern. Since the pattern resembles the interannual IOD despite the longer time scale, the mode is named the decadal IOD. One of the most interesting suggestions is that the decadal air-sea interaction in the Tropics could be a statistical artifact; the decadal IOD may be interpreted as decadal modulation of interannual IOD events (TLMY). The appearance of the model decadal IOD is related to (a) frequency modulation, (b) amplitude modulation and, most importantly, (c) asymmetric occurrence of positive and negative events. The origin of the decadal behavior of IOD both in models and observations needs to be clarified. Possible tropical and subtropical interactions through oceanic processes in response to monsoon variability, in addition to roles of the Indonesian throughflow, appear to be a key for the understanding of the decadal IOD.

\section{b. Remote influence from the Pacific}

The importance of the remote influence of Pacific ENSO on variability in the Indian Ocean has long been recognized. In fact, the conventional view was that the variability in the Indian Ocean sector is completely dominated by the remote influence of ENSO. Indeed, a basinwide SST anomaly of almost uniform polarity that is highly correlated with ENSO in the Pacific is present as the most dominant interannual mode in the Indian Ocean (Cadet 1985; Klein et al. 1999). In most cases, the basinwide anomaly is first established in the west through the weakening of the Findlater jet and then spreads eastward as the warm ENSO matures. The weakening of the Indian summer monsoon is caused by the anomalous downdraft related to a warm ENSO episode. Compared to the zonal SST dipole anomalies associated with IOD, those ENSO-induced monopole SST anomalies dominate the basin and occur more frequently with longer persistence (see Fig. 1 in Yamagata et al. 2004). For these reasons, this pattern emerges as the leading mode in statistical analyses, such as empirical orthogonal function (EOF) analysis, whereas the IOD often appears as the second mode.

It is quite rare for climate dynamists to discuss a second mode of variability. Hence, it is not a surprise that the concept of IOD needed some time to be accepted (cf. Allan et al. 2001; Hastenrath 2002). In fact, in the wavelet spectra of raw SST anomalies of the eastern pole $\left(10^{\circ} \mathrm{S}-0^{\circ}, 90^{\circ}-110^{\circ} \mathrm{E}\right)$ and western pole $\left(10^{\circ} \mathrm{S}-10^{\circ} \mathrm{N}, 50^{\circ}-70^{\circ} \mathrm{E}\right)$, we do not find much coherence (Fig. 2 in Yamagata et al. 2003b), so we are apt to deny the existence of IOD. However, as shown in Yamagata et al. (2003b), a remarkable seesaw is found between those two poles after removing the external ENSO effect (readers are referred to Fig. 3 of their article), which is consistent with a few preceding studies that 


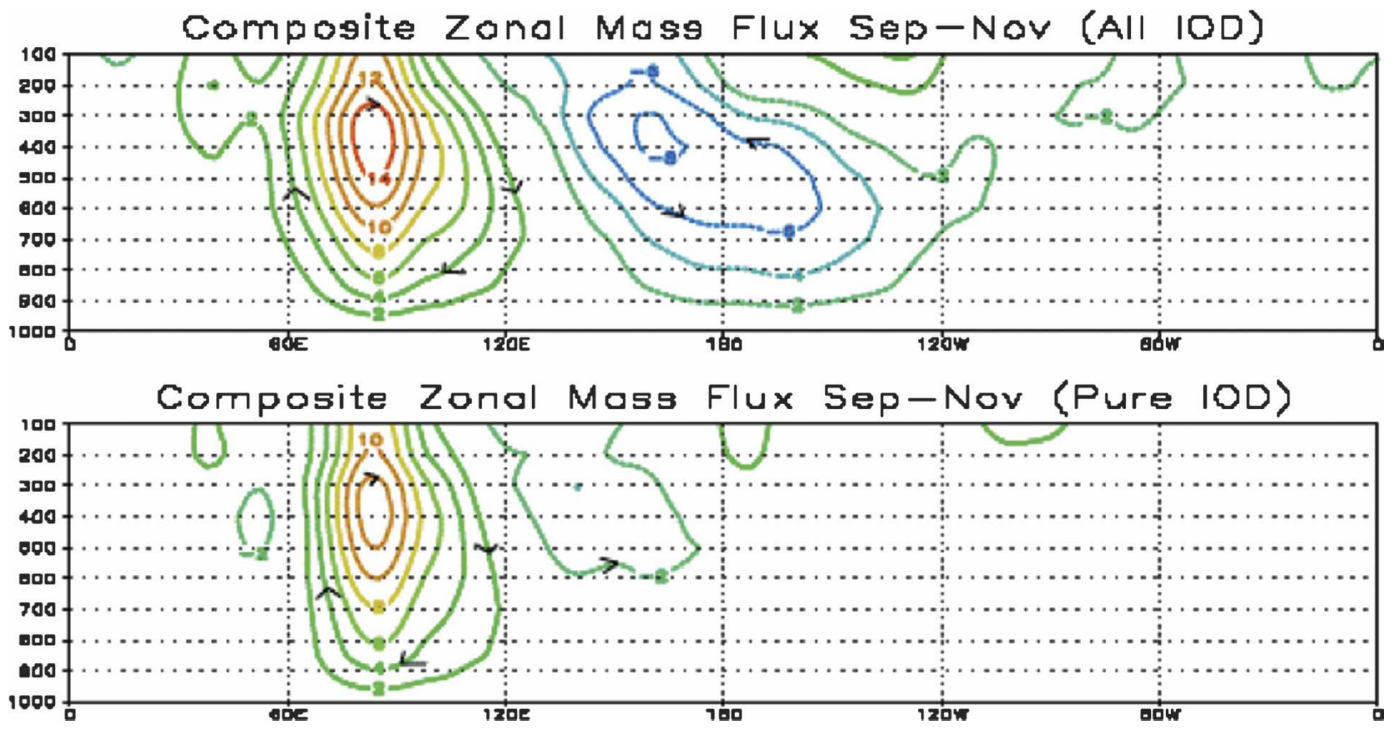

FIG. 16. Same as in Fig. 14, but for the zonal mass flux anomalies that represent anomalous Walker circulation (from Yamagata et al. 2003b).

intuitively draw attention to some apects of such an inherent mode (e.g., Reverdin 1985; Reverdin et al. 1986; Hastenrath et al. 1993). This shows quite a contrast to other major oscillatory modes such as the Southern Oscillation and the North Atlantic Oscillation. Because those are the first dominant modes, a negative correlation is detected easily between the two poles even in raw data. On the other hand, the IOD appears as the second mode statistically in SST variability. Therefore, it is necessary to remove the first dominant mode to detect the seasaw mode of IOD statistically. This is the basic reason why some statistical analyses fail to capture the IOD signal (cf. Dommenget and Latif 2002; Hastenrath 2002) even if the IOD appears as a seesaw mode dramatically in a physical space during typical event years. The above subtlety is demonstrated mathematically in Behera et al. (2003b). Another interesting divide is related to interpretation of the high correlation between ENSO and IOD phenomena. The correlation between dipole mode index (DMI) and Niño-3 index amounts to 0.53 for the peak IOD season of September-November (Nicholls and Drosdowsky 2000; Allan et al. 2001). Based on this significant correlation, one straightforward way to interpret this is that IOD events occur dynamically as a part of ENSO (Allan et al. 2001; Baquero-Bernal et al. 2002). However, we must notice that the correlation itself only denotes the statistical fact that one-third of positive IOD events co-occur with El Niño events rather than their dynamical ralation. In other words, the nonorthogonality of two time series does not nec- essarily mean that the two phenomena are connected always in physical space.

The mechanisms through which ENSO exerts its influence on the Indian Ocean have not been clearly understood. One possible candidate is through changes in zonal Walker circulation. Yamagata et al. (2003a,b), however, have demonstrated that an anomalous Walker cell exists only in the Indian Ocean during pure IOD events (Fig. 16). Although the linear analysis does not exclude completely the possible nonlinear physical interaction between the two climate signals, the above suggests the independent evolution of some IOD events. From a case study of the 1997/98 El Niño event, Ueda and Matsumoto (2000) suggested that the changes in the Walker circulation related to the El Niño could influence the evolution of IOD through changes in the monsoon circulation. Conversely, Behera and Yamagata (2003) showed that IOD modulates the Darwin pressure variability, that is, one pole of the Southern Oscillation. How two major climate modes interact in the Indo-Pacific basin is a challenging problem.

The other proposed mechanism is through changes in the ocean circulation in response to ENSO-related changes in the atmosphere. From the pure El Niño composites, we find that cold SST anomalies of the Pacific origin entering the Indian Ocean propagate along the west coast of Australia (partly seen in rightbottom corners of Fig. 14d). This is understood on the basis of the oceanic finding in both theory and observations; the mature ENSO signal in the western Pacific intrudes into the eastern Indian Ocean through the 
coastal waveguide around the Australian continent (Clarke and Liu 1994; Meyers 1996; Wijffels and Meyers 2004). The SST in the eastern Indian Ocean near the west coast of Australia during the boreal fall and winter is thus influenced by ENSO. This is known as the Clarke-Meyers effect. Schiller et al. (2000) confirmed this effect using a realistic ocean general circulation model. The changes in the SST may cause local air-sea interaction in boreal fall in this region (Hendon 2003), just like the annual coupled mode in the eastern Pacific (cf. Tozuka and Yamagata 2003). This phenomenon appears to be different from the cooling off Sumatra, which is related to the basinwide IOD phenomenon; IOD starts in May or June and involves active equatorial ocean dynamics. However, the air-sea interaction in the eastern Indian Ocean apparently enhances the IOD-ENSO correlation during the boreal fall. The eastern Indian Ocean is a unique region as crossroads of climate signals of both the Pacific Ocean and the Indian Ocean (Wijffels and Meyers 2004). The interaction of equatorial and coastal waveguides influenced by the presence of the barrier layer is a complex phenomenon that still is not well understood.

\section{c. Teleconnections}

Like ENSO, the IOD can exert its influence on various parts of the globe via atmospheric bridge effects, interfering with other modes of climate variability. Saji and Yamagata (2003b) demonstrated that the positive IOD and El Niño have opposite influences in the Far East, including Japan and Korea; positive IOD events give rise to warm and dry summers, while negative IOD events lead to cold and wet summers. For example, the record-breaking hot and dry summer during 1994 (just like 1961) in East Asia was actually linked to the IOD (Guan and Yamagata 2003; Yamagata et al. 2003a 2004). It is well known that the summer climate condition over East Asia is dominated by activities of the East Asian summer monsoon system. Since the East Asian summer monsoon system is a subsystem of the Asian monsoon (Wang and Fan 1999), it interacts with another subsystem, the Indian summer monsoon, via variations of the Tibetan high and the Asian jet (Rodwell and Hoskins 1996; Enomoto et al. 2003). The precipitation over the northern part of India, the Bay of Bengal, Indochina, and the southern part of China was enhanced during the 1994 positive IOD event (Behera et al. 1999; Guan and Yamagata 2003; Saji and Yamagata 2003b). Using the NCEP-NCAR reanalysis data (Kalnay et al. 1996) from 1979 through 2001 and the Climate Prediction Center (CPC) Merged Analysis of Precipitation (CMAP) data from 1979 through 1999, several studies found that the equivalent barotropic

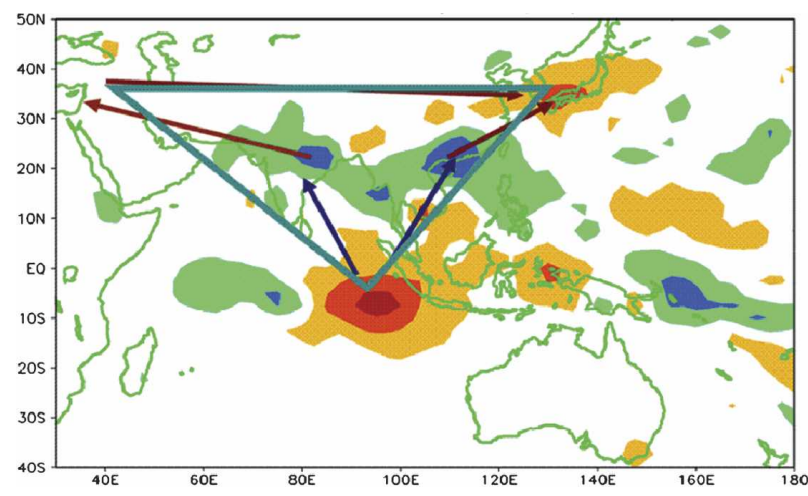

FIG. 17. Schematic triangular relation among three key regions: the eastern Indian Ocean, eastern Europe-the Mediterranean Sea, and the Far East. Warm (cold) colors denote anomalously dry (wet) conditions. (From Yamagata et al. 2004.)

high was strengthened over East Asia (e.g., Guan and Yamagata 2003; Yamagata et al. 2003a, 2004). The anomalous pressure pattern bringing unusually hot summer is well known to Japanese weather forecasters as a "whale tail" pressure pattern. The tail part is equivalent barotropic in contrast to the larger baroclinic head part of the Pacific high. The IOD-induced summer circulation changes over East Asia are thus understood schematically through a triangular mechanism (Fig. 17). One process is that a Rossby wave train is excited in the upper troposphere by the IOD-induced divergent flow over the Indochina (Sardeshmukh and Hoskins 1988). This wave train propagates northeastward from the southern part of China. This is quite similar to Nitta's Pacific-Japan (PJ) pattern (Nitta 1987) although the whole system is shifted a little westward. Another process is that the IOD-induced diabatic heating around the Bay of Bengal excites a long atmospheric Rossby wave to the west of the heating. The latter reminds us of the monsoon-desert mechanism that connects the circulation changes over the Mediterranean Sea-Sahara region with the heating over India (Rodwell and Hoskins 1996). Interestingly, this monsoon-desert mechanism was introduced by examining the anomalous summer condition of 1994 prior to the discovery of IOD (cf. Hoskins 1996). The westerly Asian jet acts as a waveguide for eastward-propagating tropospheric disturbances to connect the circulation change around the Mediterranean Sea with the anomalous circulation changes over East Asia. This mechanism called the Silk Road process may contribute to strengthening of the equivalent barotropic high over East Asia (Enomoto et al. 2003). The scenario is confirmed by calculating the wave activity flux (cf. Plumb 1986; Takaya and Nakamura 2001) by Guan and Yamagata (2003). 
The SINTEX-F1 coupled model simulation demonstrated the paramount influence of IOD on East African short rains; about $80 \%$ of extreme-short rain years are related to IOD as in the observations (Behera et al. 2003a, 2005). The DMI was successful in predicting anomalous short rains one season ahead in $92 \%$ of the years. The slow propagation of the air-sea coupled mode in the western Indian Ocean (Yamagata et al. 2004; Rao and Behera 2005; Behera et al. 2005) provides us with a scope for the predictability of the IODinduced short rains. The anomalous westward low-level winds in response to the anomalous zonal gradient of SST increase the moisture transport to the western Indian Ocean and enhance atmospheric convection in East Africa. The correlation analysis demonstrates that positive IOD (El Niño) events are related to enhanced (reduced) rainfall in East Africa as in the observations. Interestingly, the current coupled model captures even the higher impact of IOD on the Sri Lankan Maha rainfall as discussed by Zubair et al. (2003). In the Indonesian region, the model rain anomaly shows higher negative partial correlation with the IOD index as compared to that of ENSO.

In the Southern Hemisphere, the impact of the IOD is remarkable over Australia in a band from the northwest shelf to southeastern Australia (Saji and Yamagata 2003a,b; Ashok et al. 2003b) and Brazil (Saji and Yamagata 2003b); positive IOD events cause warm and dry conditions in a band from the northwest shelf to southeastern Australia and negative events cause cold and wet conditions (Fig. 15). The IOD teleconnection in the winter hemisphere is more due to a Rossby wave train (S. Chan et al. 2006, personal communication) and its impact on the weather phenomenon that Australian meteorologists call the "northwest cloudband." The study of teleconnection due to IOD events has just started, and serious efforts to understand more about its mechanism are needed to improve predictability of regional climate over the globe.

\section{d. Oceanic dynamics in the IOD}

\section{1) TropicAl oceAn PROCESSES}

Several recent studies have discussed various roles the ocean dynamics play in the evolution of the Indian Ocean coupled phenomenon (Vinayachandran et al. 1999, 2002; Murtugudde et al. 2000; Feng et al. 2001; Li and $\mathrm{Mu}$ 2001; Rao et al. 2002b; Xie et al. 2002; Huang and Kinter 2002; Saji and Yamagata 2003a; Guan et al. 2003; Masson et al. 2004; Ashok et al. 2003a; Annamalai et al. 2003; Shinoda et al. 2004a) using observed data and ocean model simulations.
The oceanic condition in the eastern Indian Ocean was first reported by Meyers (1996); the study based on a repeated expendable bathythermograph (XBT) section near the outlet for the Indonesian throughflow showed unusually cold anomalies off Java in close association with the zonal wind anomalies in the eastern equatorial Indian Ocean and their frequent occurrence in the past. This is consistent with the study by Yamagata et al. (1996), which suggested the arrival of equatorial Kelvin waves generated in the Indian Ocean contributing to the throughflow variability.

The dipole mode originally introduced using the SST anomalies is coupled strongly with subsurface temperature variability (Murtugudde et al. 2000; Feng et al. 2001; Rao et al. 2002a; Vinayachandran et al. 2002; Shinoda et al. 2004b; Feng and Meyers 2003). In fact, the dipole mode emerges as the first dominant mode in the subsurface temperature variability (Rao et al. 2002a). The close link between the surface signal and the subsurface signal is very striking when we calculate correlation between the zonal wind index from the central Indian Ocean and the heat content/SST anomalies (Fig. 13). The high correlation with the equatorial wind anomalies shows the close coupling between the ocean and the atmosphere. Rao et al. (2002a) discussed how the evolution of the dominant dipole mode in the subsurface is controlled by equatorial ocean dynamics forced by zonal winds in the equatorial region. This evolution appears to be explained by a kind of delayed oscillator mechanism (cf. Schopf and Suarez 1988); the phase of the surface dipole reverses in the following year through propagation of oceanic Rossby/Kelvin waves (Rao et al. 2002a; Feng and Meyers 2003), which is also confirmed from coupled model studies (Gualdi et al. 2003; Yamagata et al. 2004). Thus, the turnabout of the subsurface dipole leads to the quasi-biennial oscillation (QBO) of the tropical Indian Ocean (Rao et al. 2002a; Feng and Meyers 2003). The ocean dynamics may play an important role in the QBO in the IndoPacific sector through changes of the Asian monsoon (cf. Meehl 1987). This is another challenging problem.

Interannual Rossby waves (from 3 to $5 \mathrm{yr}$ ) are reported in the southern Indian Ocean by Perigaud and Delecluse (1993), Masumoto and Meyers (1998), Chambers et al. (1999), and White (2000). Particularly, Masumoto and Meyers (1998) concluded that these waves are primarily forced by the wind stress curl along the Rossby wave characteristic. Xie et al. (2002) have suggested that Rossby waves play an important role in the air-sea interaction of the southern Indian Ocean where the shallow mean thermocline allows subsurface anomalies to affect SST. These Rossby wave-induced 
SST anomalies modulate convection in the Indian Ocean ITCZ and may further influence the onset of the Indian summer monsoon (Annamalai et al. 2005a). While Xie et al. (2002) argued that these Rossby waves are dominantly forced by ENSO, a more detailed study of Rao and Behera (2005) shows that the relative importance of ENSO and IOD varies with latitude. The wind stress curl associated with the positive IOD forces the westward-propagating downwelling long Rossby waves north of $10^{\circ} \mathrm{S}$, increasing the heat content of the upper layer in the central and western Indian Ocean (e.g., Huang and Kinter 2002). The heat content anomaly maintains the SST anomaly; this SST anomaly, in turn, influences the wind stress anomaly, thereby completing the feedback loop. In contrast, the ENSO influence dominates over the upwelling dome south of $10^{\circ} \mathrm{S}$ (cf. Schott et al. 2002b) in the southern Indian Ocean, as discussed by Xie et al. (2002) and Jury and Huang (2004). A similar response of sea level to wind forcing is found in the study by Wijffels and Meyers (2004). The cause of this is not very clear at this stage, but the ENSO-related variation of the southern trade winds is one possible candidate. Another possible candidate is the Indonesian throughflow that intrudes into this region; the oceanic anomaly of Pacific origin may propagate westward and enhance local air-sea coupling south of $10^{\circ} \mathrm{S}$ (cf. Masumoto and Meyers 1998).

The precondition for IOD evolution is another issue that requires more research. Several studies indicate the presence of a favorable mechanism in the eastern Indian Ocean that combines cold SST anomalies, anomalous southeasterlies, and suppression of convection into a feedback loop (e.g., Saji et al. 1999; Behera et al. 1999). However, recent studies suggest a few alternatives: atmospheric pressure variability in the eastern Indian Ocean (e.g., Gualdi et al. 2003; Li et al. 2003), favorable changes in winds in relation to the Pacific ENSO and the Indian monsoon (e.g., Annamalai et al. 2003), oceanic conditions in the Arabian Sea related to the Indian monsoon (Prasad and McClean 2004; Suzuki et al. 2004, manuscript submitted to J. Phys. Oceanogr., hereafter SBY), and influences from the southern extratropical region (e.g., Lau and Nath 2004). All those studies fall short on more than one occasion to answer the failure (or success) in IOD evolution in spite of favorable (or unfavorable) precondition. For example, Gualdi et al. (2003) reported the failure of their proposed favorable mechanism to excite the IOD event in 1979. We also find several instances (e.g., the aborted 2003 event) when an IOD event is aborted abruptly by intraseasonal disturbances (Rao and Yamagata 2004). The out-of-phase ENSO variabil- ity further complicates the IOD preconditioning (Behera et al. 2006). This indicates that the evolution of the IOD is more complex than thought and further studies of scale interactions are needed, which will be discussed briefly in the next subsection.

\section{2) EFFECTS OF SEASONAL CYCLE AND INTRASEASONAL VARIABILITY}

Most of the earlier studies of the Indian Ocean were aimed at understanding the seasonal characteristics of the northern Indian Ocean (e.g., McCreary et al. 1993). This is mainly because the response to seasonally reversing monsoonal winds is the dominant mode of Indian Ocean variability. The Somali Current, YoshidaWyrtki jets, circulations in the Bay of Bengal (cf. Shetye et al. 1996) and the Arabian Sea, and currents along the Indonesian coast were prominently addressed in those studies. For an extensive review of the monsoon ocean circulation, readers are referred to Schott and McCreary (2001). Below we focus on the processes that are most relevant to the IOD.

The distinct seasonal cycle of the tropical Indian Ocean is composed of annual and semiannual signals in response to monsoonal winds (Schott and McCreary 2001). Along the Somali coast in the northwestern Indian Ocean, the winds are southwesterly in boreal summer and northeasterly in boreal winter. This seasonal cycle of wind contains a semiannual component because of the skewness of the annual march. The most striking feature of the semiannual cycle in the ocean is the equatorial Kelvin waves manifested as the Yoshida-Wyrtki jet (Yoshida 1959; Wyrtki 1973; O'Brien and Hurlburt 1974). Based on climatology of relatively sparse observational data, this eastward ocean jet was shown to develop during monsoon breaks of boreal spring and fall (Wyrtki 1973). Luyten and Roemmich (1982) confirmed its existence from moored current observations in the western equatorial Indian Ocean. However, availability of continuous time series of current data from the ADCP mooring site kept by the Japan Marine Science and Technology Center (JAMSTEC) in the eastern Indian Ocean has recently revealed a more ubiquitous nature of the zonal jet in response to the intraseasonal variations of the wind forcing (Masumoto et al. 2005; Iskandar et al. 2005).

As mentioned earlier, the IOD is strongly locked to seasons; it develops in May, peaks in SeptemberOctober, and fades away in December-January. SBY have examined the role of seasonal monsoon in the evolution of IOD using harmonic and complex EOF (CEOF) analysis methods for surface and subsurface 
variables. The first CEOF mode of subsurface heat content variability is composed of annual and semiannual signals associated with the equatorial Kelvin and Rossby waves. The annual signal is generated off the coast of Somali by the open ocean upwelling/downwelling associated with the annual cycle of the Indian monsoon. The semiannual signal is partly generated by the seasonal asymmetry in the annual cycle of the Indian monsoon off Somalia and partly generated by equatorial zonal winds during the monsoon breaks. The interannual variability of this CEOF mode influences the IOD evolution; the variance of the first mode is reduced when IOD events occur (SBY). This suggests an interesting link between the IOD and the Indian monsoon through equatorial oceanic processes. The annual signal of the second subsurface mode captures the subsurface IOD events. The semiannual component of the second mode weakens during the IOD events and thus provides a favorable precondition for the IOD evolution.

The intraseasonal atmospheric variability in the Indian Ocean shows pronounced seasonality with the strongest activity along the equator in boreal winter and spring (Madden and Julian 1994; Gualdi and Navarra 1998). The role of such intraseasonal oscillations (ISOs) in triggering and terminating El Niño events has been discussed widely (Luther et al. 1983; Kessler et al. 1995; Takayabu et al. 1999, etc.). Many studies linked the ISO activity in the tropical Indian Ocean to the active and break monsoon conditions over the Indian subcontinent (e.g., Madden and Julian 1994; Sikka and Gadgil 1980; Sperber et al. 2000; Sengupta and Ravichandran 2001; Sengupta et al. 2001; Vecchi and Harrison 2002). Since the ISO originates in the tropical Indian Ocean, the role of ISO in the IOD evolution needs to be discussed more. In a recent article, Rao and Yamagata (2004) have examined the possible link between the ISO activity and the IOD termination using multiple datasets. They observed strong 30-60-day oscillations of equatorial zonal winds prior to the termination of all IOD events, except for the events of 1982 and 1997 (Fig. 18). This may be a reason for the 1997 IOD event to last until early February 1998 instead of a usual termination around December. Typically strong westerlies associated with the ISO excite anomalous downwelling Kelvin waves that terminate the coupled processes in the eastern Indian Ocean by deepening the thermocline in the east as discussed by Fischer et al. (2005) for the 1994 IOD event. Gualdi et al. (2003) suggested that the anomalously high ISO activity in the northern summer of 1974 (Lorenc 1984) might explain the aborted IOD event in the same year. The interac- tion between intraseasonal activity and development of IOD events was also simulated by their SINTEX CGCM.

The well-known Yoshida-Wyrtki jet originally discovered by climatological analysis of ship drift data may be also viewed as an oceanic response to ISO locked to monsoon break seasons. As already mentioned, Masumoto et al. (2005) demonstrated a more ubiquitous nature of the oceanic ISO activity; the Kelvin waves in the equatorial Indian Ocean have strong variances in their intraseasonal periodicity. In normal years, the ISO is more active in the central and eastern Indian Ocean. This may explain the difference between Luyten and Roemmich's (1982) observations in the western equatorial Indian Ocean and that of Masumoto et al. (2005). Han (2005) observed dominant spectral peaks at 90 days and 30-60 days in the sea level anomalies. From data and stand-alone ocean model simulations, she demonstrated that the 90-day variability in the equatorial Indian Ocean results from the propagating Kelvin and Rossby waves forced by winds. Since the amplitude of winds in the particular band is weaker compared to that of the 30-60-day winds, she suggests that the selective 90-day oceanic mode is due to the resonant response of the second baroclinic mode to the weaker 90-day winds. In the southern Indian Ocean thermocline dome, recent satellite observations detected pronounced intraseasonal SST variability in boreal winter-in fact the strongest of the entire Indo-Pacific warm pool (Saji et al. 2004, manuscript submitted to J. Climate). These intraseasonal SST anomalies are shown to be associated with large anomalies of surface wind and precipitation in the ITCZ. These intraseasonal phenomena in the Indian Ocean are important not only in understanding the complicated scale interactions in the basin but also in designing an effective observational network for predicting IOD events (cf. Masumoto et al. 2005).

\section{e. Summary}

The Indian Ocean climate study has become very active since the discovery of IOD [IOZ mode (IOZM)] during the initial phase of CLIVAR. Some major findings are summarized as follows:

1) The IOD that is locked to boreal summer and fall seasons is shown to be an intrinsic ocean-atmosphere coupled mode; associated with anomalies of surface winds and SST, subsurface ocean dynamics plays an important role in the evolution of IOD. Most of existing CGCMs are successful in reproducing most features of the IOD.

2) The IOD is seen to be significantly correlated to the 

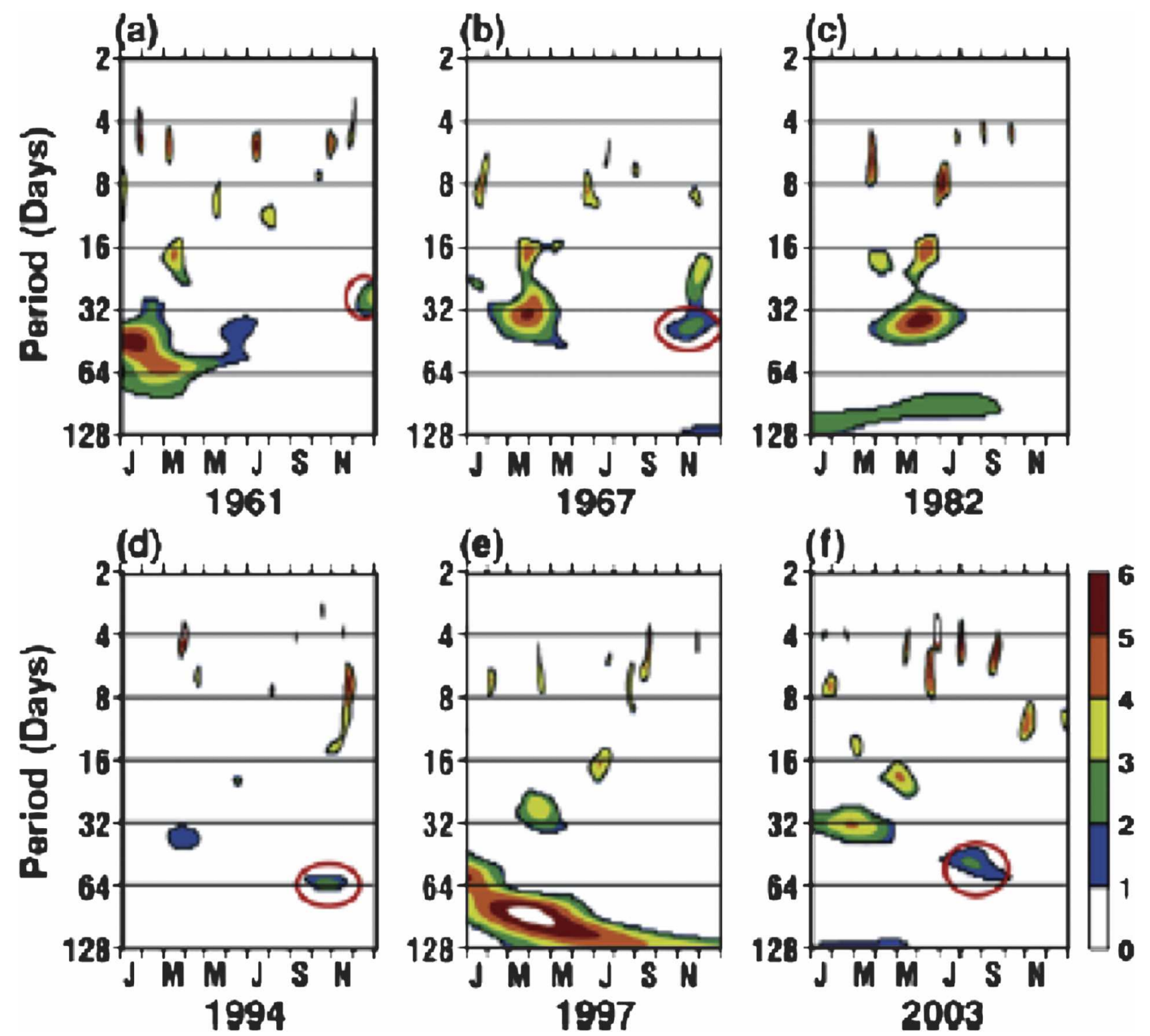

FIG. 18. Wavelet spectrum of zonal wind anomalies showing the ISO activity for six strongest IOD years.

(From Rao and Yamagata 2004.)

Pacific ENSO. However, this correlation coefficient confirms $30 \%$ of co-occurrences of those two phenomena rather than one's dependence on the other. Nevertheless, those co-occurrences are expected to affect the predictability of those two climate modes and their teleconnections.

3) The scale interaction between the IOD and oceanatmosphere variabilities of seasonal-to-intraseasonal scales in the Indian Ocean is seen to affect the IOD evolution. For example, the intraseasonal disturbances cause unusual abortion of some of the IOD events.

These findings at the dawn of IOD research are quite encouraging, though there still remain several unresolved issues as follows.

1) It is yet unclear what triggers the initial wind and SST anomalies of IOD and how much of those are intrinsic to the Indian Ocean. The interaction be- tween ENSO and IOD during the co-occurring years and its possible effect on the predictability of those two climate modes and their teleconnections are not clearly understood. Perhaps their interaction also affects the subsurface variability in both basins that in turn influences low-frequency variabilities on decadal to longer time scales. This needs to be investigated using available instrument/proxy data and CGCM results.

2) The interaction between intraseasonal disturbances and IOD is to be understood further. It is unclear how IOD could modulate the ISD activity by changing oceanic and atmospheric processes on diurnal to seasonal scales.

3) The heat balance in the tropical Indian Ocean is important for the decadal modulation of the IOD. Further research is necessary to clarify roles of the Indonesian throughflow and the tropical-subtropical interaction in the decadal variability of IOD. 


\section{Future challenges}

As the scope and dimension of CLIVAR research have expanded considerably beyond focusing merely on the study of ENSO, our appreciation of the basic role of the tropical ocean in climate has grown from adiabatic wave adjustment of the equatorial thermocline to a broad spectrum of ocean processes, including mixed layer dynamics, to tropical-extratropical exchange, and to interaction between tropical ocean circulation and MOC. In this review, we have touched upon some new ideas on how different oceanic processes can be at work for different climatic phenomena that take place at various time scales in each of the tropical basins. For example, at seasonal-to-interannual time scales, the Atlantic meridional mode involves primarily ocean mixed layer dynamics. At the same time scale, the Pacific ENSO, the Atlantic zonal mode and the Indian Ocean dipole all involve, perhaps at some different level, wave adjustment of the tropical thermocline. At decadal or longer time scales, the coupled variability in the Pacific may involve tropical-extratropical exchange, whereas in the tropical Atlantic interaction between tropical ocean circulation and MOC may also come into play. Although many of these ideas are in early stages of development and further examination and refinement are required, it remains indisputable that ocean-atmosphere interaction is most intense and active over the tropical oceans. The important question concerning the role of the tropical oceans in climate is how the information (heat, momentum, and water) absorbed by the ocean from the atmosphere can be sequestered below the surface, carried around the ocean while mixing with the surrounding water masses, and eventually brought back to the atmosphere as tropical SSTs at a later time and possibly at a different location. The processes involved are enormously complex, and our current understanding is inadequate to quantify much of the detailed physics, particularly at decadal or longer time scales. The crucial role of mixing parameterizations remains a key barrier to producing credible model representations, especially at these long time scales. An improved understanding of these processes is vital to our understanding of the predictability of climate fluctuations in the tropical coupled system, as the long-term memory of these climate fluctuations resides in the oceans.

In the Pacific, the advancement of our understanding of ENSO has laid a theoretical basis for its predictability where oceanic memory associated with adiabatic wave adjustment of the equatorial thermocline plays a fundamental role. The central remaining issue is our inability to come to grips with the issue of a predict- ability limit for ENSO. Is the inability of present generation models to adequately forecast beyond a few seasons due to an inherent limit of predictability or merely the shortcomings of our models and observing system? The tantalizing results of Chen et al. (2004) of predictability of up to $2 \mathrm{yr}$ indicate that more work may well pay off in improved predictions. At present, we have a number of competing theories for what determines the predictability, a number of coupled GCMs that have serious internal deficiencies, and an observing system and assimilation methodology that is still under development. The early hope that ENSO prediction was a "solved" problem has not been fulfilled, but neither has it been demonstrated to be intractable.

Related to the question of ENSO predictability is the issue of decadal variation in the tropical ocean. Are there low-frequency modes of variability arising from extratropical sources that do not interact with a separate ENSO mode, or is the interaction direct and strong? The work of Yeh and Kirtman (2004) indicates that a coupled GCM favors the first interpretation. But an examination of their results reveals that over short (50 yr) periods there may appear a very high correlation between ENSO variability and the (independent) low-frequency mode. This implies that existing observational records may be woefully insufficient to resolve the issue.

The general concept of the STCs and the observational record of their large-scale structure seem consistent, and monitoring of their variation has been demonstrated (McPhaden and Zhang 2002). What remains, however, is the examination of the western boundary currents and their variation. If the changes in meridional transport within the ocean interior are counteracted by variations in the western boundary current transport, the net effect on the tropical warm water balance may be unaffected. Observations and model studies indicate that the low-latitude western boundary currents vary (Qu and Lukas 2003; Kim et al. 2004), including a change in the latitude of bifurcation, which may indicate changes in the distribution of water between that flowing to the equator versus that recirculating within the subtropical gyres. As mentioned above, a theoretical treatment of the baroclinic structure of the western boundary current is lacking.

An interesting study using the adjoint modeling technique probed the question of what perturbations in the subtropical thermocline were most effective at changing the equatorial thermal structure (Galanti and Tziperman 2003). They found that baroclinic instability near the subtropical gyre boundary appeared as the leading effect, indicating that the role of eddies in mixing potential vorticity may have a significant impact on 
the simulation of the equatorial cold tongue by altering the PV pathways. A consideration here is whether the level of baroclinic activity is a climate-scale variabledoes it change on decadal time scales-or is it a stationary process that simply adds complexity to the ventilated thermocline theory?

Aside from the lack of adequate data, our ability to tackle the difficult issue concerning the relationship between Pacific interdecadal variability and ENSO has been hampered by large biases in coupled climate models. It has been a long-standing problem that the simulated equatorial cold tongue in the Pacific is excessively cold and extends too far west along the equator but is not wide enough in the meridional direction, while the Atlantic cold tongue is not well developed in coupled simulations (e.g., Davey et al. 2002). Maintaining a realistic thermocline structure along the equator in coupled climate models has also been a challenge. This has greatly undermined our ability to identify and examine real physical processes responsible for changes at decadal or longer time scales, as these changes are relatively small and the processes are closely linked to those that determine the mean state of the coupled system. While atmospheric forcing and ocean-atmosphere coupling issues certainly contribute to model deficiencies, much of the uncertainty can be laid to ocean processes. The Pacific Upwelling and Mixing Physics (PUMP; Kessler et al. 2004) program aims to address this cold tongue bias issue in the tropical Pacific. It focuses on the interaction of mixing and upwelling in the strongly sheared environment of the equatorial undercurrent, particularly in the region in the east, where the thermocline surfaces. Field measurements of microstructure, turbulent dissipation, and estimates of the larger-scale context for the mixing processes will be combined with a hierarchy of process and climate-scale models to provide the necessary observational guidance for developing model parameterizations of mixing in this critical region. PUMP combined with the enhanced backbone ocean observational network, such as the TAO/Triangle TransOcean Buoy Network (TRITON), Argo Profiling Floats, and satellite observations, will allow us to further validate the importance of STCs and related oceanic processes in ENSO and Pacific interdecadal climate variability.

The research during the early years of CLIVAR has made it more evident that predicting ENSO-related SST variability in the tropical Pacific alone is not sufficient to make an accurate seasonal climate forecast over the entire Tropics, even though ENSO is recognized as the most prominent climate fluctuation at seasonal-to-interannual time scales and does contribute significantly to climate variability outside the tropical
Pacific sector. Local SST anomalies in other tropical basins play an indispensable role in determining climate variability and predictability in these regions. Yet unlike ENSO where the oceanic memory mechanism associated with the delayed oscillator has been identified to be critical in determining its predictability, we have not identified a clear set of mechanisms through which the ocean dynamics contribute to the predictability of the climate fluctuations in these regions. Studies thus far suggest that the coupled air-sea feedbacks outside the tropical Pacific are generally much weaker than those associated with ENSO, and can take a variety of forms. The predictable dynamics in weakly coupled systems are generally more complex than those in strongly coupled systems that support self-sustained oscillations, and can be affected by many factors (Chang et al. 2004).

In the tropical Atlantic, the oceanic processes that influence TAV predictability are likely to be seasonally dependent. Two oceanic processes that hold special importance in the seasonal variation of the warm water formation and escape process in the upper tropical Atlantic may deserve particular attention: the first is the heat capacitor mechanism (Philander and Pacanowski 1986) that regulates the meridional heat/mass transport due to the seasonal change in the North Brazil Current (NBC)/NECC system in response to the annual migration of the ITCZ and the second is the entrainment process that regulates the SST seasonal cycle in the eastern equatorial Atlantic. Simple modeling studies (e.g., Lee and Csanady 1999) suggest that both processes contribute to the mixed layer heat budget but operate in different ways and different seasons. The former alters adiabatically the mixed layer heat storage rate through changing the depth of the mixed layer. This process is most effective during the boreal winter/ spring when the entrainment halts, the NECC is weakened, and the NBC flows continuously northwestward along the South American coastline. Consequently, the warm water that accumulated during the previous seasons escapes to the north from the Tropics and the mixed layer depth decreases. Conceivably, this process is highly relevant to the development of the tropical Atlantic (TA) meridional mode, as this mode develops during these seasons and its evolution involves interaction with the ocean mixed layer. Yet, little is known about how the heat capacitor mechanism operates at interannual or longer time scales. At issue are how effective changes in the meridional heat/mass transport induced by ITCZ fluctuations at interannual or longer time scales can affect the mixed layer heat budget in the western tropical Atlantic, whether these changes are strong enough to interact with the local thermodynamic air-sea feedback in the region, and more importantly 
whether the heat capacitor mechanism can provide an oceanic memory that contributes to the predictability of this phenomenon.

The entrainment cooling that takes place during boreal summer contributes diabatically to the seasonal mixed layer heat budget by transporting thermocline water into the mixed layer, causing the rapid development of the cold SST. At the same time, the mixed layer deepens as the gateway for transporting the water northward is blocked by the NBC retroflection and the NECC during these seasons. This process is highly relevant to the onset and decay of the TA zonal mode that develops during the same season. However, progress in our understanding of this process in this mode is hampered by the lack of sufficient observations and the difficulty that ocean models encounter in simulating realistic variability in the equatorial Atlantic. The OGCM simulation conducted by Carton et al. (1996) yielded a correlation value of only 0.3 between the observed and simulated SST anomalies in the eastern equatorial Atlantic. Even some of the advanced ocean data assimilation (ODA) systems have difficulties in reproducing the ocean state in the tropical Atlantic basin. For example, the European Centre for Medium-Range Weather Forecasts (ECMWF) ODA systems show considerable systematic bias in estimating the upper-ocean state in the equatorial Atlantic region, even though the same system works very well in the tropical Pacific (T. Stockdale 2002, personal communication). Apart from the obvious reason that the upper-ocean variability in the Atlantic is much weaker than that in the Pacific, deficiencies in model physics are most likely to be blamed for poor model performance. One potential problem may be related to models' inability to handle correctly vertical mixing in the equatorial region. During the boreal summer, the thermocline becomes very shallow in the equatorial eastern Atlantic, while the mixed layer deepens. Therefore, the thermocline water is nearly depleted. This poses a challenge for numerical models, particularly those with low vertical resolution.

At interdecadal or longer time scales, the Atlantic Ocean plays a uniquely important role because of the potential interaction between the STCs and MOC. The intriguing modeling results (e.g., Vellinga and Wood 2002; Dong and Sutton 2002) that show a change in MOC strength can lead to a TAV response raises the possibility that the Atlantic coupled system may be of particular importance to anthropogenic influences. The potentially relevant oceanic mechanisms include the influence of the MOC return flow on the Atlantic STC structure (e.g., Fratantoni et al. 2000; Jochum and Malanotte-Rizzoli 2001) and the "equatorial buffer" mechanism (Johnson and Marshall 2002; Yang 1999).
The challenge that lies ahead is how to quantify these mechanisms. Clearly, the existing observations are hopelessly inadequate to give a full account of these mechanisms, and a much-improved observational base is badly needed. The questions are as follows: What types of observations are necessary and what is the optimal design for tropical Atlantic observing system to effectively understand and monitor the important oceanic changes? Further modeling studies can shed light on these issues.

At the beginning of CLIVAR, a Pilot Research Moored Array in the Tropical Atlantic (PIRATA) was implemented with the goal of gaining understanding of ocean-atmosphere interactions in the tropical Atlantic that are relevant to regional climate variability at seasonal-to-interannual time scales. The observation data from PIRATA have proven to be extremely valuable in documenting and understanding local air-sea feedbacks in the region, despite its limited spatial coverage and time span. Discussions are currently underway on how to expand PIRATA and evolve it into a more comprehensive and focused ocean observing system that is better suited to study TAV and its predictability at various time scales. Worth mentioning is the "Tropical Atlantic Climate Experiment" (TACE), which is being planned. TACE is envisioned as a program of enhanced observations and process studies with an emphasis on the eastern tropical Atlantic. The 5-yr (200610) program will consist of an expanded PIRATA array as the backbone observational system, and enhanced Argo float and surface drifter coverage in the eastern tropical Atlantic region. Its aim is to quantify the importance of oceanic advection, upwelling, and vertical mixing in the predictability of SST associated with the TA zonal mode in this region. The improved observations will also put us in a better position to refine our current understanding of the role of the STCs and MOC in TAV. Figure 19 shows a schematic of TACE Observational Strategy. The details on scientific issues addressed by TACE can be found in a "white paper" by Schott et al. (2004).

Recent progress in our understanding of the oceanatmosphere coupled variability in the Indian Ocean, together with the evolution of high-resolution CGCMs, has opened a door to a new stage of predicting IOD events and Indo-Pacific SST paterns. This rapid movement in modeling needs to be supported by ocean observing technologies. The collective effort will contribute to societal needs of the most heavily populated region of the world.

Up to the present time, we have attempted to understand ENSO. Future research will require understanding the Indo-Pacific climate system as a whole, made up 


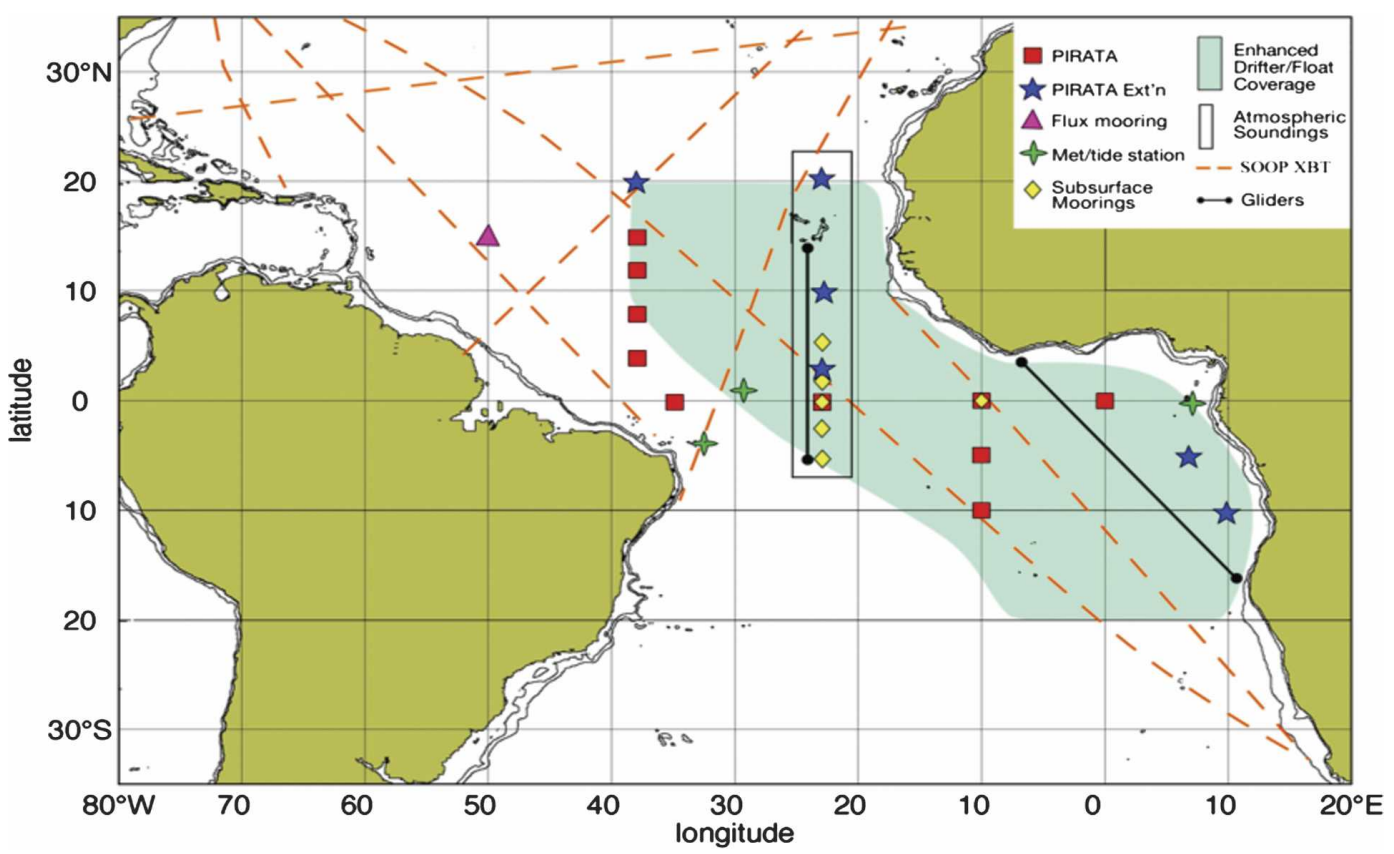

FIG. 19. TACE Observational Strategy. The proposed observing system components include (see legend) the following: continuation of PIRATA moorings, PIRATA extensions along $23^{\circ} \mathrm{W}$ and $5^{\circ}-10^{\circ} \mathrm{E}$, equatorial subsurface (non-real time) moorings along $23^{\circ} \mathrm{E}$ and at $10^{\circ} \mathrm{W}$, island meteorological and tide gauge stations, enhanced float/drifter coverage in the eastern TA, repeated atmospheric soundings along $23^{\circ} \mathrm{W}$, ship-of-opportunity XBT lines, and selected glider transects.

of interacting subsystems that include ENSO, IOD, the Indian monsoon, the East Asian monsoon, land-ocean interactions, and possibly other elements, all of which interact probably in a nonlinear way, across a range of time scales from intraseasonal to decadal. Our future understanding of this complex system will require an adequate observing system that captures the essential physics of those elements and resolves all the relevant time scales.

Compared to two other tropical oceans, the Indian Ocean has not been observed intensively. Since it is now clear that the Indian Ocean gives birth to an ocean-atmsophere coupled mode of its own, this situation must be improved. As we have seen in the previous sections, Pacific ENSO plays a dominant role in determining a basinwide pattern of SST in the Indian Ocean through changes of surface fluxes and thus influences seasonal climate conditions in countries surrounding the Indian Ocean. However, climatic conditions of countries surrounding the Indian Ocean appear to be equally or more influenced by a regional SST structure, particularly related to IOD. This has provided policy makers as well as scientists with strong motives of introducing a systematic ocean observing system for climate prediction.

A strategy for establishing an integrated observing system in the Indian Ocean that makes use of all the available types of instrumentation is illustrated in Fig. 20. The general attributes of this sytem have been well established within the Global Ocean Observing System (GOOS) community. The observational effort has to be long term and sustained. The data streams will include complementary satellite and in situ observations. The need for resources makes multinational support essential. There is a priority for real-time data to support seasonal climate prediction. And finally, to realize the potential for delivering societal benefits, free and open access to data and enhanced products need to be guaranteed.

The in situ observing system envisioned in Fig. 20 shows a proposed equatorial buoy network (e.g., TRITON/TAO) as the backbone for observing the fast, upper-ocean variability. The network also includes well-sampled XBT lines (focused on specifc features of oceanic structure), ARGO floats, surface drifters, and tide gauges. Special arrays are proposed for boundary regions. The sustained observations will provide a background for climate monitoring and process studies in key regions such as the upwelling region off Java, climate crossroads west of Australia, and the Sri Lanka dome, Arabian dome, and the southern upwelling dome to better understand how these processes play a 


\section{Indian Ocean Integrated Observing System}

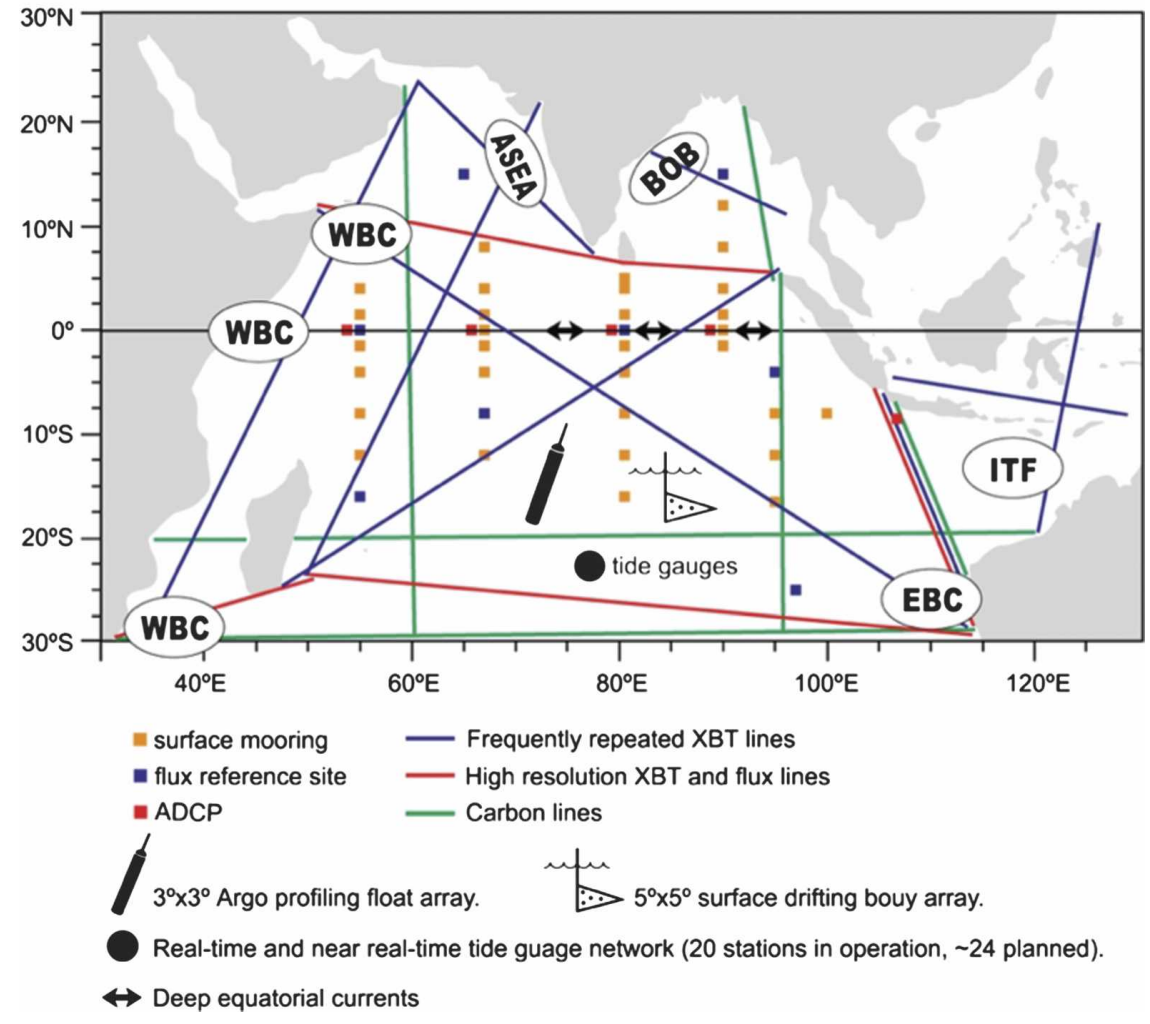

FIG. 20. The evolving design of a sustained observing system for the Indian Ocean. The systems includes $3 \times 3$ Argo profiling float array, $5 \times 5$ surface drifting bouy arrays, and a real-time tide guage network.

role in the climate system and to validate how they are represented in climate models.

In the southern subtropical Indian Ocean, another dipole mode is also identified in SST anomalies (Behera and Yamagata 2001; Reason 2001; Fauchereau et al. 2003; Terray et al. 2003; Suzuki et al. 2004; Hermes and Reason 2005). To develop a field program to understand the possible link between the IOD and subtropical climate signals such as the Indian Ocean subtropical dipole is also important. Although the atmospheric surface fluxes related to modulation of the midlatitude high play a dominant role in determining the SST signals, the southern Indian Ocean appears to contribute to the anomalous condition in Tropics.

In summary, we are now at break of dawn of integrated research covering the complete Indo-Pacific climate system (Meyers et al. 2001), and of new management systems that will help society adapt to the impacts of climate driven by tropical oceans.

Acknowledgments. This review benefitted from useful discussions with many of our colleagues. In particular, we are grateful to Benjamin Kirtman and Syukuro
Manabe for their insightful discussions and comments that helped improve the manuscript considerably. We also thank an anonymous reviewer for his/her constructive comments and suggestions. This work is supported by NOAA and NSF through Research Grants NA16GP2020, NA16GP1572, and ATM-0337846.

\section{REFERENCES}

Abram, N. J., M. K. Gagan, M. T. McCulloch, J. Chappell, and W. S. Hantoro, 2003: Coral reef death during the 1997 Indian Ocean Dipole linked to Indonesian wildfires. Science, 301, 952-955.

Aceituno, P., 1988: On the functioning of the Southern Oscillation in the South American sector. Part I: Surface climate. Mon. Wea. Rev., 116, 505-524.

Alexander, M., and J. Scott, 2002: The influence of ENSO on air-sea interaction in the Atlantic. Geophys. Res. Lett., 29, 1701, doi:10.1029/2001GL014347.

Allan, R., and Coauthors, 2001: Is there an Indian Ocean dipole, and is it independent of the El Niño-Southern Oscillation? CLIVAR Exchanges, Vol. 6, International CLIVAR Project Office, Southampton, United Kingdom, 18-22.

An, S.-I., and F.-F. Jin, 2000: An eigen analysis of the interdecadal changes in the structure and frequency of ENSO mode. Geophys. Res. Lett., 27, 2573-2576. 
, and — 2004: Nonlinearity and asymmetry of ENSO. $J$. Climate, 17, 2399-2412.

Anderson, D. L. T., and A. E. Gill, 1975: Spin-up of a stratified ocean, with applications to upwelling. Deep-Sea Res., 22, 583596.

Annamalai, H., R. Murtugudde, J. Potemra, S. P. Xie, P. Liu, and B. Wang, 2003: Coupled dynamics over the Indian Ocean: Spring initiation of the zonal mode. Deep-Sea Res., 50B, 2305-2330.

—, P. Liu, and S.-P. Xie, 2005a: Southwest Indian Ocean SST variability: Its local effect and remote influence on Asian monsoons. J. Climate, 18, 4150-4167.

— , S. P. Xie, J. P. McCreary, and R. Murtugudde, 2005b: Impact of Indian Ocean sea surface temperature on developing El Niño. J. Climate, 18, 302-319.

Ashok, K., Z. Guan, and T. Yamagata, 2001: Impact of the Indian Ocean Dipole on the decadal relationship between the Indian monsoon rainfall and ENSO. Geophys. Res. Lett., 28, 44994502 .

- — - and - 2003a: A look at the relationship between the ENSO and the Indian Ocean Dipole. J. Meteor. Soc. Japan, 81, 41-56.

,-- _ and $\_$, 2003b: Influence of the Indian Ocean Dipole on the Australian winter rainfall. Geophys. Res. Lett., 30, 1821, doi:10.1029/2003GL017926.

_- W. Chan, T. Motoi, and T. Yamagata, 2004: Decadal variability of the Indian Ocean Dipole. Geophys. Res. Lett., 31, L24207, doi:10.1029/2004GL021345 .

Balmaseda, M. A., D. L. T. Anderson, and M. K. Davey, 1994: ENSO prediction using a dynamical ocean model coupled to statistical atmospheres. Tellus, 46A, 497-511.

Baquero-Bernal, A., M. Latif, and S. Legutke, 2002: On dipolelike variability in the tropical Indian Ocean. J. Climate, 15, 13581368.

Barreiro, M., P. Chang, L. Ji, R. Saravanan, and A. Giannini, 2005: Dynamical elements of predicting boreal spring tropical Atlantic sea-surface temperatures. Dyn. Atmos. Oceans, 31, 61-85.

Battisti, D. S., 1988: Dynamics and thermodynamics of a warming event in a coupled tropical atmosphere-ocean model. J. Atmos. Sci., 45, 2889-2919.

—_, and A. C. Hirst, 1989: Interannual variability in the tropical atmosphere-ocean model: Influence of the basic state, ocean geometry and nonlinearity. J. Atmos. Sci., 46, 1687-1712.

Behera, S. K., and T. Yamagata, 2003: Influence of the Indian Ocean Dipole on the Southern Oscillation. J. Meteor. Soc. Japan, 81, 169-177.

-, R. Krishnan, and T. Yamagata, 1999: Unusual oceanatmosphere conditions in the tropical Indian Ocean during 1994. Geophys. Res. Lett., 26, 3001-3004.

_ - J.-J. Luo, S. Masson, T. Yamagata, P. Delecluse, S. Gualdi, and A. Navarra, 2003a: Impact of the Indian Ocean Dipole on the East African short rains: A CGCM study. CLIVAR Exchanges, Vol. 27, International CLIVAR Project Office, Southampton, United Kingdom, 43-45.

— S. A. Rao, H. N. Saji, and T. Yamagata, 2003b: Comments on "A cautionary note on the interpretation of EOFs." $J$. Climate, 16, 1087-1093.

— , J.-J. Luo, S. Masson, P. Delecluse, S. Gualdi, A. Navarra, and T. Yamagata, 2005: Paramount impact of the Indian Ocean Dipole on the East African short rains: A CGCM Study. J. Climate, 18, 4514-4530.

,$--\longrightarrow$, A. S. Rao, H. Sakuma, and T. Yamagata, 2006:
A CGCM Study on the interaction between IOD and ENSO. J. Climate, 19, 1688-1705.

Behringer, D. W., M. Ji, and A. Leetmaa, 1998: An improved coupled model for ENSO prediction and implication for ocean initialization. Part I: The ocean data assimilation system. Mon. Wea. Rev., 126, 1013-1021.

Bjerknes, J., 1969: Atmospheric teleconnections from the equatorial Pacific. Mon. Wea. Rev., 97, 163-172.

Black, D. E., L. C. Peterson, J. T. Overpeck, A. Kaplan, M. N. Evans, and M. Kashgarian, 1999: Eight centuries of North Atlantic Ocean atmosphere variability. Science, 286, 17091713.

Black, E., J. Slingo, and K. R. Sperber, 2003: An observational study of the relationship between excessively strong short rains in coastal East Africa and Indian Ocean SST. Mon. Wea. Rev., 131, 74-94.

Blanke, B., S. Speich, G. Madec, and K. Doos, 2001: A global diagnostic of interocean mass transfers. J. Phys. Oceanogr., 31, 1623-1632.

Boccaletti, G., R. C. Pacanowski, S. G. H. Philander, and A. Fedorov, 2004: The thermal structure of the upper ocean. $J$. Phys. Oceanogr., 34, 888-902.

Bourlès, B., Y. Gouriou, and R. Chuchla, 1999a: On the circulation in the upper layer in the western equatorial Atlantic. $J$. Geophys. Res., 104 (C9), 21 151-21 170.

_, R. L. Molinari, E. Johns, W. D. Wilson, and K. D. Leaman, 1999b: Upper layer currents in the western tropical Atlantic (1989-1991). J. Geophys. Res., 104 (C1), 1361-1375.

Boyer, D. C., H. J. Boyer, I. Fossen, and A. Kreiner, 2001: Changes in abundance of the northern Benguela sardine stock during the decade 1990-2000, with comments on the relative importance of fishing and the environment. S. Afr. J. Mar. Sci., 23, 76-84.

Bratcher, A. J., and B. S. Giese, 2002: Tropical Pacific decadal variability and global warming. Geophys. Res. Lett., 29, 1918, doi:10.1029/2002GL015191.

Bryden, H., and E. C. Brady, 1989: Eddy momentum and heat fluxes and their effects on the circulation of the equatorial Pacific Ocean. J. Mar. Res., 47, 55-79.

Burgers, G., and D. B. Stephenson, 1999: The "normality" of El Niño. Geophys. Res. Lett., 26, 1027-1030.

Cadet, D. L., 1985: The Southern Oscillation over the Indian Ocean. J. Climatol., 5, 189-212.

Cai, W., H. Hendon, and G. Meyers, 2005: Indian Ocean dipolelike variability in the CSIRO Mark 3 coupled climate model. J. Climate, 18, 1449-1468.

Cane, M. A., 1989: A mathematical note on Kawase's study of the deep-ocean circulation. J. Phys. Oceanogr., 19, 548-550.

Carton, J. A., and B. Huang, 1994: Warm events in the tropical Atlantic. J. Phys. Oceanogr., 24, 888-903.

- and Z. X. Zhou, 1997: Annual cycle of sea surface temperature in the tropical Atlantic Ocean. J. Geophys. Res., 102, $27813-27824$

—, X. Cao, B. S. Giese, and A. M. da Silva, 1996: Decadal and interannual SST variability in the tropical Atlantic Ocean. $J$. Phys. Oceanogr., 26, 1165-1175.

_ G. Chepurin, X. Cao, and B. Giese, 2000: A simple ocean data assimilation analysis of the global upper ocean 1950-95. Part I: Methodology. J. Phys. Oceanogr., 30, 294-309.

Chambers, D. P., B. D. Tapley, and R. H. Stewart, 1999: Anomalous warming in the Indian Ocean coincident with El Niño. $J$. Geophys. Res., 104, 3035-3047.

Chang, P., and G. Philander, 1994: A coupled ocean-atmosphere 
instability of relevance to the seasonal cycle. J. Atmos. Sci., 51, 3627-3648.

—_ B. Wang, T. Li, and L. Ji, 1994: Interaction between seasonal cycle and the Southern Oscillation frequency entrainment and chaos in a coupled ocean-atmospheric model. Geophys. Res. Lett., 21, 2817-2820.

— L. L. Ji, and H. Li, 1997: A decadal climate variation in the tropical Atlantic Ocean from thermodynamic air-sea interactions. Nature, 385, 516-518.

_ , R. Saravanan, L. Ji, and G. C. Hegerl, 2000: The effects of local sea surface temperatures on atmospheric circulation over the tropical Atlantic sector. J. Climate, 13, 2195-2216.

— B. B. Giese, L. Ji, H. F. Seidel, and F. Wang, 2001a: Decadal change in the south tropical Pacific in a global assimilation analysis. Geophys. Res. Lett., 28, 3461-3464.

—, L. Ji, and R. Saravanan, 2001b: A hybrid coupled model study of tropical Atlantic variability. J. Climate, 14, 361-390.

_- R. Saravanan, and L. Ji, 2003: Tropical Atlantic seasonal predictability: The roles of El Niño remote influence and thermodynamic air-sea feedback. Geophys. Res. Lett., 30, 1501, doi:10.1029/2002GL016119.

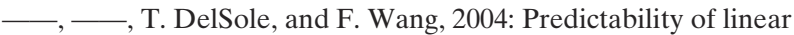
coupled systems. Part I: Theory. J. Climate, 17, 1474-1486.

Chao, Y., M. Ghil, and J. C. McWilliams, 2000: Pacific interdecadal variability in this century's sea surface temperatures. Geophys. Res. Lett., 27, 2261-2264.

Chen, D., S. E. Zebiak, A. J. Busalacchi, and M. A. Cane, 1995: An improved procedure for El Niño forecasting: Implications for predictability. Science, 269, 1699-1702.

_- M. A. Cane, A. Kaplan, S. E. Zebiak, and D. Huang, 2004: Predictability of El Niño for the past 148 years. Nature, 428, 733-735.

Chepurin, G., and J. A. Carton, 1996: Hydrographic data of the Soviet SECTIONS tropical Atlantic Program and the circulation of the upper 1200 meters. J. Mar. Res., 55, 633-670.

Chiang, J. C. H., and A. H. Sobel, 2002: Tropical tropospheric temperature variations caused by ENSO and their influence on the remote tropical climate. J. Climate, 15, 2616-2631.

—_, and D. J. Vimont, 2004: Analogous Pacific and Atlantic meridional modes of the tropical atmosphere-ocean variability. J. Climate, 17, 4143-4158.

—, Y. Kushnir, and A. Giannini, 2002: Deconstructing Atlantic Intertropical Convergence Zone variability: Influence of the local cross-equatorial sea surface temperature gradient and remote forcing from the eastern equatorial Pacific. J. Geophys. Res., 107, 4004, doi:10.1029/2000JD000307.

—, M. Biasutti, and D. S. Battisti, 2003: Sensitivity of the Atlantic Intertropical Convergence Zone to Last Glacial Maximum boundary conditions. Paleoceanography, 18, 1094, doi:10.1029/2003PA000916.

Clark, C. O., P. J. Webster, and J. E. Cole, 2003: Interdecadal variability of the relationship between the Indian Ocean zonal mode and East African coastal rainfall anomalies. $J$. Climate, 16, 548-554.

Clarke, A. J., and X. Liu, 1994: Interannual sea level in the northern and eastern Indian Ocean. J. Phys. Oceanogr., 24, 12241235.

Cobb, K. M., C. D. Charles, H. I. Cheng, and R. L. Edwards, 2003: El Niño/Southern Oscillation and tropical Pacific climate during the last millennium. Nature, 424, 271-276.

Collins, M., 2000: The El Niño-Southern Oscillation in the second Hadley Centre coupled model and its response to greenhouse warming. J. Climate, 13, 1299-1312.
Covey, D. L., and S. Hastenrath, 1978: The Pacific El Niño phenomenon and the Atlantic circulation. Mon. Wea. Rev., 106, $1280-1287$.

Csanady, G. T., 1984: Warm water mass formation. J. Phys. Oceanogr., 14, 264-275.

Czaja, A., P. van der Vaart, and J. Marshall, 2002: A diagnostic study of the role of remote forcing in tropical Atlantic variability. J. Climate, 15, 3280-3290.

Da Silva, M., and P. Chang, 2004: Seasonal variation of the subtropical/tropical pathways in the Atlantic Ocean from an ocean date assimilation experiment. Earth Climate: The Ocean-Atmosphere Interaction, Geophys. Monogr., Vol. 147, Amer. Geophys. Union, 305-318.

Davey, M. K., and Coauthors, 2002: STOIC: A study of coupled model climatology and variability in tropical ocean regions. Climate Dyn., 18, 403-420.

Delecluse, P., J. Servain, C. Levy, K. Arpe, and L. Bengtsson, 1994: On the connection between the 1984 Atlantic warm event and the 1982-1983 ENSO. Tellus, 46, 448-464.

Deser, C., M. A. Alexander, and M. S. Timlin, 1996: Upper-ocean thermal variations in the North Pacific during 1970-1991. J. Climate, 9, 1840-1855.

_ A. S. Phillips, and J. W. Hurrell, 2004: Pacific interdecadal climate variability: Linkages between the Tropics and the North Pacific during boreal winter since 1900. J. Climate, 17, 3109-3124.

Dettinger, M. D., D. R. Cayan, G. M. McCabe, and J. A. Marengo, 2000: Multiscale streamflow variability associated with El Niño-Southern Oscillation. El Niño and the Southern Oscillation-Multiscale Variability and Global and Regional Impacts, H. F. Diaz and V. Markgraf, Eds., Cambridge University Press, 113-146.

Dommenget, D., and M. Latif, 2000: Interannual to decadal variability in the tropical Atlantic. J. Climate, 13, 777-792.

- and -2002 : A cautionary note on the interpretation of EOFs. J. Climate, 15, 216-225.

Dong, B.-W., and R. T. Sutton, 2002: Adjustment of the coupled ocean-atmosphere system to a sudden change in the thermohaline circulation. Geophys. Res. Lett., 29, 1728, doi:10.1029/ 2002GL015229.

Enfield, D. B., and D. A. Mayer, 1997: Tropical Atlantic SST variability and its relation to El Niño-Southern Oscillation. $J$. Geophys. Res., 102, 929-945.

- A. M. Mestas-Nunez, D. A. Mayer, and L. Cid-Serrano, 1999: How ubiquitous is the dipole relationship in tropical Atlantic sea surface temperatures? J. Geophys. Res., 104, 7841-7848.

Enomoto, T., B. J. Hoskins, and Y. Matsuda, 2003: The formation of the Bonin high in August. Quart. J. Roy. Meteor. Soc., 129, 157-178.

Fauchereau, N., S. Trzasaka, Y. Richard, P. Roucou, and P. Camberlin, 2003: Sea-surface temperature co-variability in the southern Atlantic and Indian Oceans and its connections with the atmospheric circulation in the Southern Hemisphere. Int. J. Climatol., 23, 663-677.

Fedorov, A. V., and S. G. H. Philander, 2000: Is El Niño changing? Science, 288, 1997-2000.

_ S. L. Harper, S. G. Philander, B. Winter, and A. Wittenberg, 2003: How predictable is El Niño? Bull. Amer. Meteor. Soc., 84, 911-919.

Feng, M., and G. Meyers, 2003: Interannual variability in the tropical Indian Ocean: A two-year time scale of IOD. DeepSea Res., 50B, 2263-2284. 
$\longrightarrow,-$, and S. Wijffels, 2001: Interannual upper ocean variability in the tropical Indian Ocean. Geophys. Res. Lett., 28, 4151-4154.

Fischer, A. S., P. Terray, E. Guilyardi, and S. Gualdi, 2005: Two independent triggers for the Indian Ocean dipole/zonal mode in a coupled GCM. J. Climate, 18, 3428-3449.

Florenchie, P., J. R. E. Lutjeharms, C. J. C. Reason, S. Masson, and M. Rouault, 2003: The source of Benguela Niños in the South Atlantic Ocean. Geophys. Res. Lett., 30, 1505, doi:10.1029/2003GL017172.

— C. J. C. Reason, J. R. E. Lutjeharms, M. Rouault, C. Roy, and S. Masson, 2004: Evolution of interannual warm and cold events in the southeast Atlantic Ocean. J. Climate, 17, 2318 2334.

Flügel, M., and P. Chang, 1996: Impact of dynamical and stochastic processes on the predictability of ENSO. Geophys. Res. Lett., 23, 2089-2092.

— tion of El Niño-Southern Oscillation. Geophys. Res. Lett., 26, 2473-2476.

- - - , and C. Penland, 2004: The role of stochastic forcing in modulating ENSO predictability. J. Climate, 17, 3125-3140.

Frankignoul, C., E. Kestenare, M. Botzet, A. F. Carril, H. Drange, A. Pardens, L. Terray, and R. Sutton, 2004: An intercomparison between the surface heat flux feedback in five coupled models, COADS, and the NCEP reanalysis. Climate Dyn., 22, 373-388.

Fratantoni, D. M., W. E. Johns, T. L. Townsend, and H. E. Hurlburt, 2000: Low-latitude circulation and mass transport pathways in a model of the tropical Atlantic Ocean. J. Phys. Oceanogr., 30, 1944-1966.

Fujiwara, M., K. Kita, S. Kawakami, T. Ogawa, N. Komala, S. Saraspriya, and A. Suripto, 1999: Tropospheric ozone enhancements during the Indonesian forest fire events in 1994 and 1997 as revealed by ground-based observations. Geophys. Res. Lett., 26, 2417-2420.

Fukumori, I., T. Lee, B. Cheng, and D. Menemnlis, 2004: The origin, pathway, and destination of Niño-3 water estimated by a simulated passive tracer and its adjoint. J. Phys. Oceanogr., 34, 582-604.

Galanti, E., and E. Tziperman, 2003: A midlatitude ENSO teleconnection mechanism via baroclinically unstable long Rossby waves. J. Phys. Oceanogr., 33, 1877-1888.

Gammelsrød, T., C. H. Bartholomae, D. C. Boyer, V. L. L. Filipe, and M. J. O'Toole, 1998: Intrusion of warm surface water along the Angolan-Namibian coast in February-March 1995: The 1995 Benguela Niño, Benguela Dynamics. S. Afr. J. Mar. Sci., 19, 51-56.

Ganachaud, A., and C. Wunsch, 2001: Improved estimates of global ocean circulation, heat transport and mixing from hydrographic data. Nature, 408, 453-457.

Giannini, A., Y. Kushnir, and M. A. Cane, 2000: Interannual variability of Caribbean rainfall, ENSO, and the Atlantic Ocean. J. Climate, 13, 297-311.

_- R. Saravanan, and P. Chang, 2003: Oceanic forcing of Sahel rainfall on interannual to interdecadal time scales. Science, 302, 1027-1030.

$\longrightarrow, \ldots$, and $—$ 2004: The preconditioning role of Tropical Atlantic Variability in the development of the ENSO teleconnection: Implications for the prediction of Nordeste rainfall. Climate Dyn., 22, 839-855.

Giese, B. S., S. C. Urizar, and N. S. Fuckar, 2002: The Southern
Hemisphere origins of the 1976 climate shift. Geophys. Res. Lett., 29, 1014, doi:10.1029/2001GL013268.

Graham, N. E., T. P. Barnett, R. Wilde, M. Ponater, and S. Schubert, 1994: On the roles of tropical and midlatitude SSTs in forcing interannual to interdecadal variability in the winter Northern Hemisphere circulation. J. Climate, 7, 1416-1441.

Gregg, M. C., 1998: Estimation and geography of diapycnal mixing in the stratified ocean. Coastal Est. Stud., 54, 305-338.

Gu, D., and S. G. H. Philander, 1997: Interdecadal climate fluctuations that depend on exchanges between the tropics and extratropics. Science, 275, 805-807.

Gualdi, S., and A. Navarra, 1998: A study of the seasonal variability of the tropical intraseasonal oscillation. Global Atmos. Ocean Syst., 6, 337-372.

_, E. Guilyardi, A. Navarra, S. Masina, and P. Delecluse, 2003: The interannual variability in the tropical Indian Ocean as simulated by a CGCM. Climate Dyn., 20, 567-582.

Guan, Z., and T. Yamagata, 2003: The unusual summer of 1994 in East Asia: IOD teleconnections. Geophys. Res. Lett., 30, 1544, doi:10.1029/2002GL016831.

_, K. Ashok, and T. Yamagata, 2003: Summer-time response of the tropical atmosphere to the Indian Ocean dipole sea surface temperature anomalies. J. Meteor. Soc. Japan, 81, 531-561.

Guilyardi, E., and Coauthors, 2004: Representing El Niño in coupled ocean-atmosphere GCMs: The dominant role of the atmosphere component. J. Climate, 17, 4623-4629.

Han, W., 2005: Origins and dynamics of the 90-day and 30-60-day variations in the equatorial Indian Ocean. J. Phys. Oceanogr., 35, 708-728.

Harper, S., 2000: Thermocline ventilation and pathways of tropical-subtropical water mass exchange. Tellus, 52A, 330-345.

Harrison, D. E., and G. A. Vecchi, 1999: On the termination of El Niño. Geophys. Res. Lett., 26, 1593-1596.

Hashizume, H., S.-P. Xie, W. T. Liu, and K. Takeuchi, 2001: Local and remote atmospheric response to tropical instability waves: A global view from space. J. Geophys. Res., 106, $10173-10185$

Hastenrath, S., 2002: Dipoles, temperature gradient, and tropical climate anomalies. Bull. Amer. Meteor. Soc., 83, 735-738.

, and L. Greischar, 1993: Further work on the prediction of northeast Brazil rainfall anomalies. J. Climate, 6, 743-758.

- - A. Nicklis, and L. Greischar, 1993: Atmospherichydrospheric mechanisms of climate anomalies in the western equatorial Indian Ocean. J. Geophys. Res., 98, 20219 20235 .

Hazeleger, W., M. Visbeck, M. Cane, A. Karspack, and N. Naik, 2001: Decadal upper ocean temperature variability in the tropical Pacific. J. Geophys. Res., 106, 8971-8988.

_, P. de Vries, and Y. Friocourt, 2003: Sources of the Equatorial Undercurrent in the Atlantic in a high-resolution ocean model. J. Phys. Oceanogr., 33, 677-693.

Held, I. M., 2001: The partitioning of the poleward energy transport between the tropical ocean and atmosphere. J. Atmos. Sci., 58, 943-948.

Hendon, H. H., 2003: Indonesian rainfall variability: Impacts of ENSO and local air-sea interaction. J. Climate, 16, 17751790.

Hermes, J. C., and C. J. C. Reason, 2005: Ocean model diagnosis of interannual coevolving SST variability in the south Indian and South Atlantic Oceans. J. Climate, 18, 2864-2882.

Hirst, A. C., 1986: Unstable and damped equatorial modes in 
simple coupled ocean-atmosphere models. J. Atmos. Sci., 43, 606-632.

—_ 1988: Slow instabilities in tropical ocean basin-global atmosphere models. J. Atmos. Sci., 45, 830-852.

_ , and S. Hastenrath, 1983: Atmosphere-ocean mechanisms of climate anomalies in the Angola-tropical Atlantic sector. $J$. Phys. Oceanogr., 13, 1146-1157.

Hisard, P., 1980: Observation de réponses de type "El Niño" dans l'Atlantique tropical oriental, Golfe de Guinée. Oceanol. Acta, 3, 69-78.

— C. Henin, R. Houghton, B. Piton, and P. Rual, 1986: Oceanic conditions in the tropical Atlantic during 1983 and 1984. Nature, 322, 243-245.

Horel, J. D., and J. M. Wallace, 1981: Planetary-scale atmospheric phenomena associated with the Southern Oscillation. Mon. Wea. Rev., 109, 813-829.

Hoskins, B. J., 1996: On the existence and strength of the summer subtropical anticyclones. Bull. Amer. Meteor. Soc., 77, 12871292.

— spherical atmosphere in thermal and orographic forcing. $J$. Atmos. Sci., 38, 1179-1196.

Huang, B., and Z. Liu, 1999: Pacific subtropical-tropical thermocline water exchange in the National Centers for Environmental Prediction ocean model. J. Geophys. Res., 104, $11065-11076$.

— tropical Indian Ocean. J. Geophys. Res., 107, 3199, doi:10.1029/2001JC001278.

_, P. S. Schopf, and Z. Pan, 2002: The ENSO effect on the tropical Atlantic variability: A regionally coupled model study. Geophys. Res. Lett., 29, 2039, doi:10.1029/ 2002GL014872.

Huang, R. X., and J. Pedlosky, 1999: Climate variability inferred from a layered model of the ventilated thermocline. J. Phys. Oceanogr., 29, 779-790.

Hurrell, J., 1995: Decadal trends in the North Atlantic Oscillation: Regional temperature and precipitation. Science, 269, 676679.

Iizuka, S., T. Matsuura, and T. Yamagata, 2000: The Indian Ocean SST dipole simulated in a coupled general circulation model. Geophys. Res. Lett., 27, 3369-3372.

Inui, T., A. Lazar, P. Malanotte-Rizzoli, and A. Busalacchi, 2002: Wind stress effects on subsurface pathways from the subtropical to tropical Atlantic. J. Phys. Oceanogr., 32, 22572276.

Iskandar, I., W. Mardiansyah, Y. Masumoto, and T. Yamagata, 2005: Intraseasonal Kelvin waves along the southern coast of Sumatra and Java. J. Geophys. Res., 110, C04013, doi:10.1029/ 2004JC002508.

Ji, M., A. Leetmaa, and J. Derber, 1995: An ocean analysis system for seasonal to interannual climate studies. Mon. Wea. Rev., 123, 460-481.

Jin, F.-F., 1997: An equatorial ocean recharge paradigm for ENSO. Part I: Conceptual model. J. Atmos. Sci., 54, 811-829. , and J. D. Neelin, 1993a: Modes of interannual tropical ocean-atmosphere interaction-A unified view. Part I: Numerical results. J. Atmos. Sci., 50, 3477-3503.

— atmosphere interaction-A unified view. Part III: Analytical results in fully coupled cases. J. Atmos. Sci., 50, 3523-3540.

— _ - and M. Ghil, 1994: ENSO on the devil's staircase. Science, 264, 70-72.
—, S.-I. An, A. Timmermann, and J. Zhao, 2003: Strong El Niño events and nonlinear dynamical heating. Geophys. Res. Lett., 30, 1120, doi:10.1029/2002GL016356.

Jochum, M., and P. Malanotte-Rizzoli, 2001: Influence of the meridional overturning circulation on tropical-subtropical pathways. J. Phys. Oceanogr., 31, 1313-1323.

$\longrightarrow, \ldots$, and A. Busalacchi, 2004a: Tropical instability waves in the Atlantic ocean. Ocean Modell., 7, 145-163.

- , R. Murtugudde, P. Malanotte-Rizzoli, and A. J. Busalacchi, 2004b: Intrinsic variability in the tropical Atlantic Ocean. Earth Climate: The Ocean-Atmosphere Interaction, Geophys. Monogr., Vol. 147, Amer. Geophys. Union, 181-188.

Johnson, G. C., and M. J. McPhaden, 1999: Interior pycnocline flow from the subtropical to the equatorial Pacific Ocean. $J$. Phys. Oceanogr., 29, 3073-3089.

Johnson, H. L., and D. P. Marshall, 2002: A theory for the surface Atlantic response to thermohaline variability. J. Phys. Oceanogr., 32, 1121-1132.

Joyce, T. M., C. Frankignoul, J. Yang, and H. E. Phillips, 2004: Ocean response and feedback to the SST dipole in the tropical Atlantic. J. Phys. Oceanogr., 34, 2525-2540.

Jury, R. M., and B. Huang, 2004: The Rossby wave as a key mechanism of Indian Ocean climate variability. Deep-Sea Res., 51, 2123-2136.

Kalnay, E., and Coauthors, 1996: The NCEP/NCAR 40-Year Reanalysis Project. Bull. Amer. Meteor. Soc., 77, 437-471.

Katz, E. J., P. Hisard, J. M. Verstraete, and S. Garzoli, 1986: Annual change of sea surface slope along the equator of Atlantic Ocean in 1983 and 1984. Nature, 222, 245-247.

Kawase, M., 1987: Establishment of deep ocean circulation driven by deep-water production. J. Phys. Oceanogr., 17, 2294-2317.

Kessler, W. S., 2002a: Is ENSO a cycle or a series of events? Geophys. Res. Lett., 29, 2125, doi:10.1029/2002GL015924.

_ 2002b: Mean three-dimensional circulation in the northeast tropical Pacific. J. Phys. Oceanogr., 32, 2457-2471.

_ the 1991-93 El Niño. J. Climate, 8, 1757-1774.

, and R. Kleeman, 2000: Rectification of the Madden-Julian oscillation into the ENSO cycle. J. Climate, 13, 3560-3575.

_ M. J. McPhaden, and K. M. Weickmann, 1995: Forcing of intraseasonal Kelvin waves in the equatorial Pacific. J. Geophys. Res., 100, 10 613-10 631.

, J. N. Moum, M. F. Cronin, P. S. Schopf, D. L. Rudnick, and L. Thomson, 2004: Pacific upwelling and mixing physics: Science and implementation plan. U.S. CLIVAR Project Office, 47 pp. [Available online at http://www.pmel.noaa.gov/ $\sim$ kessler/clivar/pump.html.]

Kim, Y. Y., T. Qu, T. Jensen, T. Miyama, H. Mitsudera, H.-W. Kang, and A. Ishida, 2004: Seasonal and interannual variations of the North Equatorial Current bifurcation in a highresolution OGCM. J. Geophys. Res., 109, C03040, doi:10.1029/2003JC002013.

Kirtman, B. P., 1997: Oceanic Rossby wave dynamics and the ENSO period in a coupled model. J. Climate, 10, 1690-1704. , and P. S. Schopf, 1998: Decadal variability in ENSO predictability and prediction. J. Climate, 11, 2804-2822.

—_, and J. Shukla, 2002: Interactive coupled ensemble: A new coupling strategy for CGCMs. Geophys. Res. Lett., 29, 1367, doi:10.1029/2002GL014834.

_ K. Pegion, and S. Kinter, 2005: Internal atmospheric dynamics and tropical Indo-Pacific climate variability. J. Atmos. Sci., 62, 2220-2233.

Kleeman, R., and A. M. Moore, 1997: A theory for the limitations 
of ENSO predictability due to stochastic atmospheric transients. J. Atmos. Sci., 54, 753-767.

— J. J. McCreary Jr., and B. A. Klinger, 1999: A mechanism for generating ENSO decadal variability. Geophys. Res. Lett., 26, 1743-1746.

— , Y. Tang, and A. M. Moore, 2003: The calculation of climatically relevant singular vectors in the presence of weather noise as applied to the ENSO problem. J. Atmos. Sci., 60, $2856-2868$.

Klein, S. A., B. J. Soden, and N. C. Lau, 1999: Remote sea surface temperature variations during ENSO: Evidence for a tropical atmospheric bridge. J. Climate, 12, 917-932.

Klinger, B. A., and J. Marotzke, 2000: Meridional heat transport by the subtropical cell. J. Phys. Oceanogr., 30, 696-705.

— _ J. P. McCreary, and R. Kleeman, 2002: The relationship between oscillating subtropical wind and equatorial temperature. J. Phys. Oceanogr., 32, 1507-1521.

Knutson, T. R., and S. Manabe, 1994: Impact of increased $\mathrm{CO}_{2}$ on simulated ENSO-like phenomena. Geophys. Res. Lett., 21, 2295-2298.

— _ _ - and D. Gu, 1997: Simulated ENSO in a global coupled ocean-atmosphere model: Multidecadal amplitude modulation and $\mathrm{CO}_{2}$ sensitivity. J. Climate, 10, 138-161.

Koberle, C., and S. G. H. Philander, 1994: On the processes that control seasonal variations of sea surface temperatures in the tropical Pacific Ocean. Tellus, 46A, 481-496.

Kushnir, Y., W. A. Robinson, I. Blad, N. M. J. Hall, S. Peng, and R. T. Sutton, 2002: Atmospheric GCM response to extratropical SST anomalies: Synthesis and evaluation. J. Climate, 15, 2233-2256.

—,- , P. Chang, and A. W. Robertson, 2004: The physical basis for predicting Atlantic sector seasonal-to-interannual climate variability. CLIVAR Workshop on Atlantic Predictability, Reading, United Kingdom, University of Reading, 290 pp.

Larkin, N. K., and D. E. Harrison, 2002: ENSO warm (El Niño) and cold (La Niña) event life cycles: Ocean surface anomaly patterns, their symmetries, asymmetries, and implications. $J$. Climate, 15, 1118-1140.

Latif, M., and T. P. Barnett, 1995: Interactions of the tropical oceans. J. Climate, 8, 952-964.

Lau, N.-C., and M. Nath, 2004: Coupled GCM simulation of atmosphere-ocean variability associated with zonally asymmetric SST changes in the tropical Indian Ocean. J. Climate, 17, 245-265.

Lazar, A., T. Inui, P. Malanotte-Rizzoli, A. J. Busalacchi, L. Wang, and R. Murtugudde, 2002: Seasonality of the ventilation of the tropical Atlantic thermocline in an ocean general circulation model. J. Geophys. Res., 107, 3104, doi:10.1029/ 2000JC000667.

Lee, S.-K., and G. T. Csanady, 1999: Warm water formation and escape in the upper tropical Atlantic Ocean, 2. Literature review. J. Geophys. Res., 104, 29 561-29 571.

Lengaigne, M., J.-P. Boulanger, C. Menkes, P. Delecluse, and J. Slingo, 2004: Westerly wind events in the tropical Pacific and their influence on the coupled ocean-atmosphere system. Earth Climate: The Ocean-Atmosphere Interaction, Geophys. Monogr., Vol. 147, Amer. Geophys. Union, 49-69.

Li, B., and A. J. Clarke, 1994: An examination of some ENSO mechanisms using interannual sea level at the eastern and western equatorial boundaries and the zonally averaged equatorial wind. J. Phys. Oceanogr., 24, 681-690.
$\mathrm{Li}, \mathrm{C}$., and M. Mu, 2001: Influence of the Indian Ocean dipole on Asian monsoon circulation. CLIVAR Exchanges, Vol. 6, International CLIVAR Project Office, Southampton, United Kingdom, 11-14.

Li, T., B. Wang, C. P. Chang, and Y. Zhang, 2003: A theory for the Indian Ocean dipole-zonal mode. J. Atmos. Sci., 60, 21192135 .

Lindzen, R. S., and S. Nigam, 1987: On the role of sea surface temperature gradients in forcing low-level winds and convergence in the tropics. J. Atmos. Sci., 44, 2418-2436.

Liu, Z., 1999a: Forced planetary wave response in a thermocline gyre. J. Phys. Oceanogr., 29, 1036-1055.

_ 1999b: Planetary waves in thermocline circulation: NonDoppler-shift mode, advective mode and Green mode. Quart. J. Roy. Meteor. Soc., 125, 1315-1339.

Lorenc, A. C., 1984: The evolution of planetary-scale 200divergent flow during the FGGE year. Quart. J. Roy. Meteor. Soc., 110, 427-441.

Lu, P., J. P. McCreary, and B. A. Klinger, 1998: A numerical investigation of the source waters of the Pacific Equatorial Undercurrent. J. Phys. Oceanogr., 28, 62-84.

Luo, J. J., S. Masson, S. Behera, P. Delecluse, S. Gualdi, A. Navarra, and T. Yamagata, 2003: South Pacific origin of the decadal ENSO-like variations as simulated by a coupled GCM. Geophys. Res. Lett., 30, 2250, doi:10.1029/ 2003 GL018649.

,,--- S. Shingu, and T. Yamagata, 2005a: Seasonal climate predictability in a coupled OAGCM using a different approach for ensemble forecasts. J. Climate, 18, 4474-4497.

,$- \ldots$, E. Roeckner, G. Madec, and T. Yamagata, 2005b: Reducing climatology bias in an ocean-atmosphere CGCM with improved coupling physics. J. Climate, 18, 2344-2360.

Luther, D. S., D. E. Harrison, and R. A. Knox, 1983: Zonal winds in the central equatorial Pacific and El Niño. Science, 222, 327-330.

Luyten, J. R., and D. H. Roemmich, 1982: Equatorial currents at semiannual period in the Indian Ocean. J. Phys. Oceanogr., 12, 406-413.

— J. Pedlosky, and H. Stommel, 1983: The ventilated thermocline. J. Phys. Oceanogr., 13, 292-309.

Lysne, J. A., P. Chang, and B. Giese, 1997: Impact of the extratropical Pacific on decadal variability in the Tropics. Geophys. Res. Lett., 24, 2589-2592.

Madden, R. A., and P. R. Julian, 1994: Observations of the 4050-day oscillation-A review. Mon. Wea. Rev., 122, 813-837.

Malanotte-Rizzoli, P., K. Hedstrom, H. Arango, and D. B. Haidvogel, 2000: Water mass pathways between the subtropical and tropical ocean in a climatological simulation of the North Atlantic Ocean circulation. Dyn. Atmos. Ocean, 32, 331-371.

Mantua, N. J., and D. S. Battisti, 1995: A periodic variability in the Zebiak-Cane coupled ocean-atmosphere model: Air-sea interaction in the western equatorial Pacific. J. Climate, 8, 2897-2927.

- , and S. J. Hare, 2002: The Pacific Decadal Oscillation. $J$. Oceanogr., 58, 35-44.

_ _ _ , Y. Zhang, J. M. Wallace, and R. C. Francis, 1997: A Pacific interdecadal oscillation with impacts on salmon production. Bull. Amer. Meteor. Soc., 78, 1069-1079.

Marshall, J., and Coauthors, 2001: North Atlantic climate variability, phenomena, impacts and mechanisms. Int. J. Climatol., 21, 1863-1898. 
Masson, S., J.-P. Boulanger, C. Menkes, P. Delecluse, and T. Yamagata, 2004: Impact of salinity on the 1997 Indian Ocean dipole event in a numerical experiment. J. Geophys. Res., 109, C02002, doi:10.1029/2003JC001807.

— spring variability of the southeastern Arabian Sea. Geophys. Res. Lett., 32, L07703, doi:10.1029/2004GL021980.

Masumoto, Y., and G. Meyers, 1998: Forced Rossby waves in the southern tropical Indian Ocean. J. Geophys. Res., 103, 27 589-27 602.

— , H. Hase, Y. Kuroda, H. Matsuura, and K. Takeuchi, 2005: Intraseasonal variability in the upper-layer currents observed in the eastern equatorial Indian Ocean. Geophys. Res. Lett., 32, L02607, doi:10.1029/2004GL021896.

McCreary, J. P., Jr., and P. Lu, 1994: On the interaction between the subtropical and the equatorial oceans: The subtropical cell. J. Phys. Oceanogr., 24, 466-497.

—, P. K. Kundu, and R. Molinari, 1993: A numerical investigation of dynamics, thermodynamics and mixed-layer processes in the Indian Ocean. Progress in Oceanography, Vol. 31, Pergamon, 181-244.

McPhaden, M. J., and D. Zhang, 2002: Slowdown of the meridional overturning circulation in the upper Pacific Ocean. $\mathrm{Na}$ ture, 415, 603-608.

— , and - 2004: Pacific Ocean circulation rebounds. Geophys. Res. Lett., 31, L18301, doi:10.1029/2004GL020727.

Meehl, G. A., 1987: The annual cycle and the interannual variability in the tropical Pacific and Indian Ocean regions. Mon. Wea. Rev., 115, 27-50.

— , P. R. Gent, J. M. Arblaster, B. L. Otto-Bliesner, E. C. Brady, and A. Craig, 2001: Factors that affect the amplitude of El Niño in global coupled models. Climate Dyn., 17, 515527.

Mehta, V. M., 1998: Variability of the tropical ocean surface temperatures at decadal multidecadal time scales. Part I: The Atlantic Ocean. J. Climate, 11, 2351-2375.

Meinen, C. S., M. J. McPhaden, and G. C. Johnson, 2001: Vertical velocities and transports in the equatorial Pacific during 1993-99. J. Phys. Oceanogr., 31, 3230-3248.

Melice, J.-L., and J. Servain, 2003: The tropical Atlantic meridional SST gradient index and its relationships with the SOI, NAO and Southern Ocean. Climate Dyn., 20, 447-464.

Mercier, 2003: A comparison of kinematic evidence for tropical cells in the Atlantic and Pacific oceans. Interhemispheric Water Exchange in the Atlantic Ocean, G. Goni and P. Malanotte-Rizzoli, Eds., Elsevier Oceanographic Series, Vol. 68, Elsevier, 269-286.

Merle, J., 1980: Variabilité thermique annuelle et interannuelle de l'océan Atlantique équatorial Est. L'hypothèse d'un "El Niño" Atlantique. Oceanol. Acta, 3, 209-220.

Mestas-Nunez, A. M., and D. B. Enfield, 2001: Eastern equatorial Pacific SST variability: ENSO and non-ENSO components and their climatic associations. J. Climate, 14, 391-402.

Meyers, G., 1996: Variation of Indonesian throughflow and El Niño-Southern Oscillation. J. Geophys. Res., 101, 12 25512263.

, S. Godfrey, A. Gordon, P. Hacker, M. Jury, W. Lau, V. V. Gopalakrishna, T. Sribimawati and T. Yamagata, 2001: Monsoon, seasonal and interannual applications of an Indian Ocean Observing System. Observing the Oceans in the 21st Century, C. J. Koblinsky and N. R. Smith, Eds., GODAE Project Office and Bureau of Meteorology, 48-66.
Minobe, S., 1997: A 50-70 year climatic oscillation over the North Pacific and North America. Geophys. Res. Lett., 24, 683-686.

Mitchell, T. P., and J. M. Wallace, 1992: The annual cycle in equatorial convection and sea surface temperature. J. Climate, $\mathbf{5}$, 1140-1156.

Molinari, R. L., R. A. Fine, W. D. Wilson, R. G. Curry, J. Abell, and M. S. McCartney, 1998: The arrival of recently formed Labrador Sea Water in the Deep Western Boundary Current at $26.5^{\circ}$ N. Geophys. Res. Lett., 25, 2249-2252.

Moore, A. M., and R. Kleeman, 1999a: The nonnormal nature of El Niño and intraseasonal variability. J. Climate, 12, $2965-$ 2982.

_, and — 1999b: Stochastic forcing of ENSO by the intraseasonal oscillation. J. Climate, 12, 1199-1220.

Murtugudde, R. G., J. P. McCreary, and A. J. Busalacchi, 2000: Oceanic processes associated with anomalous events in the Indian Ocean with relevance to 1997-1998. J. Geophys. Res., 105, 3295-3306.

_ J. Ballabrera-Poy, J. Beauchamp, and A. J. Busalacchi, 2001: Relationship between zonal and meridional modes in the tropical Atlantic. Geophys. Res. Lett., 28, 4463-4466.

Mutai, C. C., and M. N. Ward, 2000: East African rainfall and the tropical circulation/convection on intraseasonal to interannual timescales. J. Climate, 13, 3915-3939.

Namias, J., 1972: Influence of northern hemisphere general circulation on drought in Northeast Brazil. Tellus, 24, 336-342.

Neelin, J. D., 1991: The slow sea surface temperature mode and the fast-wave limit: Analytic theory for tropical interannual oscillations and experiments in a hybrid coupled model. $J$. Atmos. Sci., 48, 584-606.

_ , and F.-F. Jin, 1993: Modes of interannual tropical oceanatmosphere interaction-A unified view. Part II: Analytical results in the weak-coupling limit. J. Atmos. Sci., 50, 3504 3522.

— M. Matif, and F.-F. Jin, 1994: Dynamics of coupled oceanatmosphere models: The tropical problem. Annu. Rev. Fluid Mech., 26, 617-659.

- D. S. Battisti, A. C. Hirst, F. Jin, Y. Wakata, T. Yamagata, and S. E. Zebiak, 1998: ENSO theory. J. Geophys. Res., 103, 14 261-14 290

Nicholls, N., and W. Drosdowsky, 2000: Is there an equatorial Indian Ocean SST dipole, independent of the El NiñoSouthern Oscillation? Preprints, Symp. on Climate Variability, the Oceans, and Societal Impacts, Albuquerque, NM, Amer. Meteor. Soc., 17-18.

Nitta, T., 1987: Convective activities in the tropical western Pacific and their impact on the Northern Hemisphere summer circulation. J. Meteor. Soc. Japan, 65, 373-390.

Nonaka, M., and K. Takeuchi, 2001: Tropical subsurface salinity and tritium distributions in the Pacific: Their differences and formation mechanisms. J. Phys. Oceanogr., 31, 1388-1395.

—, S.-P. Xie, and J. P. McCreary, 2002: Decadal variations in the subtropical ceils and equatorial pacific SST. Geophys. Res. Lett., 29, 1116, doi:10.1029/2001GL013717.

O'Brien, J. J., and H. E. Hurlburt, 1974: Equatorial jet in the Indian Ocean: Theory. Science, 184, 1075-1077.

Ogallo, L., 1989: The spatial and temporal patterns of the East African seasonal rainfall derived from principal component analysis. Int. J. Climatol., 9, 145-167.

Okajima, H., S.-P. Xie, and A. Numaguti, 2003: Interhemispheric coherence of tropical climate variability: Effect of climatological ITCZ. J. Meteor. Soc. Japan, 81, 1371-1386.

Okumura, Y., and S.-P. Xie, 2004: Interaction of the Atlantic 
equatorial cold tongue and African monsoon. J. Climate, 17, 3588-3601.

,$- \ldots$, A. Numaguti, and Y. Tanimoto, 2001: Tropical Atlantic air-sea interaction and its influence on NAO. Geophys. Res. Lett., 28, 1507-1510.

Pedlosky, J., 1996: Ocean Circulation Theory. Springer-Verlag, $464 \mathrm{pp}$.

Penland, C., and P. D. Sardeshmukh, 1995: The optimal growth of tropical sea surface temperature anomalies. J. Climate, 8, 1999-2024.

— surface temperatures using linear inverse modeling. J. Climate, 11, 483-496.

Penland, C. M., M. Flügel, and P. Chang, 2000: Identification of dynamical regimes in an intermediate coupled oceanatmosphere model. J. Climate, 13, 2105-2115.

Perigaud, C., and P. Delecluse, 1993: Interannual sea level variations in the tropical Indian Ocean from Geosat and shallow water simulations. J. Phys. Oceanogr., 23, 1916-1934.

Philander, S. G. H., 1986: Unusual conditions in the tropical Atlantic Ocean in 1984. Nature, 322, 236-238.

_ 1990: El Niño, La Niña, and the Southern Oscillation. Academic Press, 293 pp.

— , and P. Delecluse, 1983: Coastal currents in low latitudes (with application to the Somali and El Niño Currents). DeepSea Res., 30, 887-902.

— , and R. C. Pacanowski, 1986: The mass and heat budgets in a model of the tropical Atlantic. J. Geophys. Res., 91, 14212 14220.

— Pacific in a simulation of the 1982-83 El Niño. J. Phys. Oceanogr., 18, 926-931.

Picaut, J., 1985: Major dynamics affecting the eastern tropical Atlantic and Pacific oceans. CalCOFI Rep., Vol. XXVI, $41-49$.

_- F. Masia, and Y. du Penhoat, 1997: An advective-reflective conceptual model for the oscillatory nature of the ENSO. Science, 277, 663-666.

Plumb, R. A., 1986: Three-dimensional propagation of transient quasi-geostrophic eddies and its relationship with the eddy forcing of the time-mean flow. J. Atmos. Sci., 43, 1657-1678.

Prasad, T. G., and J. L. McClean, 2004: Mechanisms for anomalous warming in the western Indian Ocean during dipole mode events. J. Geophys. Res., 109, C02019, doi:10.1029/ 2003JC001872.

Qu, T., and E. J. Lindstrom, 2002: A climatological interpretation of the circulation in the western South Pacific. J. Phys. Oceanogr., 32, 2492-2508.

— and R. Lukas, 2003: The bifurcation of the North Equatorial Current in the Pacific. J. Phys. Oceanogr., 33, 5-18.

— - T. Kagimoto, and T. Yamagata, 1997: A subsurface countercurrent along the east coast of Luzon. Deep-Sea Res., 44A, 413-423.

—, H. Mitsudera, and T. Yamagata, 1999: A climatology of the circulation and water mass distribution near the Philippine coast. J. Phys. Oceanogr., 29, 1488-1505.

Rajagopalan, B., Y. Kushnir, and Y. Tourre, 1998: Observed decadal midlatitude and tropical Atlantic climate variability. Geophys. Res. Lett., 25, 3967-3970.

Rao, S. A., and T. Yamagata, 2004: Abrupt termination of Indian Ocean dipole events in response to intra-seasonal oscilla- tions. Geophys. Res. Lett., 31, L19306, doi:10.1029/ 2004GL020842.

- and S. K. Behera, 2005: Subsurface influence on SST in the tropical Indian Ocean structure and interannual variabilities. Dyn. Atmos. Oceans, 39, 103-135.

- _ - Y. Masumoto, and T. Yamagata, 2002a: Interannual variability in the subsurface tropical Indian Ocean with a special emphasis on the Indian Ocean Dipole. Deep-Sea Res., 49B, 1549-1572.

—, V. V. Gopalakrishna, S. R. Shetye, and T. Yamagata, 2002b: Why were cool SST anomalies absent in the Bay of Bengal during the 1997 Indian Ocean Dipole Event? Geophys. Res. Lett., 29, 1555, doi:10.1029/2001GL014645.

Reason, C. J. C., 2001: Subtropical Indian Ocean SST dipole events and southern African rainfall. Geophys. Res. Lett., 28, 2225-2228

Reid, J. L., and R. S. Arthur, 1975: Interpretation of maps of geopotential anomaly for the deep Pacific Ocean. J. Mar. Res., 33 (Suppl.), 37-52.

Reverdin, G., 1985: Convergence in the equatorial surface jets of the Indian Ocean. J. Geophys. Res., 90, 11 741-11 750.

- D. L. Cadet, and D. Gutzler, 1986: Interannual displacements of convection and surface circulation over the equatorial Indian Ocean. Quart. J. Roy. Meteor. Soc., 112, 43-67.

Rodgers, K. B., B. Blanke, G. Madec, O. Aumont, P. Ciais, and J.-C. Dutay, 2003: Extratropical sources of Equatorial Pacific upwelling in an OGCM. Geophys. Res. Lett., 30, 1084, doi:10.1029/2002GL016003.

— , P. Friederichs, and M. Latif, 2004: Tropical Pacific decadal variability and its relation to decadal modulations of ENSO. J. Climate, 17, 3761-3774.

Rodwell, M. J., and B. J. Hoskins, 1996: Monsoons and the dynamics of deserts. Quart. J. Roy. Meteor. Soc., 122, 13851404.

Roemmich, D., 1983: The balance of geostrophic and Ekman transports in the tropical Atlantic Ocean. J. Phys. Oceanogr., 13, 1534-1539.

Ropelewski, F., and M. S. Halpert, 1987: Global and regional scale precipitation patterns associated with the El Niño/Southern Osicllation. Mon. Wea. Rev., 115, 1602-1626.

Rothstein, L. M., R.-H. Zhang, A. J. Busalacchi, and D. Chen, 1998: A numerical simulation of the mean water pathways in the subtropical and tropical Pacific Ocean. J. Phys. Oceanogr., 28, 322-342.

Rouault, M., P. Florenchie, N. Faucherau, and C. J. C. Reason, 2003: South East tropical Atlantic warm events and southern African rainfall. Geophys. Res. Lett., 30, 8009, doi:10.1029/ 2002GL014840.

Ruiz-Barradas, A., J. A. Carton, and S. Nigam, 2000: Structure of interannual-to-decadal climate variability in the tropical Atlantic sector. J. Climate, 13, 3285-3297.

Saji, N. H., and T. Yamagata, 2003a: Structure of SST and surface wind variability during Indian Ocean dipole mode events: COADS observations. J. Climate, 16, 2735-2751.

_ , and _ 2003b: Possible impacts of Indian Ocean Dipole Mode events on global climate. Climate Res., 25, 151-169.

— B. B. Goswami, P. N. Vinayachandran, and T. Yamagata, 1999: A dipole mode in the tropical Indian Ocean. Nature, 401, 360-363.

Saravanan, R., and P. Chang, 2000: Interaction between tropical Atlantic variability and El Niño-Southern Oscillation. J. Climate, 13, 2177-2194. 
$\longrightarrow$, and - 2004: Thermodynamic coupling and predictability of tropical sea surface temperature. Earth Climate: The Ocean-Atmosphere Interaction, Geophys. Monogr., Vol. 147, Amer. Geophys. Union, 171-180.

Sardeshmukh, P. D., and B. J. Hoskins, 1988: The generation of global rotational flow by steady idealized tropical divergence. J. Atmos. Sci., 45, 1228-1251.

Schiller, A., J. S. Godfrey, P. C. McIntosh, G. Meyers, and R. Fiedler, 2000: Interannual dynamics and thermodynamics of the Indo-Pacific Oceans. J. Phys. Oceanogr., 30, 987-1012.

Schmitz, W. J., 1996: On the world ocean circulation: Vol. 1, some global features/North Atlantic circulation. WHOI Tech. Rep. WHOI-96-03, 140 pp.

—_, and M. S. McCartney, 1993: On the North Atlantic circulation. Rev. Geophys., 31, 29-49.

Schneider, E. K., B. Huang, and J. Shukla, 1995: Ocean wave dynamics and El Niño. J. Climate, 8, 2415-2439.

Schneider, N., 2000: A decadal spiciness mode in the tropics. Geophys. Res. Lett., 27, 257-260.

— A. A. Miller, M. A. Alexander, and C. Deser, 1999: Subduction of decadal North Pacific temperature anomalies: Observations and dynamics. J. Phys. Oceanogr., 29, 1056-1070.

Schopf, P. S., and M. J. Suarez, 1988: Vacillations in a coupled ocean-atmosphere model. J. Atmos. Sci., 45, 549-566.

— and 1990: Ocean wave dynamics and the timescale of ENSO. J. Phys. Oceanogr., 20, 629-645.

— , and R. J. Burgman, 2006: A simple mechanism for ENSO residuals and asymmetry. J. Climate, 19, 3167-3179.

Schott, F., and J. P. McCreary, 2001: The monsoon circulation of the Indian Ocean. Progress in Oceanography, Vol. 51, Pergamon, 1-123.

_ - J. Fischer, and L. Stramma, 1998: Transports and pathways of the upper-layer circulation in the western tropical Atlantic. J. Phys. Oceanogr., 28, 1904-1928.

_ , P. Brandt, M. Hamann, J. Fischer, and L. Stramma, 2002a: On the boundary flow off Brazil at $5-10^{\circ} \mathrm{S}$ and its connection to the interior tropical Atlantic. Geophys. Res. Lett., 29, 1840, doi:10.1029/2002GL014786.

— - M. Dengler, and R. Schoenefeldt, 2002b: The shallow overturning circulation of the Indian Ocean. Progress in Oceanography, Vol. 53, Pergamon, 57-103.

—_, and Coauthors, 2003: The zonal currents and transports at $35^{\circ} \mathrm{W}$ in the tropical Atlantic. Geophys. Res. Lett., 30, 1349, doi:10.1029/2002GL016849.

— , and Coauthors, cited 2004: A white paper on "Tropical Atlantic Climate Experiment (TACE)." [Available online at http://www.usclivar.org/Meeting_Files/SSC-11/TACE_ whitepaper_draft2_text.pdf.]

Seager, R., Y. Kushnir, M. Visbeck, N. Naik, J. Miller, G. Krahmann, and H. Cullen, 2000: Causes of Atlantic Ocean climate variability between 1958 and 1998. J. Climate, 13, 2845-2862.

—_ - P. P. Chang, N. Naik, J. Miller, and W. Hazeleger, 2001: Looking for the role of the ocean in tropical Atlantic decadal climate variability. J. Climate, 14, 638-655.

Sengupta, D., and M. Ravichandran, 2001: Oscillations of the Bay of Bengal sea surface temperatures during 1998 summer monsoon. Geophys. Res. Lett., 28, 2033-2036.

_- B. N. Goswami, and R. Senan, 2001: Coherent intraseasonal oscillations of the ocean and atmosphere during the Asian summer monsoon. Geophys. Res. Lett., 28, 4127-4130.

Servain, J., J. Picaut, and J. Merle, 1982: Evidence of remote forcing in the equatorial Atlantic Ocean. J. Phys. Oceanogr., 12, 457-463.

_ - M. Seva, S. Lulcas, and G. Rougier, 1987: Climatic atlas of the tropical sea surface temperature and wind stress; 1980 1984. Ocean Air Interactions, 1, 109-182.

_, I. Wainer, J. P. McCreary, and A. Dessier, 1999: Relationship between the Equatorial and meridional modes of climatic variability in the tropical Atlantic. Geophys. Res. Lett., 26, 485-488.

— - _ H. L. Ayina, and H. Roquet, 2000: The relationship between the simulated climatic variability modes of the tropical Atlantic. Int. J. Climatol., 20, 939-953.

Shannon, L. V., A. J. Boyd, G. B. Bundrit, and J. Taunton-Clark, 1986: On the existence of an El Niño-type phenomenon in the Benguela system. J. Mar. Sci., 44, 495-520.

Shetye, S., A. Gouveia, D. Shankar, S. Shenoi, P. Vinayachandran, D. Sundar, G. Michael, and G. Nampoothiri, 1996: Hydrography and circulation in the western Bay of Bengal during the Northeast monsoon. J. Geophys. Res., 101, $14011-$ 14025 .

Shinoda, T., M. A. Alexander, and H. H. Hendon, 2004a: Remote response of the Indian Ocean to interannual SST variations in the tropical Pacific. J. Climate, 17, 362-372.

- H. H. Hendon, and M. A. Alexander, 2004b: Surface and subsurface dipole variability in the Indian Ocean and its relation with ENSO. Deep-Sea Res., 51A, 619-635.

Sikka, D. R., and S. Gadgil, 1980: On the maximum cloud zone and the $1 \mathrm{TCZ}$ over the Indian longitudes during the southwest monsoon. Mon. Wea. Rev., 108, 1122-1135.

Snowden, D. P., and R. L. Molinari, 2003: Subtropical cells in the Atlantic Ocean: An observational summary. Interhemispheric Water Exchange in the Atlantic Ocean, G. Goni and P. Malanotte-Rizzoli, Eds., Elsevier Oceanographic Series, Vol. 68, Elsevier, 287-312.

Solow, A. R., and A. Huppert, 2003: On non-stationarity of ENSO. Geophys. Res. Lett., 30, 1910, doi:10.1029/ 2003 GL018225.

Sperber, K. R., J. M. Slingo, and H. Annamalai, 2000: Predictability and the relationship between subseasonal and interannual variability during the Asian summer monsoons. Quart. J. Roy. Meteor. Soc., 126, 2545-2574.

Sprintall, J., and M. Tomczak, 1993: On the formation of Central Water in the southern hemisphere. Deep-Sea Res., 40, 827848.

Sterl, A., and W. Hazeleger, 2003: Coupled variability and air-sea interaction in the South Atlantic Ocean. Climate Dyn., 21, $559-571$.

Stramma, L., and F. Schott, 1999: The mean flow field of the tropical Atlantic Ocean. Deep-Sea Res., 46B, 279-303.

_ J. Fischer, P. Brandt, and F. Schott, 2003: Circulation, variability and nearequatorial meridional flow in the central tropical Atlantic. Interhemispheric Water Exchange in the Atlantic Ocean, G. Goni and P. Malanotte-Rizzoli, Eds., Elsevier Oceanographic Series, Vol. 68, Elsevier, 1-22.

- D. Kieke, M. Rhein, F. Schott, I. Yashayaev, and K. P. Koltermann, 2004: Recent Deep Water changes of the western boundary of the subpolar North Atlantic. Deep-Sea Res., 51A, 1033-1056.

Suarez, M. J., and P. S. Schopf, 1998: A delayed action oscillator for ENSO. J. Atmos. Sci., 45, 3283-3287.

Sutton, R. T., S. P. Jewson, and D. P. Rowell, 2000: The elements of climate variability in the tropical Atlantic region. J. Climate, 13, 3261-3284. 
Suzuki, R., S. K. Behera, S. Iizuka, and T. Yamagata, 2004: The Indian Ocean subtropical dipole simulated using a CGCM. J. Geophys. Res., 109, C09001, doi:10.1029/2003JC001974.

Takaya, K., and H. Nakamura, 2001: A formulation of a phaseindependent wave-activity flux for stationary and migratory quasigeostrophic eddies on a zonally varying basic flow. $J$. Atmos. Sci., 58, 608-627.

Takayabu, Y. N., T. Iguchi, M. Kachi, A. Shibata, and H. Kanzawa, 1999: Abrupt termination of the 1997-98 El Niño in response to a Madden-Julian oscillation. Nature, 402, 279282.

Tanimoto, Y., and S.-P. Xie, 2002: Inter-hemispheric decadal variations in SST, surface wind, heat flux and cloud cover over the Atlantic Ocean. J. Meteor. Soc. Japan, 80, 11991219.

Terray, L., and C. Cassou, 2002: Tropical Atlantic sea surface temperature forcing of quasidecadal climate variability over the North Atlantic-European region. J. Climate, 15, 31703187.

Terray, P., P. Delecluse, S. Labattu, and L. Terray, 2003: Sea surface temperature associations with the late Indian summer monsoon. Climate Dyn., 21, 593-618.

Tett, S. F. B., 1995: Simulation of El Niño-Southern Oscillationlike variability in a global AOGCM and its response to $\mathrm{CO}_{2}$ increase. J. Climate, 8, 1473-1502.

Thompson, C. J., and D. S. Battisti, 2000: A linear stochastic dynamical model of ENSO. Part I: Model development. J. Climate, 13, 2818-2832.

—, and —, 2001: A linear stochastic dynamical model of ENSO. Part II: Analysis. J. Climate, 14, 445-466.

Timmermann, A., J. Oberhuber, A. Bacher, M. Esch, M. Latif, and E. Roeckner, 1999: Increased El Niño frequency in a climate model forced by future greenhouse warming. Nature, 398, 694-697.

_ , F.-F. Jin, and J. Abshagen, 2003: A nonlinear theory for El Niño bursting. J. Atmos. Sci., 60, 152-165.

Tomczak, M., and J. S. Godfrey, 1994: Regional Oceanography: An Introduction. Pergamon, $422 \mathrm{pp}$.

Tourre, Y. M., B. Rajagopalan, and Y. Kushnir, 1999: Dominant patterns of climate variability in the Atlantic Ocean during the last 136 years. J. Climate, 12, 2285-2299.

Tozuka, T., and T. Yamagata, 2003: Annual ENSO. J. Phys. Oceanogr., 33, 1564-1578.

—, J.-J. Luo, S. Masson, and T. Yamagata, 2006: Decadal Indian Ocean dipole in a high-resolution coupled GCM. J. Climate, in press.

Trenberth, K. E., and J. W. Hurrell, 1994: Decadal atmosphericocean variations in the Pacific. Climate Dyn., 9, 303-319.

— - and J. M. Caron, 2001: Estimates of meridional atmosphere and ocean heat transports. J. Climate, 14, 3433-3443.

Tziperman, E., L. Stone, M. A. Cane, and H. Jarosh, 1994: El Niño chaos: Overlapping of resonances between the seasonal cycle and the Pacific ocean-atmosphere oscillator. Science, 264, 72-74.

Ueda, H., and J. Matsumoto, 2000: A possible process of eastwest asymmetric anomalies over the Indian Ocean in relation to 1997/98 El Niño. J. Meteor. Soc. Japan, 78, 803-818.

Umatani, S., and T. Yamagata, 1991: Response of the eastern tropical Pacific to meridional migration of the ITCZ: The generation of the Costa Rica Dome. J. Phys. Oceanogr., 21, 346-363.
Urban, F. E., J. E. Cole, and J. T. Overpack, 2000: Influence of mean climate change on climate variability from a 155 -year tropical Pacific coral record. Nature, 407, 989-993.

Vauclair, F., and Y. du Penhoat, 2001: Interannual variability of the upper layer of the tropical Atlantic Ocean from in situ data between 1979 and 1999. Climate Dyn., 17, 527-546.

Vecchi, G. A., and D. E. Harrison, 2002: Monsoon breaks and subseasonal sea surface temperature variability in the Bay of Bengal. J. Climate, 15, 1485-1493.

—, A. Rosati, and D. E. Harrison, 2004: Setting the timing of El Niño termination. Bull. Amer. Meteor. Soc., 85, 1065-1066.

Vellinga, M., and R. A. Wood, 2002: Global climatic impacts of a collapse of the Atlantic thermohaline circulation. Climate Change, 54, 251-267.

Venegas, S., L. A. Mysak, and D. N. Straub, 1997: Atmosphereocean coupled variability in the South Atlantic. J. Climate, 10, 2904-2920.

Vinayachandran, P. N., N. H. Saji, and T. Yamagata, 1999: Response of the equatorial Indian Ocean to an anomalous wind event during 1994. Geophys. Res. Lett., 26, 1613-1616.

_ - S. Izuka, and T. Yamagata, 2002: Indian Ocean Dipole mode events in an ocean general circulation model. Deep-Sea Res., 49B, 1573-1596.

Visbeck, M., H. M. Cullen, G. Krahmann, and N. Naik, 1998: An ocean model's response to North Atlantic Oscillation-like wind forcing. Geophys. Res. Lett., 25, 4521-4524.

Vossepoel, F. C., and D. W. Behringer, 2000: Impact of sea level assimilation on salinity variability in the western equatorial Pacific. J. Phys. Oceanogr., 30, 1706-1721.

Wagner, R. G., and A. da Silva, 1994: Surface conditions associated with anomalous rainfall in the Guinea coastal region. Int. J. Climatol., 14, 179-200.

Wajsowicz, R. C., 2005: Potential predictability of tropical Indian Ocean SST anomalies. Geophys. Res. Lett., 32, L24702, doi:10.1029/2005GL024169.

Wallace, J. M., and D. S. Gutzler, 1981: Teleconnections in the geopotential height field during the Northern Hemisphere winter. Mon. Wea. Rev., 109, 784-812.

— , E. M. Rasmusson, T. P. Mitchell, V. E. Kousky, E. S. Sarachik, and H. von Storch, 1998: On the structure and evolution of ENSO-related climate variability in the tropical Pacific: Lessons from TOGA. J. Geophys. Res., 103, $14241-$ 14259.

Wang, B., and Z. Fan, 1999: Choice of South Asian summer monsoon indices. Bull. Amer. Meteor. Soc., 80, 629-638.

— , and S.-I. An, 2001: Why the properties of El Niño changed during the late 1970s. Geophys. Res. Lett., 28, 3709-3712.

— and - 2002: A mechanism for decadal changes of ENSO behavior: Roles of background wind changes. Climate Dyn., 18, 475-486.

- A. Barcilon, and Z. Fang, 1999: Stochastic dynamics of EI Niño-Southern Oscillation. J. Atmos. Soc., 56, 5-20.

Wang, C., and D. B. Enfield, 2001: The tropical Western Hemisphere warm pool. Geophys. Res. Lett., 28, 1635-1638.

_ - S.-P. Xie, and J. A. Carton, 2004: A global survey of oceanatmosphere and climate variability. Earth Climate: The Ocean-Atmosphere Interaction, Geophys. Monogr., Vol. 147, Amer. Geophys. Union, 1-19.

Wang, J., and J. A. Carton, 2003: Modeling climate variability in the tropical Atlantic atmosphere. J. Climate, 16, 3858-3876.

Webster, P. J., A. Moore, J. Loschnigg, and M. Leban, 1999: 
Coupled ocean-atmosphere dynamics in the Indian Ocean during 1997-98. Nature, 40, 356-360.

Weisberg, R. H., and C. Colin, 1986: Upper ocean temperature and current variations along the equator in the Atlantic Ocean during 1983-1984. Nature, 322, 240-243.

—_, and T. Weingartner, 1988: Instability waves in the equatorial Atlantic Ocean. J. Phys. Oceanogr., 18, 1641-1657.

—_, and C. Wang, 1997: A western Pacific oscillator paradigm for the El Niño-Southern Oscillation. Geophys. Res. Lett., 24, 779-782.

—, and L. Qiao, 2000: Equatorial upwelling in the central Pacific estimated from moored velocity profilers. J. Phys. Oceanogr., 30, 105-124.

White, W. B., 2000: Coupled Rossby waves in the Indian Ocean on interannual time scales. J. Phys. Oceanogr., 30, 2972-2989.

Wijffels, S., and G. Meyers, 2004: An intersection of oceanic waveguides: Variability in the Indonesian throughflow region. J. Phys. Oceanogr., 34, 1232-1253.

Wilson, W. D., E. Johns, and R. L. Molinari, 1994: Upper layer circulation in the western tropical North Atlantic Ocean during August 1989. J. Geophys. Res., 99 (C11), 22 513-22 523.

Wu, L., and Z. Liu, 2002: Is tropical Atlantic variability driven by the North Atlantic Oscillation? Geophys. Res. Lett., 29, 1653, doi:10.1029/2002GL014939.

Wu, R., and B. P. Kirtman, 2004: Understanding the impacts of the Indian Ocean on ENSO variability in a coupled GCM. $J$. Climate, 17, 4019-4031.

Wyrtki, K., 1973: An equatorial jet in the Indian Ocean. Science, 181, 262-264.

Xie, S.-P., 1999: A dynamic ocean-atmosphere model of the tropical Atlantic decadal variability. J. Climate, 12, 64-70. and S. G. H. Philander, 1994: A coupled ocean-atmosphere model of relevance to the ITCZ in the eastern Pacific. Tellus, 46A, 340-350.

__ and Y. Tanimoto, 1998: A pan-Atlantic decadal climate oscillation. Geophys. Res. Lett., 25, 2185-2188.

_, and J. A. Carton, 2004: Tropical Atlantic variability: Patterns, mechanisms, and impacts. Earth Climate: The OceanAtmosphere Interaction, Geophys. Monogr., Vol. 147, Amer. Geophys. Union, 121-142.

— , H. Annamalai, F. Schott, and J. P. McCreary, 2002: Structure and mechanisms of South Indian Ocean climate variability. J. Climate, 15, 864-878.

Yamagata, T., and S. Iizuka, 1995: Simulation of the tropical thermal domes in the Atlantic: A seasonal cycle. J. Phys. Oceanogr., 25, 2129-2140.

— , S. K. Behera, S. A. Rao, Z. Guan, K. Ashok, and H. N. Saji, 2002: The Indian Ocean dipole: A physical entity. CLIVAR Exchanges, Vol. 24, International CLIVAR Project Office, Southampton, United Kingdom, 15-18 and 20-22.

- - - and Z. Guan, 2003a: The role of the Indian Ocean in climate forecasting with a particular emphasis on summer conditions in East Asia. Proc. ECMWF Workshop, Reading, United Kingdom, ECMWF, 102-114.

$\longrightarrow,-$ S. A. Rao, Z. Guan, K. Ashok, and H. N. Saji, 2003b: Comments on "Dipoles, temperature gradient, and tropical climate anomalies." Bull. Amer. Meteor. Soc., 84, 1418-1422. $\longrightarrow,-$ J.-J. Luo, S. Masson, M. Jury, and S. A. Rao, 2004: Coupled ocean-atmosphere variability in the tropical Indian Ocean. Earth Climate: The Ocean-Atmosphere Interaction, Geophys. Monogr., Vol. 147, Amer. Geophys. Union, 189212.

Yang, J., 1999: A linkage for decadal climate variations in the Labrador Sea and the tropical Atlantic Ocean. Geophys. Res. Lett., 26, 1070-1073.

Yeager, S. G., and W. G. Large, 2004: Late-winter generation of spiciness on subducted isopycnals. J. Phys. Oceanogr., 34, $1528-1547$.

Yeh, S.-W., and B. P. Kirtman, 2004: Tropical Pacific decadal variability and ENSO amplitude modulation in a CGCM. J. Geophys. Res., 109, C11009, doi:10.1029/2004JC002442.

_ , and —-, 2005: Pacific decadal variability and decadal ENSO amplitude modulation. Geophys. Res. Lett., 32, L05703, doi:10.1029/2004GL021731.

—, J.-G. Jhun, I.-S. Kang, and B. P. Kirtman, 2004: The decadal ENSO variability in a hybrid coupled model. J. Climate, 17, 1225-1238.

Yoshida, K., 1959: A theory of the Cromwell current and of the equatorial upwelling-An interpretation in a similarity to a coastal circulation. J. Oceanogr. Soc. Japan, 15, 159-170.

Yu, J.-Y., and K. M. Lau, 2004: Contrasting Indian Ocean SST variability with and without ENSO influence: A coupled atmosphere-ocean GCM study. Meteor. Atmos. Phys., 90, doi:10.1007/s00703-004-0094-7.

_ C. Mechoso, J. McWilliams, and A. Arakawa, 2002: Impacts of the Indian Ocean on the ENSO cycle. Geophys. Res. Lett., 29, 1204, doi:10.1029/2001GL014098.

Zang, X., L.-L. Fu, and C. Wunsch, 2002: Observed reflectivity of the western boundary of the equatorial Pacific Ocean. J. Geophys. Res., 107, 3150, doi:10.1029/2000JC000719.

Zebiak, S. E., 1993: Air-sea interaction in the equatorial Atlantic region. J. Climate, 6, 1567-1586.

Zhang, D., M. J. McPhaden, and W. E. Johns, 2003: Observational evidence for flow between the subtropical and tropical Atlantic: The Atlantic subtropical cells. J. Phys. Oceanogr., 33, 1783-1797.

Zhang, R., and T. L. Delworth, 2005: Simulated tropical response to a substantial weakening of the Atlantic thermohaline circulation. J. Climate, 18, 1853-1860.

Zhang, R.-H., and L. M. Rothstein, 2000: Role of off-equatorial subsurface anomalies in initiating the 1991/1992 El Niño as revealed by the NCEP ocean reanalysis data. J. Geophys. Res., 105, 6326-6339.

_ _ _ , and A. J. Busalacchi, 1999: Interannual and decadal variability of the subsurface thermal structure in the Pacific Ocean: 1961-90. Climate Dyn., 15, 703-717.

— North Pacific thermal anomalies in an ocean GCM. Geophys. Res. Lett., 28, 2449-2452.

Zhang, Y., J. M. Wallace, and D. S. Battisti, 1997: ENSO-like interdecadal variability: 1900-93. J. Climate, 10, 1004-1020.

Zubair, L., S. A. Rao, and T. Yamagata, 2003: Modulation of Sri Lankan Maha rainfall by the Indian Ocean Dipole. Geophys. Res. Lett., 30, 1063, doi:10.1029/2002GL015639. 